\title{
Review of annual progress of bridge engineering in 2019
}

Renda Zhao, Yuan Yuan, Xing Wei, Ruili Shen, Kaifeng Zheng, Yongjiu Qian, Qianhui Pu, Qinghua Zhang, Haili Liao, Xiaozhen Li, Canhui Zhao, Guoji Xu, Hongye Gou, Ziyang Zhang and Chuanjin Yu* (D)

$\overline{\text { *Correspondence: ycj@swjtu.edu.cn }}$ Department of Bridge Engineering Southwest Jiaotong University, Chengdu, Sichuan 610031, PR China

\begin{abstract}
Bridge construction is one of the cores of traffic infrastructure construction. To better develop relevant bridge science, this paper introduces the main research progress in China and abroad in 2019 from 13 aspects, including concrete bridges and the highperformance materials, the latest research on steel-concrete composite girders, advances in box girder and cable-supported bridge analysis theories, advance in steel bridges, the theory of bridge evaluation and reinforcement, bridge model tests and new testing techniques, steel bridge fatigue, wind resistance of bridges, vehiclebridge interactions, progress in seismic design of bridges, bridge hydrodynamics, bridge informatization and intelligent bridge and prefabricated concrete bridge structures.
\end{abstract}

Keywords: Bridge science, Annual progress in 2019, Review

\section{Introduction}

Bridge construction is closely related to the development of human civilization and is also an important part of human civilization. Building bridges and surmounting obstacles are mankind's unremitting pursuit and dream. In recent years, China's bridge projects have entered the world's advanced ranks in terms of construction scale and scientific and technological levels. With the development of bridge science and technology and the needs of national development and construction, the construction of tens of kilometers of sea-crossing and channel bridges, high-speed railway bridges, and light rail transit viaducts and other grand projects have gradually begun. At the same time, with the continuous deepening of relevant research in the field of bridge engineering, new bridge structures, new processes, new materials, and so on are emerging, and the application level and research level of new technologies have reached a new breadth and depth. However, future bridge projects will face more severe construction conditions, such as strong winds, strong earthquakes, deep-water and harsh weather conditions (such as Sichuan-Tibet railway); More functional requirements, such as the joint construction of public railways, all-weather traffic, high-speed railways, etc.; More huge projects, such as Qiongzhou Strait and Taiwan Strait. At the same time, it also brings more development opportunities to bridge workers.

(c) The Author(s). 2020, corrected publication 2020. Open Access This article is licensed under a Creative Commons Attribution 4.0 International License, which permits use, sharing, adaptation, distribution and reproduction in any medium or format, as long as you give appropriate credit to the original author(s) and the source, provide a link to the Creative Commons licence, and indicate if changes were made. The images or other third party material in this article are included in the article's Creative Commons licence, unless indicated otherwise in a credit line to the material. If material is not included in the article's Creative Commons licence and your intended use is not permitted by statutory regulation or exceeds the permitted use, you will need to obtain permission directly from the copyright holder. To view a copy of this licence, visit http://creativecommons.org/licenses/by/4.0/. 
In the past year, bridge construction in China has continued its strong momentum in previous years and developed rapidly. To achieve more outstanding achievements in 2020 , it is very necessary to analyze, summarize the researches about bridges in the past year, and even prospect its research hot spot in the future. Therefore, the following sections of this article respectively introduce the relevant progress of bridges in 2019, including concrete bridges and the high-performance materials, the latest research on steel-concrete composite girders, advances of analysis theories in box girder and cablesupported bridges, advances in steel bridges, the theory of bridge evaluation and reinforcement, bridge model tests and new testing techniques, steel bridge fatigue, wind resistance of bridges, vehicle-bridge interactions, progress in seismic design of bridges, bridge hydrodynamics, bridge informatization and intelligent bridge and prefabricated concrete bridge structures.

\section{Concrete bridges and high-performance materials}

To understand the development trend of concrete bridges and the application of highperformance materials in the past year, the recent literature at home and abroad of three aspects, including concrete bridges, high-performance concrete materials, and high-performance reinforced materials, are summarized in this review.

\subsection{Concrete bridge}

Concrete bridge has always been the main type of bridges. In recent years, the research focus of concrete bridge has gradually shifted to the operation management and maintenance (Zhou and Zhang 2019). At the beginning of 2019, Gao et al. (2019) pointed out that it is of great importance to study the structural durability, the whole life cycle design, and the combined environmental effects of the bridge structures in China.

For the durability of concrete bridges, Li et al. (2019e) used model-based methods and multi-level principles to study the different durability risks of the Hong KongZhuhai-Macao Bridge. Some scholars have proposed that research should be carried out in terms of exposure environment, durability test age, and test methods (Hooton 2019), and pointed out that the widely accepted durability design theory should be established based on the service life estimation tool (Demis and Papadakis 2019), and the existing specifications should be revised accordingly. Besides, Wu et al. (2019d) provided ideas for solving the problem of long-term service performance of long-span bridges in the marine environment from the perspective of the development of lightweight, high-strength, and durable materials.

For the life cycle of concrete bridges, Akhnoukh (2019) pointed out that the bridge with longer service life should be developed from the concept of combining the high performance concrete, prefabricated beam members, and rapid construction methods. Some scholars have developed more reasonable life cycle predictions and cost analysis methods based on life prediction model (Alexander and Beushausen 2019) and reliability theory (Sajedi and Huang 2019), respectively.

For the performance of concrete bridges in extreme environments, some scholars have studied the failure mechanism and protection level of actual bridges under flood scour (Ren 2019) and multi-disaster coupling action (Mei 2019). Beneberu and Yazdani (2019) believed that the research on fire resistance of bridges was inadequate compared 
to that on earthquake, wind, and flood. Some scholars have studied the performance of prestressed concrete bridges after fire damage (Liu et al. 2019c) and that of UHPC beams subjected to long periods of high temperature action (Ahmad et al. 2019). It was found that high temperature had a great influence on stiffness and bending strength of the members, but not on compressive strength and toughness of the materials and basic frequency of the structure.

Based on the above analyses, it is suggested that the future work should be carried out from the following aspects: durability research based on the combination of structure and material, durability design concept based on "the whole-parts-components", service life design concept based on cost and performance, and performance of concrete bridges under multi-disaster coupling action.

\subsection{High-performance concrete materials}

In 2019, the development of new concrete materials continues to be dominated by selfcompacting concrete (SCC), high toughness cement-based materials, and green concrete. SCC can be self-compacting under the action of gravity, which brings great convenience to the construction operation. How to quantify and ensure self-compacting properties will still be the focus of SCC research.

Ultra-high performance concrete (UHPC) and engineering cement-based composite materials (ECC) are prominent representatives of high-toughness cement-based materials. The UHPC not only has high strength and toughness but also has high durability, which has been successfully applied to bridge engineering. The transition zone between the binder and the aggregate interface (ITZ) is a weak link inside the UHPC, and some studies have tried to improve it by adjusting the mix ratio and curing method (Zhao et al. 2019f; Shen et al. 2019a; Raheem et al. 2019). UHPCs are often costly, and mineral admixtures were added to UHPC to reduce the costs but improve the performance in some studies. Norhasri et al. (2019) incorporated nano-clay in UHPC, the later strength of which was improved without affecting the early strength. Shi et al. (2019a) prepared low-carbon emission UHPC using fly ash, slag, silicon powder, nano- $\mathrm{SiO}_{2}$, and other multi-scale reactive mineral powder.

The great shrinkage of the UHPC is also a concern. Liu et al. (2019a) effectively reduced the shrinkage of the UHPC by using low-dose saturated pumice as the internal curing agent. Li et al. (2019a) carried out the ring constrained shrinkage test. The test results showed that the UHPC had evident constrained shrinkage cracks at $14 \mathrm{~d}$. Wu et al. (2019e) investigated the effect of steel fiber content and fiber shape on the drying shrinkage of the UHPC.

ECC is another new building material with super high toughness and a multi-crack development mechanism. Jia et al. (2019b) applied PP-ECC to the plastic hinge area at the bottom of the pier, which significantly improved the crack resistance of the pier under seismic action. Hosseini et al. (2019) further combined the ECC with superelastic alloys to control the residual deformation of piers under seismic action and enhance their self-reset capability.

Green concrete is a promising material, which can effectively reduce the depletion of the natural resources and the contamination of the environment. While compared with normal concrete, green concrete generally has weaker mechanical properties, such as 
low elasticity modulus, compressive strength and tensile strength etc. The development of green concrete mainly includes recycled aggregate concrete and geopolymer concrete. The research focus of the recycled aggregate concrete is to ensure the stability of mechanical properties. However, the research focus has shifted from the basic mechanical properties and curing method to the durability and time-dependent deformation on geopolymers. Zhao et al. (2019e) researched the frost resistance of geopolymer concrete and found that the frost resistance of fly ash-based geopolymer concrete is weak, which, however, can be improved by adding slag. Khan et al. (2019) investigated the early-age constrained shrinkage and tensile creep characteristics of geopolymer concrete to explore the cracking risk of constrained shrinkage.

\subsection{High-performance reinforced materials}

FRP composite materials are lightweight and have good corrosion resistance and high strength. They have been promoted and applied in light-weight bridges, bridge deck systems, bridge seismic / reinforcement and other aspects recently.

For lightweight bridges, Siwowski et al. (2019) conducted the prototype static and dynamic loading tests on a hybrid FRP-lightweight concrete (LWC) highway bridge with a span of $21.0 \mathrm{~m}$. Nair et al. (2019) evaluated the adhesion of a new type of FRP wrapped light wood bridge deck slab.

For bridge seismic design, Jia et al. (2019a) evaluated the aseismic performance of FRP / steel double-reinforced piers. Cai et al. (2019) studied the aseismic performance of basalt fiber-reinforced polymer (BFRP) bars reinforced prefabricated segmented bridge columns (PSBC).

For bridge reinforcement, Tang et al. (2019b) applied a composite member (PCPSFRP) of the prestressed concrete precast slab (PCPS) and embedded fiber-reinforced polymer (FRP) to the reinforcement of underwater bridge columns. Donghyuk Jung et al. (2019a) improved the seismic performance of high-strength concrete (HSC) bridge beam-columns through a mixed confinement sleeve manufactured by fiber reinforced polymer (FRP) sheets and shape memory alloy (SMA).

For hybrid bridge design research, Papapetrou et al. (2019) proposed the idea and method of FRP / RC optimal design by optimizing and analyzing several FRP / RC hybrid bridges in the United States and Europe. From the perspective of the reliability theory, Peng and Xue (2019) proposed a design method for the flexural strength of prestressed concrete bridges with bonded fiber reinforced polymer (FRP) bars.

\section{Latest research on composite girders in 2019}

The steel-concrete composite structure is a main structural form in bridge engineering, which can give full play to the performance of concrete and steel. With the popularization of green construction concepts, the proportion of steel-concrete composite structures in roads and railway bridges has gradually increased. Many scholars have carried out scientific research on various aspects of steel-concrete composite bridges. In order to promote comprehensive and further basic research on the structures and guide the practical application, four aspects of the latest research in 2019 that contains the shear connectors, the overall mechanical behavior, the concrete-filled steel 
tube truss and composite girders with corrugated webs, were sorted out and summarized.

Shear studs and PBL shear connectors are commonly used in steel-concrete composite structures. Some scholars (Ataei et al. 2019; Zhao et al. 2019b; Kim and Williamson 2019; Pu et al. 2019) studied the pull-out resistance and shear resistance of studs under fatigue, and the failure under the tensile and shear actions, which were less studied in the past. The reduction formula of the capacity affected by the tensile force was proposed. Meanwhile, some researchers proposed some novel shear connectors ( $\mathrm{Li}$ et al. 2019j; Liu et al. 2019e), compared with the conventional PBL shear connectors, improving the uneven distribution of shear force. The mechanical performance of shear studs embedded in ECC and UHPC has also received attention (Kruszewski et al. 2019; Liu et al. 2019f), which provides the theoretical support for the promotion of UHPC, ECC and helps promote the new materials in the composite structures. Assembled shear connectors, used to strengthen existing bridges such as bolts and spring pins, are studied (Balkos et al. 2019; Tan et al. 2019; Hallmark et al. 2019). Some studies show that assembled shear connectors can achieve better anti-slip performance and the fatigue performance is higher than welded studs. As for durability, accelerated corrosion tests with the current were conducted in $\mathrm{NaCl}$ solutions (Chen et al. 2019a), to simulate corroded studs, and the push-out tests under freeze-thaw conditions ( $\mathrm{Li}$ et al. 2019b) were studied. Results show that the corroded shear studs exhibit different failure modes when under monotonic and fatigue loads. The freeze-thaw circumstance reduces the cracking load of concrete.

Due to the deformation of flexible shear connectors, the slip at the interface reduces the girder's stiffness. Zhang et al. (2019k) established a mechanical model and engineer-friendly program, considering the slide effects, to evaluate the bending performance. El-Zohairy et al. (2019) studied the retrofitted performance of the steelconcrete composite continuous girder with external prestressing tendon that was damaged by cyclic loads.

As an important part of the composite bridges, the concrete-filled steel tube (CFST) has been applied in more than 400 domestic bridges since the early 1990s. Because of the excellent mechanical properties, CFST trusses are mostly used in arch bridges as well as some beam bridges. CFST truss bridges, CFST lattice columns and CFST joints are studied in 2019. Based on the random characteristics of initial imperfections (Chen et al. 2019b), the flexural behavior was studied, and the reliabilities and related system resistance factors were proposed. Yuan et al. (2019c) studied the vibration characteristics and seismic performance of CFST lattice columns, and verified that such structures have good capacity of strength and deformability. Wu et al. (2019b) studied the hot spot stress concentration factor of tube-tube intersecting joints, tube-plate joints and broom-type joints to evaluate the different fatigue performance. Jin et al. (2019) studied the mechanical behavior of two types of detachable joints. The failure mode and strength of the detachable K-type joints and the initial stiffness of the K-type tube-plate joints are evaluated respectively.

The corrugated steel webs are commonly applied in composite box girders. The shear performance, bending performance, spatial behavior and fatigue details have been further studied in 2019. Wang et al. (2019k) studied the shear buckling performance of locally enhanced corrugated steel webs with horizontal and vertical stiffeners. Wen et al. 
(2019b) conducted an experimental study on the shear buckling performance of corrugated steel webs with artificial corrosion pits. Zhou et al. (2019a) applied an improved softened membrane model to study the pure torsion problem of prestressed box girders with corrugated webs. Zhou et al. (2019d) established a full-scale experiment to study the damage mode and deformability of the segmental box girder with corrugated webs and the transverse mechanical properties under vehicle loads. Chen et al. (2019e) studied a composite girder with corrugated steel webs and the CFST trusses. Xu et al. (2019b) evaluated the fatigue performance and vulnerable welding details of corrugated steel web under dynamic actions. Ye et al. (2019a) proposed the solution of the bending behavior of corrugated steel web beams using the triangular function, and compared the solution by the method of the Timoshenko beam.

Through reviewing the research on the steel-concrete composite structures in bridge engineering, novel type of composite structures, high performance materials, detailed analysis methods, and complex environments are important directions for studying composite structures in bridge engineering in the future. As for shear connectors, the degradation under complex environments, the mechanical behavior in new concrete materials, and the development of novel connectors will become research hotspots. The spatial stress distribution of steel-concrete composite girders under complicated loads and the assessment of bridge reinforcement and durability are the focus. The mechanical behavior of CFST trusses joints and the detailed analysis of long-span concrete-filled steel tube truss girders are hot topics. The spatial mechanical behavior and the fatigue performance of composite beams with corrugated steel web may receive attention. The application of corrugated steel webs is still developing, and the mechanical behavior and performance are studied, including fatigue-vulnerable points, theoretical solution, etc.

\section{Advances in box girder and cable-supported bridge analysis theories in 2019}

In recent years, with the emergence of new bridge forms such as the box girder bridge with corrugated steel webs, the multi-span cable-stayed bridge and the multi-span suspension bridge, two traditional topics in the bridge structure analysis theory, including the spatial analysis theory of box girders and cable-supported bridges analysis theory, have made great progress. In year 2019, scholars worldwide also have conducted extensive and in-depth research on these two classic topics, the following will elaborate four focused issues.

\subsection{Box girder analysis theory}

\subsubsection{Box girder with corrugated steel webs}

Owing to its many advantages such as various combinations of material, flexible connections of plates and good cooperation of external prestressing technology, the box girder with corrugated steel webs in bridges has become a main applicated form of corrugated steel webs. These box girders are mainly different in the form of the bottom plate, including (a) the concrete bottom plate, (b) the truss bottom plate and (c) the steel bottom plate, respectively, as shown in Fig. 1. The box girder with a concrete bottom plate is the most common form of the box girder with corrugated steel webs, 


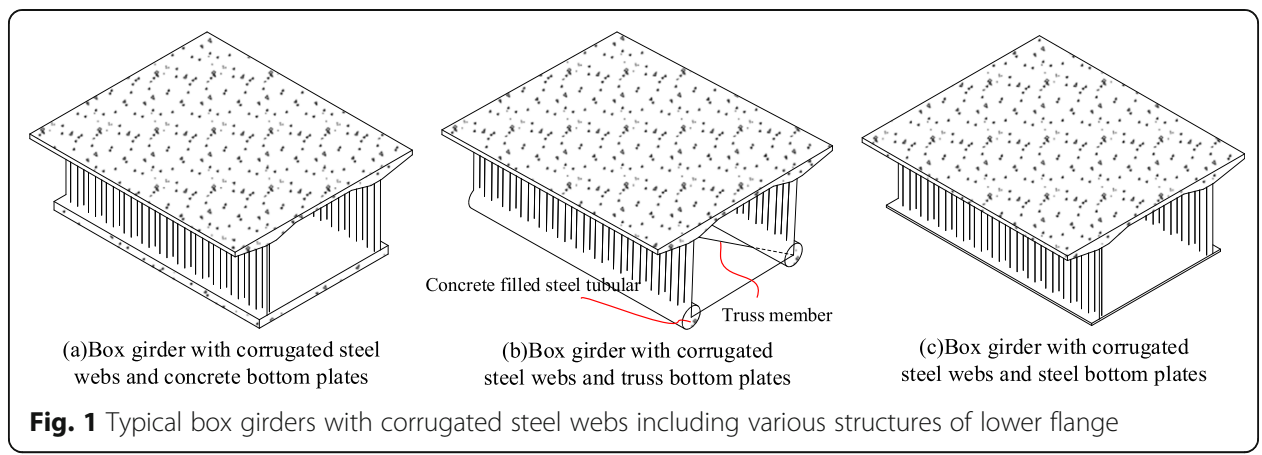

which could make full use of the characteristics of the materials compared with traditional concrete box girder, such as bending resistance of concrete top and bottom plates, shear resistance of steel webs, so as to significantly reduce the weight of girder and effectively solve the problem of cracks in the webs. The other two forms were the innovations derived from the former to further utilize the properties of materials and reduce the weight. While both they have more complex structures and more expensive costs.

Zhang et al. (2019o) and Wang et al. (2019c) deduced governing equations for shearlag of the box girder with steel corrugated webs and steel bottom plates (Fig. 1a by the energy variational method, and its accuracy has been verified using fine finite element models and experimental results. Chen et al. (2019f) studied shear-lag of the box girder with steel corrugated webs and truss bottom plate (Fig. 1b through the model test, numerical simulations and the theoretical derivation. The truss bottom plate is composed of concrete filled steel tubulars and steel connecting rods, and it leads the box girder to own high capacity and light weight. For box girder as shown in Fig. 1c, Zhou et al. (2019a) proposed a verified improved softened membrane model to evaluate its pure torsional performance, which effectively considered the tensile strength, tensile softening behavior and shear behavior of concrete.

\subsubsection{Traditional box girder}

There are also some reports on the extension of the classical box girder theory, which can be summarized into two main lines: (1) the extension of the traditional box girder theory based on the analytical method, such as Guo et al. (2019c) established the shear lag solution method of the variable section cantilever box girder by the analogy bar method, Li et al. (2019m) established the shear lag analysis method of the box girder applicable to the flange of any width by the energy method, Zhang et al. (2019n) derived the analytical solutions of the additional deflection and warping stress of the shear lag of the simply supported box girder and the two span continuous box girder by using the energy variational method based on the governing differential equation and boundary conditions of which the additional deflection is unknown; (2) the advanced beam element model of the box girder is developed by combining the spatial analysis theory of box girder with the finite element beam element theory, such as LezgyNazargah et al. (2019) used the energy principle to derive a new beam element with 25 degrees of freedom, which can consider the shear lag and the slip behavior of the steel- 
concrete interface, Henriques et al. (2019) proposed a general beam theory (GBT) which can accurately analyze concrete creep, section warping and shear lag of the box girder, Zhu et al. (2019b) proposed a finite beam element of 22 degree of freedom for curved steel-concrete composite box girder, which can consider warping, distortion and bidirectional interface slip.

\subsection{Analysis theory of cable-supported bridges}

\subsubsection{Middle tower effect of multi-span suspension bridge}

According to the research report of China's offshore bridge engineering (Gao et al. 2019), the multi-tower long-distance cable-supported bridge is a bridge type with significant technical, economic and environmental advantages, and the multi-span suspension bridge plays an important role in this type of bridge. Compared with the traditional two-tower and three-span suspension bridge, when loads are acting on one of its two main spans, the behavior of the multi-span suspension bridge is significantly influenced by middle tower effects (Fig. 2). The design of the middle tower of the multi-span suspension bridge involves key problems such as the stability of the middle tower, the slip between the main cable and the saddle groove, and the suitable longitudinal rigidity of the middle tower.

Shen et al. (2019b) presented 6 numerical models of multi-span suspension bridges with the main span of 500 to $1500 \mathrm{~m}$. By changing the longitudinal stiffness of the middle tower, they used those models to analyze the vertical deflection of the stiffening girder and the anti-slip safety factor of the main cable, and the value range of the longitudinal stiffness of the middle tower under different vertical stiffness requirements was suggested. Taking the deflection-span ratio and the anti-slipping safety factor of the main cable as control parameters, Wang and Chai (2019) proposed an analytical algorithm for upper and lower limit values of the middle tower stiffness of the multispan suspension bridge, and value range of middle tower stiffness for the multi-span suspension bridge with the main span of 1000 to $2000 \mathrm{~m}$ is suggested. zhang et al. (2019l) derived an analytical algorithm for middle tower stiffness of unequal span multi-tower suspension bridge based on the segmental catenary theory, and analyzed a background bridge with a span combination of $248 m+1060 m+1360 m+380 m$.

In addition, three papers reporting the concept design and mechanical performances of the multi-span suspension bridge are worth a mention. Taking Oujiang River North Estuary Bridge as project background, Cheng et al. (2019a) adopted bridge structural finite element models to explore the mechanical performances of two structural systems of the steel truss girder of the multi-span suspension bridge. Pan et al. (2019) studied

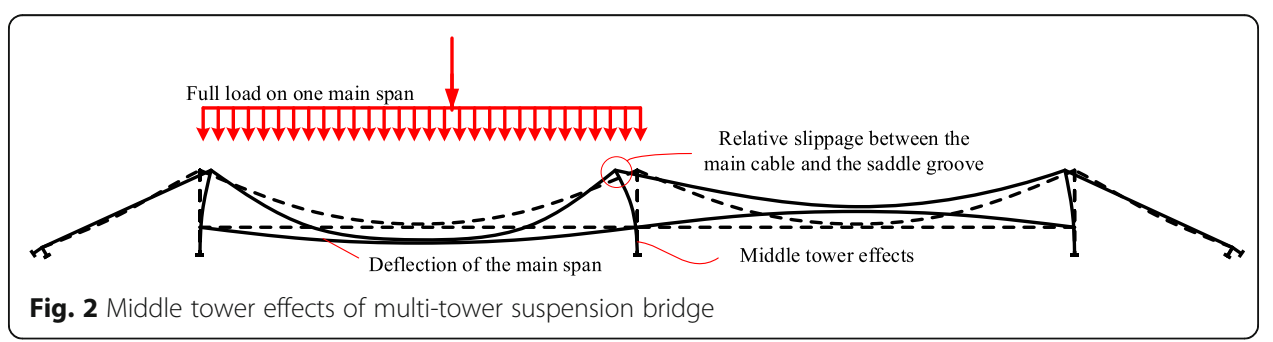


mechanical performances of a self-anchored multi-span suspension bridge with concrete girders.

Owing to various forms of the middle tower and difference among the analysis methods, the value range of the middle tower stiffness for the finished several multispan suspension bridges is not reaching a complete consensus. However, it is undeniable that designing of the middle tower of the multi-span suspension bridge (including the anti-slipping design of main cable) is gradually becoming more refined, more scientifically and more reasonable with the continuous deepening of relevant scientific research. With the development of offshore bridge engineering, the theory of the unequal-span multi-tower suspension bridge and three-more-tower suspension bridge need to be studied urgently.

\subsubsection{Ultimate capacity of bridges}

The stability issue of practical bridges mainly refers to the second category stability issue, which needs to consider geometry nonlinearity and material nonlinearity, belonging to scope of ultimate capacity. In year 2019, researches on ultimate capacity of bridges are mainly carried out on several bridges under construction.

Lyu et al. (2019) built the finite element model of the Fifth Nanjing Yangtze River Bridge which is a three-tower cable-stayed bridge in ANSYS software, and then analyzed stability coefficients of construction stages of the bridge, the ultimate capacity of each member and the effects of outer steel shell on ultimate capacity of the composite tower. Kim et al. (2019c) adopted a three-step method, which consists of initial shape analysis, construction stage analysis and external load analysis, to analyze stability of construction stages of a cable-stayed bridge. Yu et al. (2019b) studied the stability of construction stages of the Yachihe Bridge which is the longest steel truss cable-stayed bridge in the world, and studied the influence of geometric nonlinearity, material nonlinearity, temperature change and static transverse wind on the stability performance of the bridge. Wang et al. (2019a) adopted a new multi-scale finite element model to analyze ultimate capacity of the Egongyan Light-rail Bridge which is the largest selfanchored suspension bridge worldwide. It is concluded that the stiffened webs in the steel box girder would buckle before the bridge fails through the numerical simulations. Bai et al. (2019a) has innovatively proved that the in-plane overall elastic bifurcation buckling of the main girder would not lead the failure of the self-anchored suspension bridge through introducing displacement interference of the main girder to the deflection equation, as shown in Fig. 3. And they also did elastic and elastic-plastic analysis to obtain the ultimate capacity and failure modes of the Egongyan Light-rail Bridge.

At present, analysis theories of the ultimate capacity of long-span bridges is gradually deepening to the direction of refinement, and many complex factors affecting the ultimate capacity of bridges are considered more comprehensively. However, there are still many problems to be solved in the analysis method considering local-global failure interaction of bridges, such as interactive buckling of the bridge with steel box girders as main girders is not accurate enough, the contribution of different materials of components to the ultimate capacity of composite bridges is not clear, and the material constitutive model used in the ultimate capacity analysis is not uniform. For the wide box girder bridge, the influence of shear lag and transverse force of bridge decks on the 
ultimate capacity is not well taken into account. In addition, some special material behavior of concrete, such as plastic damage and cracking effects, is not considered in the area where concrete is used for bridge towers or main girders (Fig. 3).

\section{Advances in steel bridges in 2019}

\subsection{Advances in the development of steel bridges in China}

The year of 2019 has seen a series of important progresses in the development of steel bridges in China. In the April 2019, the Nansha Bridge was completed and opened to traffic in Guangdong province, China. One of the main channel bridges, the Nizhou viaduct (as shown in Fig. 4) is a steel suspension bridge with a main span of $1688 \mathrm{~m}$, ranking as the 2nd longest bridge at the time. In the October 2019, the Yangsigang Yangtze River Bridge (as shown in Fig. 5) was opened to traffic in Wuhan, Hubei province, China. After built, the Yangsigang Bridge replaced the Nizhou vidaduct as the 2nd longest bridge, with a main span of $1700 \mathrm{~m}$. It is worth noting that, the ultra-highstrength steel wires was employed for the main cable in the above two bridges, which has an ultimate strength of $1960 \mathrm{MPa}$.

The Hutong Yangtze Bridge (as shown in Fig. 6) is a double deck road-rail bridge. The cable-stayed bridge is designed with a main span of $1092 \mathrm{~m}$, in which the upper deck carries 6 lanes of road traffic while the lower deck carries 4 lanes of railway. In the July 1st, 2020, the bridge was opened to traffic as the world 2nd longest cable-stayed bridge. It is also worth stating that the $500 \mathrm{MPa}$ high strength steel plate was employed for the suspender, while the cable was made of the $2000 \mathrm{MPa}$ high strength wire.

The Zigui Yangtze River Bridge was opened to traffic in Zigui, Hubei province, China in September 2019, as shown in Fig. 7. The Zigui Bridge is a steel arch bridge with a main span of $519 \mathrm{~m}$, carrying 4 lanes of road traffic. Currently, the bridge is the 4th longest arch bridge in the world, and, all the top four arch bridges are in China up to date.

In the September 2019, the Xinshougang Bridge was opened to traffic in Beijing, China, as shown in Fig. 8. The bridge has a main span of $280 \mathrm{~m}$, supporting a deck of $54.9 \mathrm{~m}$-width and carrying 8 lanes of road traffic. According to the design conception, the two arch-shaped towers are respectively inclined towards the east and west direction, like two sitting athletes playing a tug of war. The total mass of steel used for the bridge reached an incredible number of 45,000 tons, which surpassed the total mass of steel used in the national stadium "Bird's Nest" (i.e. 42,000 tons).

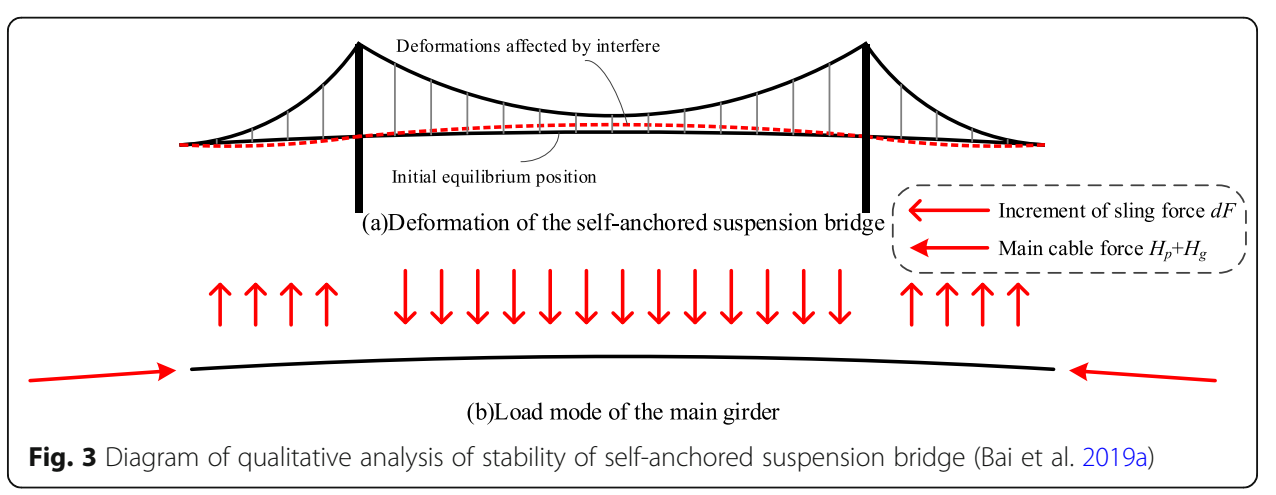




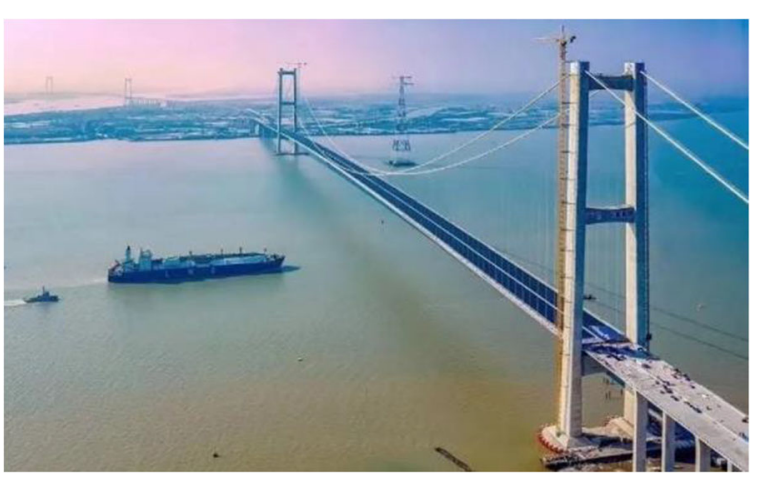

Fig. 4 Nizhou viaduct of the Nansha Bridge

\subsection{Development of weathering steels}

The application of weathering steel in bridges has advantages such as the reduced maintenance cost and enhanced environment-friendship. However, the corrosion fatigue deterioration in the weathering steel bridge becomes more prominent than in the traditional steel bridge since the coating is usually not applied.

Jie et al. (2017) carried out fatigue tests on the cruciform joint with pre-made artificial flaws. The result suggests that the influence of artificial flaws on the fatigue strength is almost negligible when their depth is below $1 \mathrm{~mm}$. Zheng et al. (2019a) performed a series of studies on the coupling mechanism of corrosion fatigue in weathering steels, as shown in Fig. 9. According to the result, the fatigue performance is largely affected by the pitting corrosion, and a notable reduction can be induced in the fatigue strength after corroded.

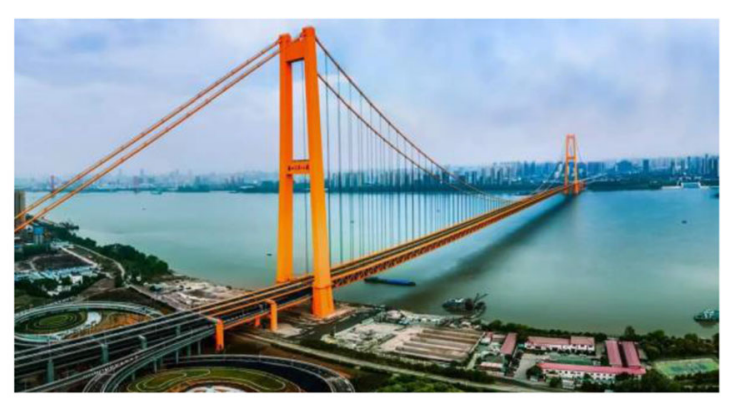

(a)

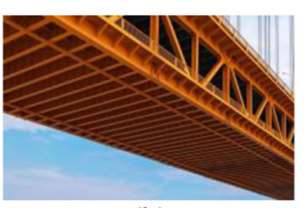

(b)

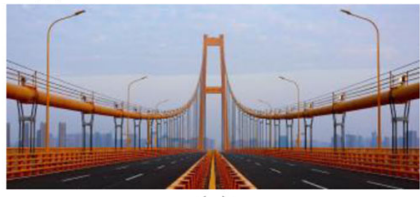

(c)

Fig. 5 Yangsigang Yangtze River Bridge: a Overview; b Suspender; c Deck 


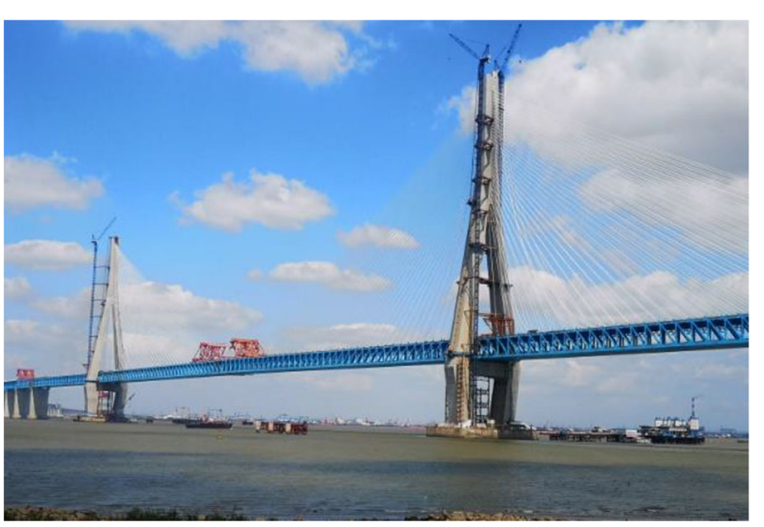

Fig. 6 Hutong Yangtze River Bridge

\subsection{Prototype of 3D-printed steel bridges}

The Dutch Hi-tech company MX3D started a construction project of the 3D-printed stainless-steel bridge in 2015. According to the project plan, an $18 \mathrm{~m}$-span stainlesssteel footbridge (as shown in Fig. 10) will be fabricated using the 3D printing and then installed on the Channel Oudezijds Achterburgwal. The project is cooperated by a list of Hi-tech companies and industrial partners. Currently, the final static loading test of 20 tons was completed. In the next, a sensor system will be installed to test the material performance and in-service data.

\subsection{Progress in orthotropic steel decks}

\subsubsection{Double-side welding of rib-to-deck joints}

The application of double-side welding (DSW) in rib-to-deck joints in orthotropic steel decks (OSDs) is at first improved by the Hanshin Expressway Company in 2011 (Kanjo et al. 2011), as shown in Fig. 11.

After that, the DSW is further updated and applied by the Wuchuan Co. Ltd. and Lixin Automation Co. Ltd. since 2016, as shown in Fig. 12. Currently, this technology has been applied in several bridges including the Jiayu Yangtze River road bridge in Hubei, Qingshan Yangtze River Bridge in Wuhan, Hubei, etc. A series of meaningful studies have been carried out the research group led by Prof. Zhang and Prof. Bu in Southwest Jiaotong University (Cui et al. 2019b; Zhang et al. 2018).

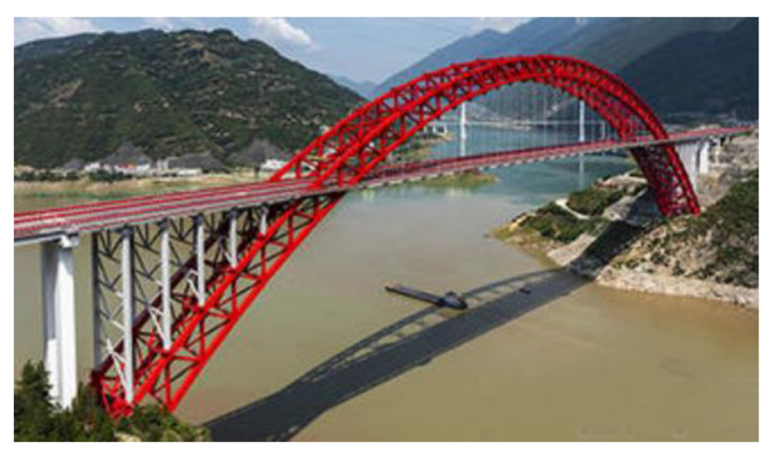

Fig. 7 Zigui Yangtze River Bridge 


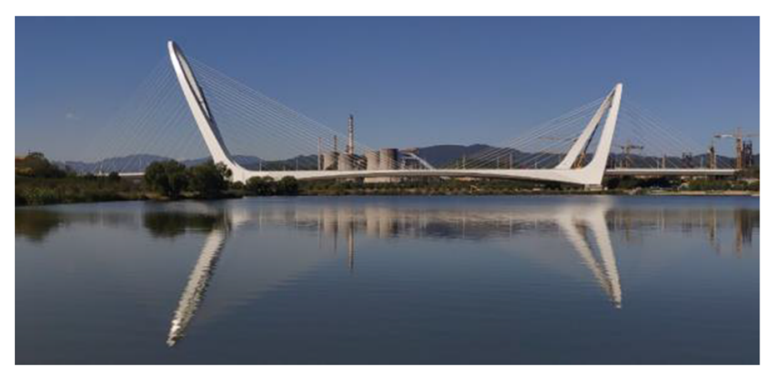

Fig. 8 Xinshougang Bridge

\subsubsection{Thickened edge U-ribs}

The conception of thickened edge U-ribs is to enhance the local thickness of rib walls without changing the shape of U-ribs, as shown in Fig. 13. A series of studies (Heng et al. 2020; Zheng et al. 2019a; Heng et al. 2017) have been carried out on the OSD with TEUs, as shown in Fig. 14. The result shows that the application of TEUs can improve the fatigue life of OSDs. Currently, the research outputs have been incorporated in several specifications and applied to several projects.

\subsubsection{Post-welding annealing}

The residual stress induced by welding process is one of the major causes for fatigue cracking in welding joints. In dealing with that, the post-welding annealing (as shown in Fig. 15) is gradually applied in the fabrication of OSDs. As per the preliminary test results (as shown in Fig. 16), the post-welding annealing can effectively improve the fatigue performance of structural details in OSDs.

\subsection{High-strength rivets for bridges}

The high-strength rivet, also called as the Huck Bolt, has been extensively applied to mechanical devices such as the locomotives, vehicles, rails and aircrafts. Recently, the application of high-strength rivets in bridges is expected to partially replace the

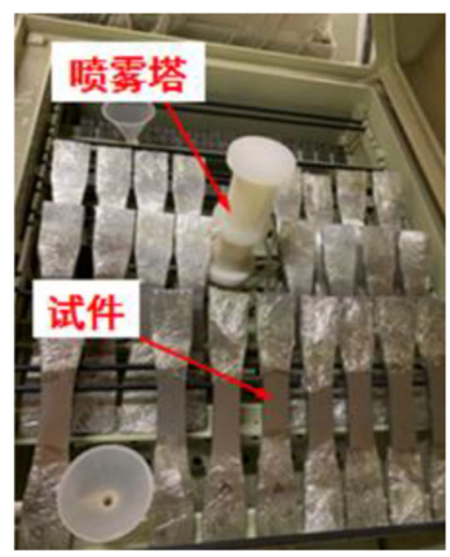

(a)

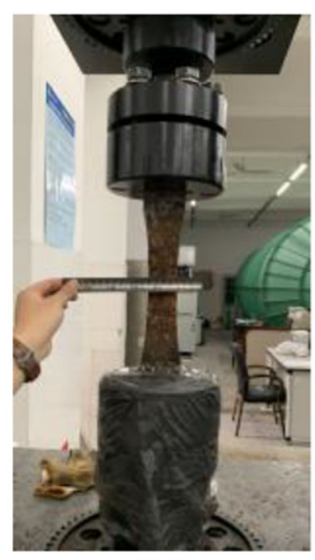

(b)

Fig. 9 Corrosion fatigue test: a Accelerated corrosion; b Fatigue test of corroded specimens 


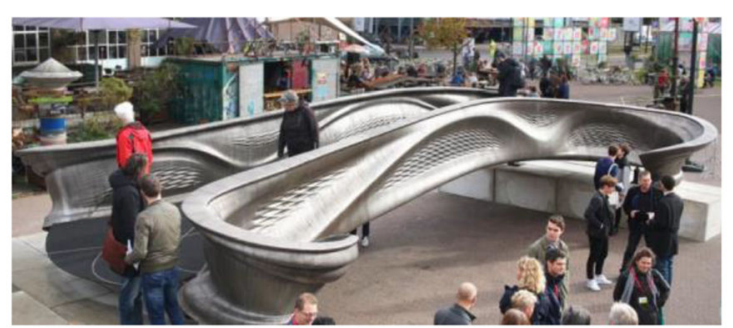

(a)

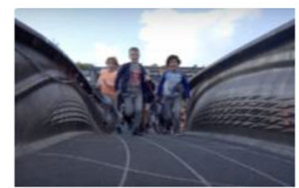

(b)

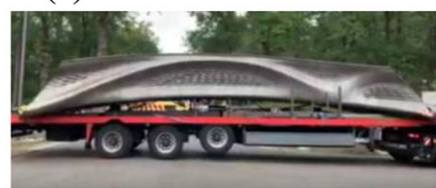

(c)

Fig. 10 The 3D-printed steel bridge by MX3D: a Overview; b Deck; c Transportation

traditional high-strength bolt to overcome its delayed fracture. Unlike the high-strength bolt, the high-strength rivet can be preloaded only once and cannot be re-loaded. Thus, it is important to investigate its time-dependent preloads. Since 2019, a series of experiments and researches were carried out in Southwest Jiaotong University, as shown in Fig. 17. The result preliminarily indicates the feasibility of high-strength rivets.

\subsection{Development of steel bridge parts in the second-generation Eurocode}

The steel structure-related parts in the second-generation Eurocode are now in the preparation by the task group SC 3 - EN 1993 in the CEN/TC 250 Committee. The task group is chaired by Prof Ulrike from the University of Stuttgart (CEN 2017). The

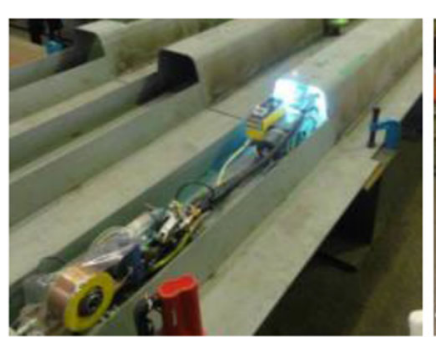

(a)

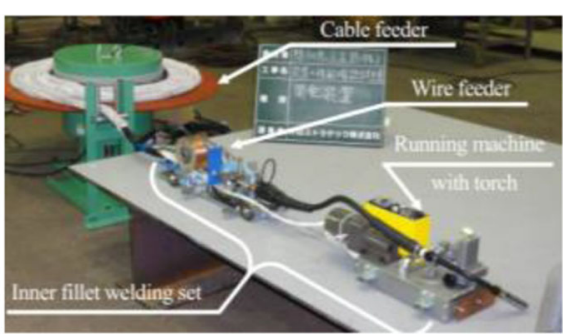

(b)

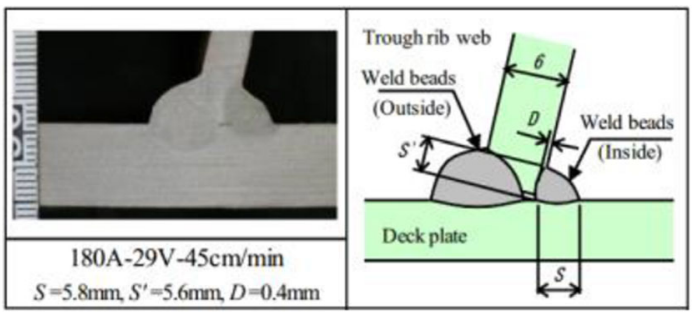

(c)

Fig. 11 The double-side welding of rib-to-deck joints by Hanshin Expressway 


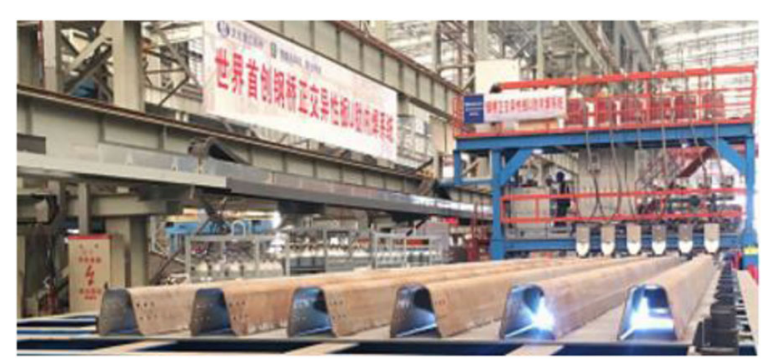

(a)

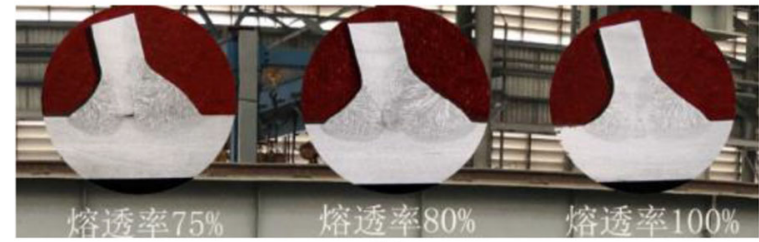

(b)

Fig. 12 Double-side welding of rib-to-deck joints: a manufacturing line; b Macro section

task is expected to be fully completed in 2021 and published in 2024 (Kuhlmann and Schmidt-Rasche 2017).

The high strength steel ranging from $460 \mathrm{MPa}$ to $700 \mathrm{MPa}$, which is previously covered in the supplementary EN 1993-1-12, will be adopted directly in the general provision EN 1993-1-1. Correspondingly, the related provision EN 1991-1-8, - 1-9 and -1-10 has been checked and modified to integrate the high-strength steel. Meanwhile, the original EN 1993-1-12 will be updated to cover the high-strength steel ranging from $700 \mathrm{MPa}$ to $900 \mathrm{MPa}$.

Besides, a brand-new part EN 1993-1-14 will be incorporated, with the title of "Eurocode 3 - Design of steel structures - Part 1-14: Design assisted by finite element analysis." The new EN 1993-1-14 will give rules respecting the application of finite element analysis and other types of numerical tools in the ultimate limit state check, serviceability limit state check and fatigue check of steel structures.

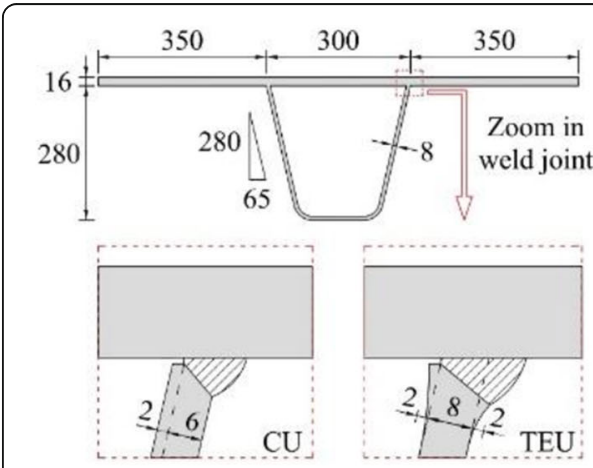

(a)

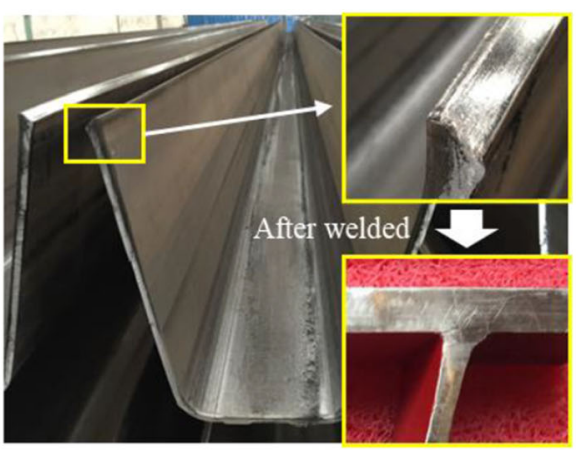

(b)

Fig. 13 Thickened Edge U-ribs (TEU) for OSDs: a Section; b Photography 


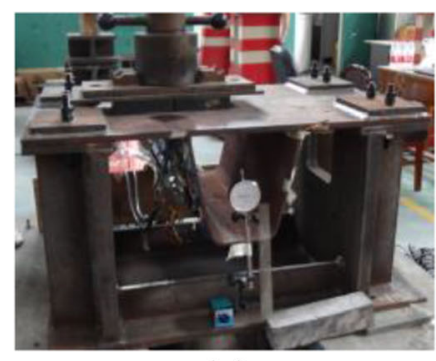

(a)

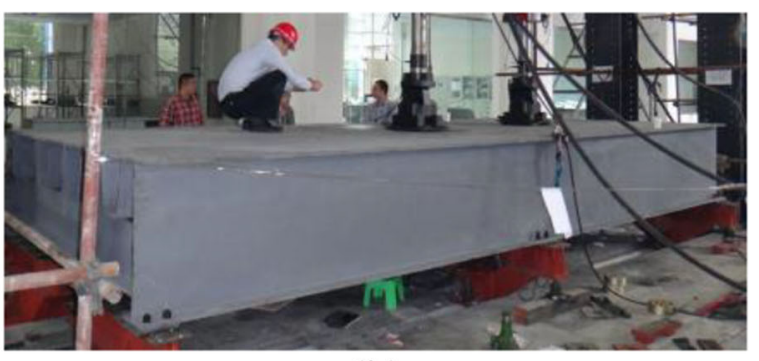

(b)

Fig. 14 Full-scale test of OSDs with TEUs: a Rib-to-deck specimen; b Segment specimen

\section{Theory of bridge evaluation and reinforcement}

There are six primary factors affecting the safe and reasonable use of existing bridge structures. First is the aging of bridges. Compared with the general design life of bridges in China (50 or 100 years for highway bridge, and 100 years for railway bridge), a lot of bridges have entered their aging period and show the problem of insufficient durability. Second, the threatening of increasing traffic volume makes the bridge safety problem more and more prominent. Third is that the common overload phenomenon aggravates the damage and brings potential safety hazards for bridge structures. Fourth is that a large number of bridges are 'working with defects', and the number of bridges with insufficient bearing capacity or dangerous bridges is increasing year by year. Fifth is that all kinds of natural disasters and man-made accidents threatens the normal use of bridges. Sixth, the upgrading and reforming of modern transportation system put forward new requirements for the long-term use of existing bridges. The research on the theory and technology of bridge's structural evaluation, reinforcement and maintenance associated with above six factors is one of the hottest academic subjects at home and abroad, which has important theoretical researching prospect and practical value.

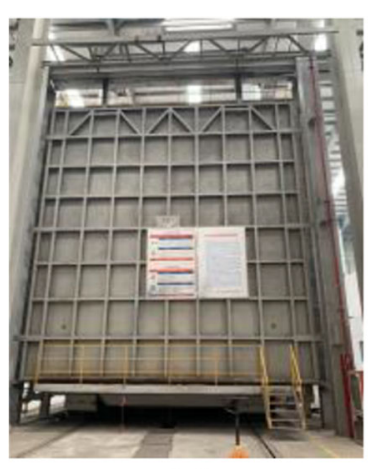

(a)

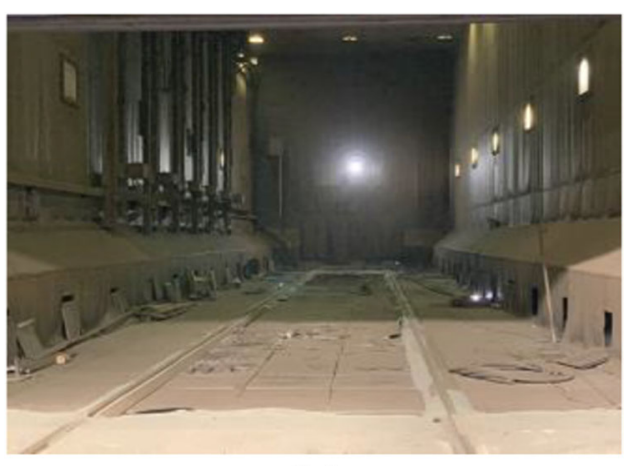

(b)

Fig. 15 Bogie-hearth furnace for annealing 


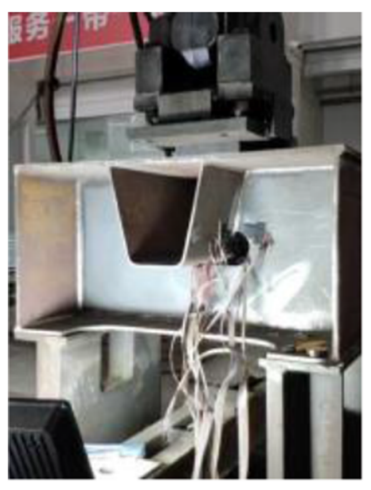

(a)

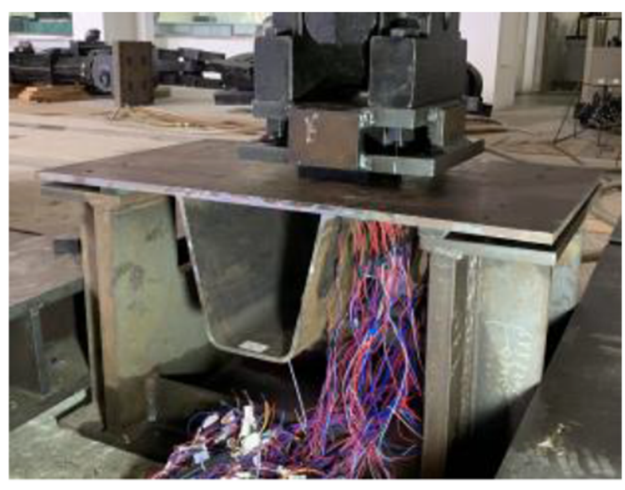

(b)

Fig. 16 Fatigue model test on annealed OSDs: a Rib-to-floor beam detail; b Rib-to-deck detail

\subsection{Research on reliability evaluation method of existing bridge based on time-variant theory}

Time-variant reliability based researches attracts a lot of academic interests in recent 2 years. The safety of existing structure in the remaining service life is not only related to its own state, but also related to the service environment, maintenance conditions and feature of loads applied to it. Generally, it is not suitable to directly use the current design criteria to evaluate the existing structure. The key to the state evaluation of bridge structure lies in the researches on structural resistance and load effect. Both the resistance and the load are time-variant. Therefore, the adoption of stochastic process theory to the structural reliability analysis accords with the objective law. In engineering field, a given time domain is often used where the stochastic processes of load and resistance are simplified into random variables, since the complexity of stochastic process theory makes it not convenient for practical application.

The load stochastic processes that are commonly used home and abroad include stationary binomial distribution, filtered Poisson process, and filtered Weibull process et al. Wang et al. (2018) referred to that when the existing bridge resistance was described by random process, the random process model of resistance was assumed to be uncorrelated or fully correlated, which was far from the objective reality. Therefore, a

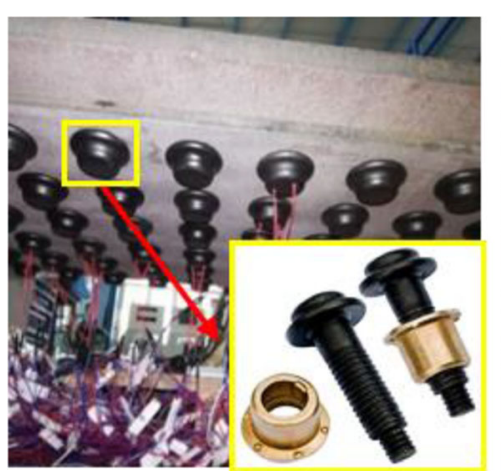

(a)

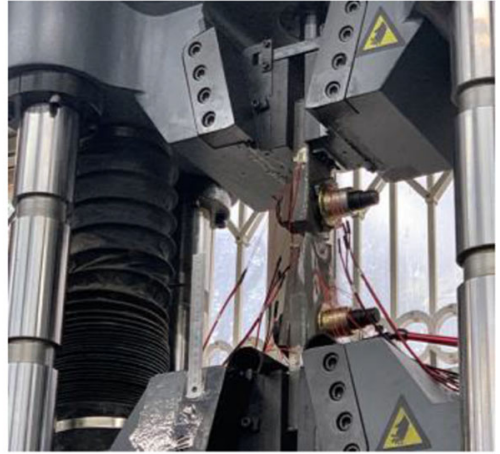

(b)

Fig. 17 Experimental studies on the high-strength rivets: a Group effect; $\mathbf{b}$ Ultimate capacity 
resistance model based on Gamma stochastic process which considered the correlation of resistance degradation was proposed. Ye et al. (2018) used Taylor series to expand the time-variant reliability formula proposed by Mori and Ellingwood and took its firstorder moment to calculate bridge reliability, which simplified the integral operation into algebraic calculation and improved the efficiency. Liu and Wang (2019) used the method of equivalent linearization and stochastic averaging to derive probability distribution function (PDF) of structural failure based on the first-passage time, and studied the first-passage problem for structural nonlinear dynamic system. Based on the Monte Carlo pseudo-random test approach, Qi and Wei (2018) used Copula function to analyze the systematical time-variant reliability by considering the correlation of bridge failure modes. Fan et al. (2019d) adopted the Bayesian dynamic linear model to provide time-variant dynamic distribution to the particle filter based on health monitoring data of time series, and proposed an improved particle-filter predicting method for the bridge dynamic reliability index. Wang and Zhang (2018) established an algorithm to consider the influence of load temporal correlation and decreasing load tendency to time-variant reliability of bridge structure, and the sensitivity of structural reliability associated with resistance, time-variant correlation and attenuating load dependency was then discussed.

Some studies are focusing on promotion of time-dependent reliability algorithm. Based on the stochastic process theory and the first-order second moment method, Gong and Frangopol (2019) proposed an analyzing approach of time-variant reliability considering the shear effect of layered building. Wang et al. (2018) proposed the hybrid time-variant reliability evaluation method in which aleatory and epistemic uncertainties were considered through the combination of a reduced model of state-space transformation and the natural set expansion theory. Li et al. (2018a) proposed a method for the time-dependent reliability analysis of structural resistance distribution based on the principle of phase distribution. Soltanian et al. (2018) proposed a time-variant reliability algorithm for railway sleeper under corrosion based on the first passage theory.

\subsection{Research on reliability calculation approach combined with engineering application}

Studies or discussions on reliability calculation methods in the background of engineering applications are multitudinous in numbers, such as main factors that affect the deterioration of bridge structural performance, including time-variant effect, creep effect, corrosion, load and crack, and carbonization, etc., as well as the reformed structural forms such as widened bridge structure, etc. Peng et al. (2018) established the timevariant reliability model of prestressed concrete box-girder bridge considering the uncertainties of chloride environment, time-variant effect of concrete, corrosion current density and chloride ion corrosion process. Zhao and Chen (2018) proposed the limit state function of time-variant fatigue reliability based on the residual strength model under multi-level loads. Based on Bayesian theory, Chen and Huang (2019) adopted Poisson stochastic process to describe the vehicle load effect and obtained the joint distribution of the aggregate of degradation data of resistance, in which the prior distribution was assumed normal distribution, and provided a predicting method of the dynamic reliability of concrete beam bridge. Based on the probability density evolution algorithm, Guo et al. (2019a) proposed the establishment method of limit state function 
of corroded reinforced concrete beams and predicted its time-variant reliability. Monte Carlo method and support vector machine method are used to study the time-variant reliability of widened concrete beam bridge (Bai et al. 2019b; Wu et al. 2019c). Based on the buckling calculation theory of simply supported purlin under atmospheric corrosion model, Liu et al. (2019b) proposed a time-varying reliability calculation method for the corrosion of purlins caused by typhoon. Based on the code for design of reinforced and prestressed concrete bridges, Zou et al. (2019a) proposed the function of camber at mid-span section of prestressed box girder by considering its creep effect, and developed a time-variant reliability calculation approach for the camber of box girder based on the third-order moment algorithm. Yang et al. (2019d) established the limit state function by considering the randomness of time-dependent model of section loss of corroded reinforcement under the general atmospheric environment, as well as the degradation models of shear and bending capacity, respectively; through introducing the boundary absorption condition, the author proposed the time-variant reliability algorithm of degraded reinforced concrete beams. Yang et al. (2019b) analyzed the cumulative effect of chloride ion on the surface of carbonated concrete, and the loadcaused crack and its effect on chloride-ion erosion acceleration. According to Fick's law, the PDFs of resistance corresponding to different service periods were obtained, and a time-variant reliability calculation approach by considering the combined effect of carbonation and chloride ion accumulation was proposed for reinforced concrete beams based on Monte Carlo method.

\subsection{Research on maintenance and reinforcement strategy}

The purpose of the research on the maintenance optimization theory of bridges in service is to coordinate the contradiction between structural safety and economy, so as to ensure the best investment benefit to bridge structures in their whole life cycle. With the increase of time, the service performance of bridge structure is deteriorating under the coupling effect of load and environmental factors (Stewart and Rosowsky 1998; Ellingwood 2005). As the uncertainty of load and environmental factors always exist, it has great significance to consider the uncertainty and degradation process with respect to the decision-making of bridge evaluation and reinforcement. The inspection and maintenance model of in-service bridge structure has time-variant characteristics, thus the degradation model of structural resistance has become the basis of optimization associated with bridge inspection and maintenance.

Based on the economical principle and engineering practices, researches on maintenance and reinforcement strategy were once a hot academic interest and had become relatively saturated, so the number of literatures in this field is few in recent 2 years. Pang (2018) proposed the optimization strategy of life cycle comprehensive maintenance and reinforcement of prestressed concrete bridge of which the objective function consisted of lowest affections of economic cost, environmental cost, environmental impact and comprehensive cost, respectively, on the premise that the reliability indexes of prestressed concrete beam in both serviceability limit state and ultimate limit state were greater than the minimum allowable values, respectively. Wang (2018) took stress and deformation as monitoring parameters, and discussed the importance of implementing monitoring over bridge construction to ensure safety and quality based on the case 
study of Zhicheng Yangtze River Bridge. Li et al. (2020) summarized the research progress of maintenance strategies and methods of bridge structure based on life-cycle seismic performance.

\subsection{Research on reinforcement theory and method}

Researches of reinforcement theory and method mainly include flexural and shear reinforcement, the problem of bonding interface between new and old concrete, the influence of environmental factors, concrete structural reinforcement method based on fiber reinforced material (FRP), etc., and the research objects are mainly reinforced concrete (RC) beams and columns. Among them, FRP strengthening is the most popular field to develop reinforcement studies. Yang et al. (2019e) proposed a predicting method for non-linear performance of RC girders after flexural strengthening by near surface mounted (NSM) reinforced polymer laminates. Jiang et al. (2018) reviewed the studies on mechanical performance, fatigue performance and corrosion-resistant performance of damaged reinforced concrete beams strengthened with FRP at home and abroad. Xing and Kong (2018), Cai et al. (2018) and Fan et al. (2019c) gave detailed overviews of shear, creep and flexural performance of concrete beams strengthened with FRP in terms of reinforcement form, effect, influencing factors and failure mechanism, etc. Naser et al. (2019) reviewed FRP strengthening and rehabilitation developments and did researches on RC-columns strengthened with FRP sheet and FRP NSM strips, respectively, and founded that the major contribution of FRP composites was its potential to extend service life, and performance of FRP strengthened structures was limited under surrounding loading and environmental effects.

Scholars at home and abroad summarized the current researching condition of FRP reinforced concrete structures, and believed that the field of torsional performance of RC beams strengthened with FRP, the influence of coupling effect of multiple environmental factors on the mechanical performance of reinforced structures, and the research field of RC beams strengthened with prestressed FRP would become hot spots in the future (Xing and Kong 2018; Fan et al. 2019c; Naser et al. 2019). Moreover, some researches about the use of the FRP reinforcements were also carried out. Kim and Kim (2019) experimentally investigated the flexural behavior of concrete beams with FRP reinforcements. Kueres et al. (2020) conducted the test research to investigate the shear performance of concrete beams with pre-tensioned CFRP reinforcements. Jia et al. (2019a) proposed a flexural-capacity design method for the configurations of the FRP/steel double-reinforced pier.

\section{Bridge model tests and new testing techniques}

With the continuous development of new materials and new technologies in bridge design, the mechanical characteristics and durability of critical parts of the bridge structure deserve attention. Compared with the original bridge test, the model test has the advantages of easier control of parameters, less restriction of environmental conditions, more economical, stronger pertinence, etc. It plays an irreplaceable role in the development of bridge engineering. 


\subsection{Static test}

Static tests have been widely used in the mechanical behavior research of bridge components and their results are very rich. For example, in the static test research of the main beam, Wang et al. (2019m) designed and made three scaled models (1:4) of corrugated steel web composite beam considering shear span ratio in order to explore whether corrugated steel plate can replace flat steel plate as beam web of transverse beam in the suspension bridge tower. In the research of the anchorage zone of cablestayed bridge pylon, Xiao et al. (2019a) studied the load transfer mechanism of the steel-concrete composite pylon anchorage zone of the cable-stayed bridge structure through the static full-scale model test and numerical simulation. To sum up, it can be seen that the static model test research mainly focuses on exploring the force transmission mechanism of the structure, design optimization, and verifying the safety and reliability of the actual structural design.

\subsection{Fatigue test}

Fatigue damage is one of the main failure modes of bridge structures, especially the bridge deck system components of steel structures which are affected by the service environment, material deterioration, structural details, etc. Due to the direct bearing of wheel loads, the bridge deck system structures often suffer from pavement damage, plate cracking and other conditions that affect the driving comfort and safety. At present, the fatigue test is one of the main means to study and verify the fatigue performance of structures and materials. Shi et al. (2019b, c) designed and manufactured a full-scale orthotropic bridge deck fatigue test model, which contains two U-ribs and two V-ribs in order to study the fatigue performance of the fatigue sensitive area at the joint of stiffening ribs and diaphragms of railway orthotropic steel bridge deck. Yuan et al. (2019c) carried out fatigue cyclic loading on a complete model to produce cracks, then repaired the cracks and poured UHPC cover on the roof.

In addition to steel structure fatigue, concrete structures also crack under long-term repeated fatigue loads. Lv et al. (2020) studied the effect of rubber particles on the uniaxial compressive fatigue performance of self-compacting rubber lightweight aggregate concrete (SCRLC) through uniaxial compressive tests.

\subsection{Shaking table test}

Shaking table test is one of the most widely used test methods in seismic research at present. Scholars have carried out a large number of shaking table tests from the perspectives of the bridge structure, construction methods, and seismic excitation modes.

Shao et al. (2019) carried out the shaking table test on a large scale simply supported beam bridge, with the consideration of more realistic seismic response and smaller impact of the dimension effect, to study the seismic performance of single-column piers. The El Centro N-S longitudinal and vertical seismic waves were simulated using a 3way 6-degree-of-freedom large-scale seismic shaking table. Sun and Xie (2019), Xie and Sun (2019) made a 1/70 super-long cable-stayed bridge model to study the seismic performance of pile-soil-bridge. Zou et al. (2019b) proposed a new isolation system for the functional separation of high-speed railway bridges, which was verified by shaking table tests. In order to study the seismic response of high-speed railway continuous girder 
bridges built in our country, Jiang et al. (2019a) made a 1/12 scaled typical high-speed railway continuous girder bridge specimen in China, and detailedly introduced the shaking table test process. When studying the seismic performance of the long-span pile foundation cable-stayed bridge, Sun and Xie (2019) conducted a 1/70 full-bridge model shaking table test study on a super-long span cable-stayed bridge. Zheng et al. (2019c) conducted shaking table tests on four and a half proportion of geosynthetic reinforced soil (GRS) abutment specimens.

To study the seismic performance and isolation effect of the traditional friction swing bearing (FPB) and the new three friction swing bearing (TFPB) isolation bridge, Wen et al. (2019a) conducted shaking table tests on the 1/10 scaled FPB and TFPB simply supported beam bridge models under the excitation of a two-direction earthquake. Brito et al. (2019) evaluated the seismic performance of a new type of reinforced concrete bridge pier with a low cost sliding pendulum system through a one-way shaking table test. Zhou et al. (2019f) conducted shaking table tests on a 1/10 scaled single span bridge, and studied the seismic response and shaking isolation effect of the bridge with a post-tensioned swing pier with negative swing stiffness.

\subsection{Hybrid testing}

Structural hybrid test, also known as the pseudo-dynamic test, is a new seismic test method which combines numerical simulation with a physical test. The hybrid test divides the whole structure into two parts. One is the test substructure, and the other is the numerical substructure, which is used in the computational simulation. This method can solve the problem that the actual structure sometimes is too large or too heavy that exceeds the loading capacity of the test equipment. Since the hybrid test technology was put forward in 1992 (Guo et al. 2019b), it has been widely used in the research of the seismic performance of building structures, and then gradually used in the research of the seismic performance of bridge structures. Yuan et al. (2019a) carried out pseudo-dynamic tests on the scaled model of concrete-filled steel tubular lattice column piers of the Ganhaizi super large bridge and studied the seismic performance of such structures under different intensity earthquakes and main aftershocks. To study the seismic performance of the tall-pier bridge with thin-walled hollow sections of the rigid frame, Zhu et al. (2019c) proposed a novel hybrid simulation method for on-line updating of the concrete constitutive parameters (UHS).

\subsection{New testing technology}

With the rapid development of various digital, automatic and intelligent modern equipment and instruments, new testing technologies continue to emerge. These new technologies could obviously improve the efficiency and quality of model testing (including detection and acquisition of stress state, micro deformation, microcracking and damage of steel and concrete materials, etc.). According to the test purpose, it can be roughly divided into the following categories: 1) stress and strain; 2) geometric displacement; 3) vibration acceleration; 4) detection of concrete cracks and internal defects; 5) detection of metal cracks; 6) detection of material damage.

In stress-strain measurement, the optical fiber method is widely used in structural strain monitoring because of its high accuracy and good economy (Ye et al. 2020). In 
addition, digital image correlation technology can also be applied to strain testing. Guo et al. (2019b) used the technology of strain measurement and digital image correlation (DIC) to determine the deformation of samples when testing the tensile properties of high-strength concrete with different compressive strength.

Geometric displacement is often used in the experiment. Displacement meter, laser scanning technology, and optical fiber method are widely used in displacement measurement. Ghaffar et al. (2019) proposed a design method of two-dimensional displacement sensor based on the coupling effect of macroscopic bending loss and optical power.

As a mature technology, accelerometers are widely used in structural vibration acceleration tests. Zhang et al. (2019e) modified the existing accelerometer with silicon on insulator technology and developed a capacitive accelerometer for the structural seismic response test, which effectively improved the test sensitivity. Besides, the vibration acceleration measurement technology based on vision is popular too.

Ultrasonic and radiation methods are the latest methods to detect cracks and internal defects in concrete model structures. Carreras et al. (2019) recorded the loaddisplacement curve and crack front geometry of composite materials by means of X-ray photography.

Infrared, metal magnetic memory, acoustic emission and eddy current are often used in metal crack detection. Sun and Zhen (2019) proposed a method of using active infrared thermal imaging technology to detect the coating of bridge steel structure, which is more able to detect and enlarge the invisible defects of the naked eye. During the quasi-static test of Q235 portal frame, Su et al. (2019b) studied the changing characteristics of the metal magnetic signal in different stress stages. They established the corresponding relationship between the magnetic signal and its gradient value and the stress concentration position.

Scanning electron microscopy is often used to observe the failure interface of materials. Ghassemi and Toufigh (2020) studied the change of the microstructure of epoxy polymer concrete after 1 year's exposure to SEM. Zhou et al. (2019b) proposed a new corrosion detection technology of galvanized steel strand cable based on metal magnetic memory technology. This method successfully solves the problem that conventional technology is difficult to detect the internal corrosion of galvanized steel strand cable.

As for the future research of bridge model test and testing technology, more attention should be to the following aspects: to develop and construct the test equipment for multi-directional and complex static and dynamic loading equipment and large scale salt spray test chamber etc.; to develop new type of test sensor with high precision, such as distributed grating sensor, multi-point laser displacement meter, distributed crack sensor, crack image recognition sensor, introduction of medical, aerospace testing methods and 5G technology into the bridge test and transmission of testing and monitoring data; to develop test data processing and error separation technology, so as to improve the analysis accuracy of the test results.

\section{Steel bridge fatigue}

In regard to evolution of fatigue damage and degradation mechanism, Macho et al. (2019) investigated fatigue performance of the component connection considering artificial accelerate corrosion and coupled complex stress, indicating that the corrosion will 
significantly accelerate fatigue damage evolution process. Gao et al. (2019) pointed out that the coupling degradation mechanism of fatigue resistance of ocean bridges subjected to vehicle load and complex ocean load, and the interaction mechanism between seawater corrosion and structural fatigue damage still need to be further studied. The deterioration and failure mechanism of fatigue resistance of steel bridge caused by initial manufacturing defects and initial welding residual stresses during the manufacturing process was investigated Cui et al. (2019a). The advanced test detection technology to elucidate the microscopic and mesoscopic mechanism of the fatigue crack initiation and propagation process, and clarify the effect mechanism of critical factors on the fatigue performance should be further developed.

In term of fatigue performance and assessment of steel bridge, the multi-crack mode and fatigue resistance of longitudinal rib-to-crossbeam welded joints in orthotropic steel decks were estimated by using the hot-spot stress method (Huang et al. 2019f). The fatigue crack propagation characteristics and failure mechanism of diaphragm cutout in orthotropic steel decks were investigated by in-site monitoring data (Zhu and Xiang 2019). Luo et al. (2019) evaluated the fatigue resistance of welded joint between thickened-edge U-rib and deck in orthotropic steel deck using the notch stress method. Wang et al. (2019j) expounded the fatigue crack propagation mechanism of rib-to-deck welds based on effective notch stress method. The dominant fatigue cracking mode and fatigue performance of welded joints under the condition of multi-crack mode of rib-to-deck welded joint in orthotropic steel deck were studied using equivalent structural stress method (Li et al. 2019d). Sun et al. (2019a, b) proposed an adaptive crossscale fatigue damage assessment method for long-span steel bridge based on the theory of microstructure damage mechanics of steel bridge. The assessment method and theory of fatigue damage and life should be further proposed considering multiple loading, micromechanics of welded joints, etc.

In respect of damage monitoring and inspection of steel bridge, structural response data obtained by the bridge structural health monitoring system to invert the damage state of the structure and identify the damage of bridge is carried out (Li et al. 2019c; Pei et al. 2019). It is an important development direction in the future to deeply integrate the new generation of information technology to develop the new generation of bridge damage monitoring and detection technology (Bao and Li 2019). Xu et al. (2019a) and Yin et al. (2019) respectively constructed different neural network models and established a complex mapping relationship between monitoring data and structural damage state to rapidly identify the structural damage state. Xu et al. (2019d) proposed a structure crack identification method based on computer vision and artificial intelligence, and realized the remote intelligent monitoring of shallow fatigue cracks on the structure surface. Currently, non-manual detection methods for fatigue crack mainly include three categories: the indirect damage identification method for strain based optical fiber strain sensor and film sensor (Bao et al. 2019b), the direct crack detection method based on acoustic emission technology (Megid et al. 2019), and the non-contact detection method for intelligent crack image recognition based on computer vision (Al-Salih et al. 2019). However, those methods are insensitive to the micro-crack in the early period of fatigue crack initiation. The development of intelligent monitoring and detection methods for fatigue micro-cracks of steel bridge and the 
establishment of a set of intelligent monitoring and detection technologies for fatigue damage of steel bridge are the critical research topics in the further.

In term of fatigue reinforcement and maintenance of steel bridge, some reinforcement and maintenance methods were proposed. Yao et al. (2019) studied the influence of stop-hole size and spatial position on the reinforcement effect of steel bridge fatigue cracking, and determined the stop-hole parameters with reinforcement effect based on the test and theoretical analysis. A cold maintenance method for microdamage or zero-damage of existing structures by means of assembly-type connections such as pasting, bolting or glue-bolting hybrid connection was proposed by Kinoshita et al. (2019b), Wang et al. (2019b) and Al-azzawi et al. (2019). Izadi et al. (2019) used a method for strengthening fatigue cracking of steel truss bridges with Fe-SMA, and verified its applicability and feasibility using fatigue test. Yuan et al. (2019d) and Wang et al. (2019l) adopted UHPC as the structural layer to investigate the enhancement effect of light composite bridge deck structure. Kinoshita et al. (2019a) strengthened the welded joints of steel bridge with ultrasonic impact method, demonstrating that ultrasonic impact could effectively decrease the stress concentration of the welded joints, reduce the local microscopic defects of the weld toe at welded joints and welding residual stress, and significantly improve the fatigue resistance of the welded joints of the steel bridge. So far, the studies are mainly non-penetrating fatigue crack, and there is still a lack of investigation on the reinforcement method of penetrating fatigue crack in real bridges. Besides, assembled and the normalized reinforcement method and theory should be developed to meet demands of rapid reinforcement of steel bridge without blocking traffic.

\section{Wind resistance of bridge}

The state-of-the-art focusing on the main aspects of wind-resistant of long-span bridges in 2019 was reviewed and discussed, which included the field measurement of wind characteristics at the bridge sites, characteristics of nonlinear flutter, buffeting, vortexinduced vibration, and their countermeasures.

The field measurement of the wind characteristics mainly paid attention on the typhoon and mountainous wind fields. As for the typhoons, the researchers examined the mean wind speed profiles and turbulent spectrum in their outer regions (Kim et al. 2019a; Tao and Wang 2019b; Zhao et al. 2019c). Based on these studies, the wind field in the outer region of typhoon can be roughly summarized as: (a) the wind characteristics in the outer region of typhoon are very similar to those of non-typhoon wind; (b) their probability density function of fluctuating wind speed almost follows a Gaussian distribution; (c) the power spectrum can be expressed by a Von Kármán-type. However, few attentions were paid on the wind characteristics in the typhoon center which needs further study. As for the field measurement of wind flow over mountainous areas, the researchers utilized Windcube Lidar and ultrasonic anemometer to obtain the wind speed histories and analyzed wind direction (Jing et al. 2019; Liao et al. 2020; Yu et al. 2019a; Zhang et al. 2019q), turbulence characteristics and so on. According to their results, some consensus can be concluded as following: (a) the deep canyon terrain has obvious effects on locking the wind direction; (b) turbulence intensity calculated based on measurement data is more appropriate for engineering applications than power law; (c) the Von Kármán spectral models have significant applicability for the turbulence 
over mountainous areas; (d) the non-stationary characteristics of mountain wind fields are more significant than those of coastal and plain areas.

Flutter analysis and amplitude prediction are two major objects of soft flutter research. Spring supported sectional model wind tunnel test is an important means to obtain the steady-state vibration response of soft flutter of a bridge deck. Lots of experimental results reveal a fact that the soft flutter state of a bridge deck is still characterized as a coupled torsional-vertical motion and will further be affected by the aerodynamic configuration, wind angle of attack, and structural damping of the bridge (Gao et al. 2020b; Tang et al. 2019a; Wu et al. 2019a; Zhu et al. 2019d). Some typical bridge sections (e.g., streamlined box girder, split box girder and truss girder, et al) that are widely used are sensitive to wind excitations that prone to perform soft flutters.

Current analysis framework of soft flutter theory can be divided into two categories: (1) nonlinear flutter analysis frameworks considering the nonlinear dependence of higher harmonic components of self-excited forces on vibration amplitude; (2) nonlinear flutter analysis frameworks only considering the nonlinear dependence of fundamental linear harmonic component of self-excited forces on vibration amplitude. For the first type of analysis framework, it is experienced from previous studies that a significant higher harmonic component was observed in self-excited force by a wind tunnel test (Gao et al. 2020a) or a CFD numerical simulation (Zhang et al. 2019j), thus it should be accounted for in an analysis. Some unnecessary higher harmonic components that have no contributions to vibration or of very small proportions, e.g., less than $1 \%$, can be neglected in the nonlinear aerodynamic model. Based on these observations, a nonlinear empirical mathematical model only considering the parameters involving the 1-st and the 3-rd harmonic component of the self-excited pitching moment was proposed. Thereafter, an SDOF torsional limit cycle oscillation (i.e., the amplitude of soft flutter) can be calculated by adopting a numerical solution method or an energy equivalent method. The second type of analysis framework is originally proposed based on the obtained self-excited forces that of no higher harmonic component but severely nonlinearly depend on the vibration amplitude (Lin et al. 2019). Accordingly, the bimodal coupled flutter solution was still adopted in the analysis and the method of the prediction of the amplitude of soft flutter was proposed (Wu et al. 2020) as shown in Fig. 18. The accuracy of the method has been validated by wind tunnel tests. The calculation of soft flutter response of bridges has been extended from 2D to 3D which can provide efficient reference for the estimation of the multimode coupled soft flutter of long-span bridges (Wu et al. 2020).

In the aspect of buffeting theory of long-span bridges, researchers have been striving to improve high accuracy buffeting force models and calculation methods, and the main attention is paid on the following three aspects: (a) modelling of aerodynamic forces exerted on bridge girders; (b) buffeting response analysis method of long-span bridges; (c) the buffeting response of bridges under the action of non-stationary winds. In the aspect of buffeting aerodynamic forces, based on the 3D buffeting theory, Yang et al. $(2019 \mathrm{~g}, \mathrm{~h})$ proposed a general spanwise coherence function of buffeting forces. In addition, by introducing the empirical model of aerodynamic admittance function (AAF) correction factor, the 2D AAF of typical bridge sections are directly identified in turbulent flow, which provides an important basis for the refined analysis of buffeting forces for long-span bridges ( $\mathrm{Li}$ et al. 2019f). Based on the results of pressure 

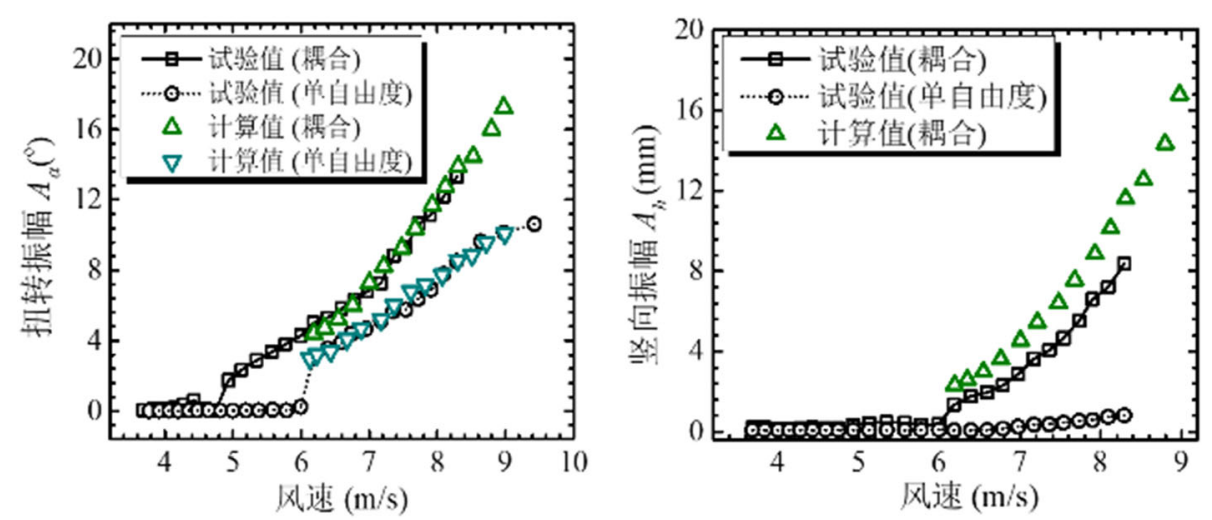

Fig. 18 Experimental and calculated steady-state amplitude vs. wind speed (Wu et al. 2020)

measurements on the streamlined box girders via wind tunnel test, Ma et al. (2019) established an empirical model of 3D AAF accounting for the 3D effects of turbulence. As the prototype bridges are in a vibrating state, Yan et al. (2019a) proposed a testing method to separate aerodynamic force into self-excited force and buffeting force. Then the AAF of a bridge girder is calculated based on the extracted buffeting forces. The results show that the AAF shows a dependence on the vibration state of bridge girders. In the aspect of buffeting response analysis method, Xu et al. (2019f) pointed out that the buffeting-induced stress (Fig. 19) analysis is one of important means to assess the local failure and fatigue damage of long-span bridges located in strong wind regions. They established a new framework for buffeting induced stress analysis of long-span twin-box girder bridges based on the proper orthogonal decomposition of windinduced pressures and the substructure-based finite element model, where the reliability of the method is verified by comparing the results with those obtained from field measurements. Based on Ribner's 3D aerodynamic theory, Li et al. (2019g) proposed a buffeting analysis method for long-span bridges in the frequency domain with full considerations to the 3D effects of turbulence. In the aspect of buffeting response of bridges under the action of non-stationary winds, taking the Sutong Bridge as an engineering background, Tao and Wang (2019a) carried out non-stationary timedomain simulations and performed buffeting analysis with a consideration to the striking non-stationary features of Typhoon.

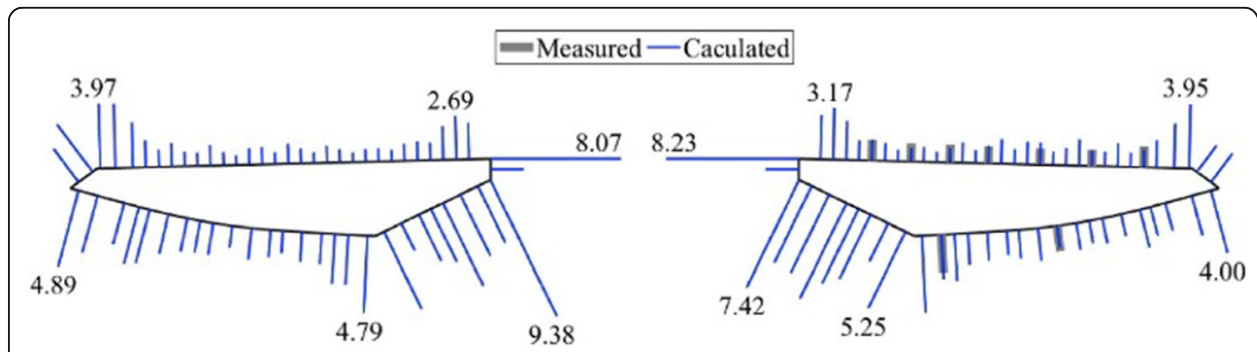

Fig. 19 Distribution of standard deviation of longitudinal stress responses over the cross-section of bridge deck at middle-span (Xu et al. 2019f) 
In terms of analytical theory and vibration control technology for vortex-induced vibration (VIV), scholars mainly focused on the researches of vortex-induced force mathematical model, vibration mechanism and mitigation countermeasure. In the research of vortex-induced force mathematical model, Zhang et al. (2019i) presented a nonlinear analysis model for the VIV analysis of bridge decks based on the describing function (DF) which is widely used in the analysis of nonlinear aeroelastic system, and VIV was treated as harmonic input description function. Extended Kalman Filter with Unknown Input (EKF-UI) was applied by Hui et al. (2019) to identify the non-linear system parameters and aerodynamic force of a single-degree-of-freedom system, and a method for identifying nonlinear self-excitation forces was proposed. For exploring the mechanism that causes VIV of bridge girder and its effect factors, Hu et al. (2019) studied the Reynolds number effect on vortex-induced aerodynamic force by using the closed box girder model with different scales. The results showed that the vortex-induced response and the vortex-induced force distribution are obviously different at different Reynolds numbers, with the increase of Reynolds number, the vortex-induced response increases, but the onset wind speed of VIV decreases. The characteristics of vortex-induced forces and span-wise correlations of rectangular cylinder, trapezoidal girder and typical streamlined girder were studied by (Sun et al. 2019d). It was pointed out that the excitation mechanism of VIV is different in different section shapes, and the span-wise correlation strength of vortex-induced force is determined by the proportion of self excited force (SEF) and vortex shedding force (VIF) acting on the model. At present, the VIV control measures are mainly divided into aerodynamic control and mechanical control. Zhao et al. (2019d) summarized the frequently-used aerodynamic measures of four main girder types (bilateral, integral box, split box and truss) which are widely used in long-span bridges. Chen et al. (2019d) proposed a new idea to suppress VIV, in his method a passive self-issuing jet was arranged in the section of the main beam (see Fig. 20), the distribution of flow field and the formation vortex which cause VIV were disturbed, in hence the vibration was suppressed.

\section{Vehicle-bridge interactions}

Vehicle-bridge interactions are a fundamental problem in the field of bridge engineering. The accurate and reliable characterizations of vehicle-bridge interactions can provide an excellent guidance for practical engineering. The related researches have been carried out for a long time, and remarkable achievements have been received. In this paper, main progresses and advances of the vehicle-bridge interaction field in 2019 are surveyed, including the vehicle-bridge dynamics, vehicle-bridge random dynamics,

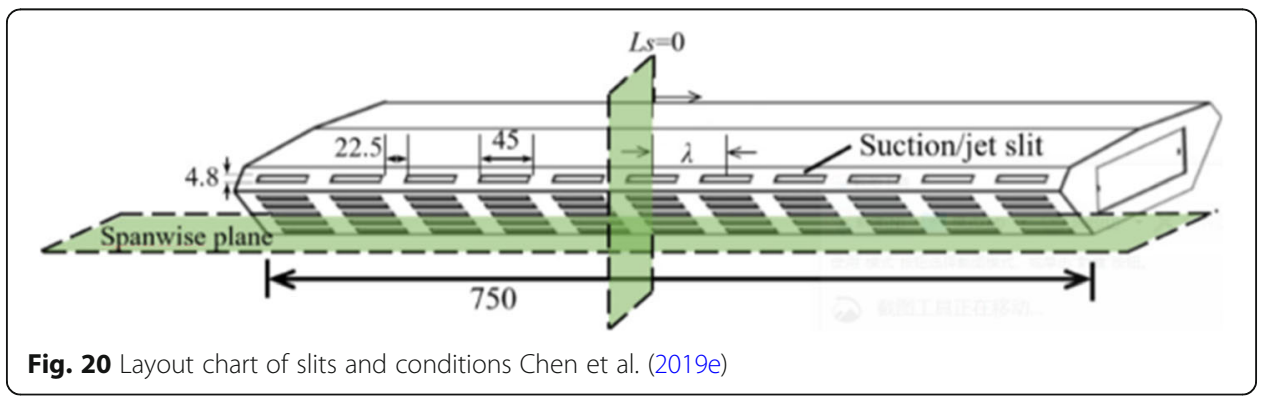


wind-vehicle-bridge dynamics, and maglev vehicle-bridge dynamics. Furthermore, the research hotspots and prospects are predicted.

\subsection{Vehicle-bridge dynamics}

Herein, the vehicle-bridge dynamics refers to the vehicle-bridge coupled system under track irregularities without any other external loading. In 2019, the vehicle-bridge dynamics was further developed in the aspects of refinement, simplification, practicality, theoretical solution, inverse problem, intelligence and visualization (Zhai et al. 2019). Specially, the simplification and practicality were in great progresses. For instance, $\mathrm{Xu}$ and Zhai (2019) combined the vehicle-track coupled dynamics and energy variation principle and proposed a time-dependent matrix-coupled model for the train-trackbridge interaction, where the displacement and force compatibility between the wheel and the rail at the condition of contact and separation are considered. Zhu et al. (2019e) combined the multi-time-step method and a moving track technique to reduce the computational burden. Jin et al. (2020) investigated the simplified vehicle-track models for assessing the running safety of vehicles on deformed bridges. It is clarified that omitting the rail vibrations may leads to large wheel-rail response errors. Yau et al. (2019) proposed an equivalent additional damping approach to assess vehicle-bridge interactions for train-induced vibrations of short-span railway bridges. The method is testified to be superior to the Additional Damping Method in Eurocode 1. Gou et al. (2019) analytically derived the relation between the bridge deformation and railway track deformation.

Summarily, the theories of vehicle-bridge dynamics have been relatively mature. In the future, vehicle-bridge dynamics are likely to develop in the direction of digitization and intelligence.

\subsection{Vehicle-bridge random dynamics}

Vehicle-bridge random dynamics is the extended concept of the conventional vehiclebridge deterministic dynamics by considering the uncertainty of physical parameters and internal/external excitations. Recently, vehicle-bridge random dynamics has been developed in an all-round way, including the efficient random approaches, uncertainty quantification, reliability assessment and sensitivity analysis.

As for the efficient approaches, Jiang et al. (2019b) and Han et al. (2019b) respectively applied the new point estimation method and artificial neural network-based surrogate model to improve the efficiency of train-bridge random analysis, and study the random responses of the coupled system under various uncertainties. In the aspects of uncertainty quantification, Mao et al. (2019) evaluated the uncertainty upper and lower bounds of random time-history responses of the train-bridge coupled system based on the probability density evolution method. In the first time, Xin et al. (2020a) defined the random resonance and random cancellation phenomena in the train-induced vibrations on bridge, characterized the probability distribution of the critical speeds, and investigated the influences of random resonance on the random responses of train-trackbridge coupled system. Xiao et al. (2019b) explored the effects of track irregularities on the random responses of the train-bridge system. With regard to the sensitivity analysis, Xin et al. (2020b) applied the probability density evolution method to quantify the 
response variabilities of train-bridge random systems subjected to uncertainties, and then identified the sensitive input factors and ranked them in the order of importance based on the extended Fourier Amplitude Sensitivity Testing. For the reliability assessment, Li et al. (2019k) provided the temporal reliability of the train-bridge coupled systems under a full probability distribution of track irregularities. Shi and Feng (2019) extracted the sensitive factors by means of factorial experimental design, and investigated the influences of the sensitive factors on the probability of the system failure by the response surface methodology. In the further, vehicle-bridge random dynamics will still be in a great progress in these aspects.

\subsection{Wind-vehicle-bridge dynamics}

The increased span of bridge and the complex wind environment induce more challenges in the driving safety and stability of high-speed train. The studies on aerodynamic parameters of the vehicle-bridge system, the wind-shielding measure and driving safety assessment recently are a research hotspot.

The sudden change of wind force will significantly impact on the safety of high-speed trains. Li et al. (2019l) adopted a moving train test system to measure aerodynamic coefficients of train with its running through the tower. The result shows a remarkable shielding effect of tower on the aerodynamic coefficients of train (as shown in Fig. 21).

The long-span bridge tends to be slender and soft, leads the response under static wind and pulsating wind to be more prominent. Liu and Lei (2019) investigated the static three-component force coefficient of typical double-layer truss girder by wind tunnel test and CFD simulation. The influence of Reynolds number is analyzed, and the recommended value for identifying the lowest Reynolds number of the third component coefficient at high wind angle of attack is proposed; Ma et al. (2019) and Li et al. (2019f) proposed the identification method of aerodynamic admittance by carrying out wind tunnel tests on the 2D and 3D streamlined box girder section.

The correct layout and reasonable selection of wind barriers are extremely important for improving the wind environment of trains running on bridge, where the related research usually focuses on aspects such as type selection, layout height and air permeability. He et al. (2019a) studied the effects of wind barrier type and air permeability on

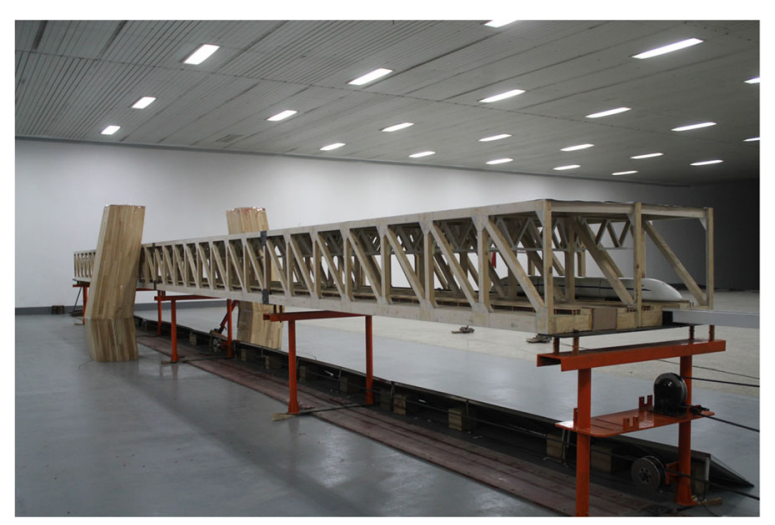

Fig. 21 Wind tunnel test of tower shielding on the aerodynamic characteristics of moving train (Li et al. 2019l) 
the flow field characteristics around the train and wind resistance performance of the wind barrier.

The assessment of driving safety needs to consider the interactions between wind force, train system and bridge system by adopting the wind-vehicle-bridge coupled system. He et al. (2019b) proposed an efficient analysis framework for high-speed trainbridge coupled vibration under non-stationary winds. By adopting a wind-vehiclebridge coupled system, Guo and Tang (2019) optimized the wind barrier based on its performance on dynamic response of train.

The further research for wind-vehicle-bridge coupling vibration mainly focuses on: the development and improvement of wind tunnel test technology for train model running on bridge structure under conditions of high vehicle speed, small yaw angle and large attack; the development of reliability analysis of the wind-vehicle-bridge system based on system and excitation randomness.

\subsection{Maglev vehicle-bridge dynamics}

With the development of maglev transportation, the problem of maglev train-bridge coupling vibration has become one of the current research topics and the relevant study is very important.

For maglev train and levitation control, based on the full-state feedback and particle swarm optimization algorithm, Li et al. (2019h) conducted the control method of the maglev train-track system coupling vibration system. Sun et al. (2019e) studied the adaptive sliding mode control of the maglev system based on the minimum parameter memory method of the RBF neural network.

For the coupling vibration, Zhang and Huang (2019) established a 10-degree-of-freedoms high-speed maglev train-bridge coupled vibration model using model modification methods and verified it based on the field tests. Based on the Changsha low-tomedium-speed (LMS) maglev commercial line, Li et al. (2018b) compared the dynamic response characteristics of the system when LMS maglev trains run on the different bridges considering the track structure (shown in Fig. 22). Adopting the refined highspeed maglev train and viaduct bridge finite element model, Xu et al. (2019g) analyzed the coupled vibration of the maglev train and the viaduct bridge of the straight and curve transition sections. These analyses provide references for the subsequent researches.

In the next few years, the following work may be further studied: (1) establishing a refined coupling vibration model of the maglev train-track-bridge system for high-speed maglev transportation with a speed of $600 \mathrm{~km} / \mathrm{h}$ or higher based on the intelligent active feedback control of the magnetic-track relationship; (2) studying and formulating design standards for the high-speed maglev transportation.

\section{Progress in seismic design of bridge}

The essences of seismic design of bridges are enhancing the seismic capacity and reducing the seismic demand. This review summarized the progresses in the seismic design of piers and development of seismic protecting device. 


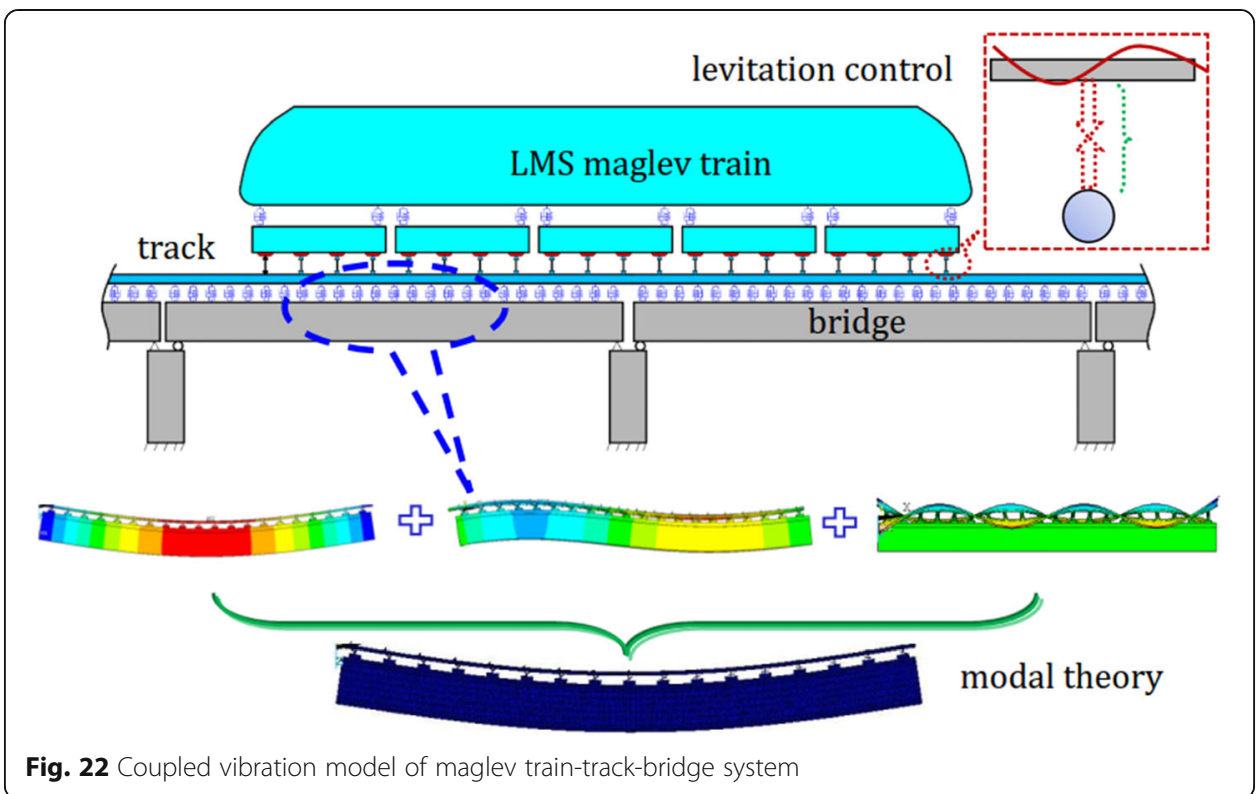

\subsection{Progress in seismic design of piers}

The bridge piers are the most important components for guaranteeing the structural safety of the bridge structures. The seismic performance of piers attracted more attentions in this year. We arranged all the studies into four sections: 1) conventional piers in beam bridge; 2) self-centering piers; 3) seismic retrofitting of piers.

\subsubsection{Common pier in beam bridge}

Conventional piers indicate the reinforced concrete (RC) piers, steel piers or concretefilled steel tube in beam bridges. Usually, the researcher focused on their seismic structural performance, i.e. damage and failure mode, hysteresis behavior, ductility and plasticity developments etc. Some novel configurations were also proposed to enhance the capacity of conventional piers. Serious physical tests and nonlinear simulations were carried out to reveal the damage mechanism of RC piers. Huang et al. (2019e) conducted an experimental study on the seismic performance of square RC piers under cyclic bending-shear-torsion coupled loads. Su et al. (2019a) studied the effect of longitudinal reinforcement yield strength and concrete compressive strength on the seismic performance of RC piers through model tests. Hao et al. (2019) studied the seismic performance of twin-column RC piers with different pier height through finite element simulations.

Concrete-filled steel tube piers reasonably utilize the circumferential confinement of steel tubes on core concrete, which have the characteristics of large bearing capacity and good toughness. During last year, there were relatively few studies on the seismic performance of this type of pier, and more typical studies are listed. For example, Chou and Wu (2019) conducted an experimental study on the seismic performance of highstrength concrete pier columns filled with steel boxes. The width-thickness ratio, axial load size and concrete filling of different steel pier columns were studied. The effects of 
the above parameters on the seismic performance of the pier column were well addressed.

Prefabricated bridge piers have been vigorously developed because of their advantages in reducing environmental / traffic interference, strengthening quality control and accelerating bridge construction. Carrying out research on the seismic performance of such bridge piers is of great significance for accelerating and improving the construction of the transportation system. Tong et al. (2019) proposed a new type of prefabricated bridge piers, with non-bonded energy dissipating steel bars with different yield strengths assembled at the top and bottom of the pier. A cyclic load test and the numerical model analysis were carried out to study the seismic capacity of the prefabricated pier.

With the continuous innovation and development of new materials, many scholars have studied the seismic performance of the new materials applied to the bridge piers. Compared with ordinary concrete materials, most of the new materials have the characteristics of high crack resistance and strain hardening. Al-Kaseasbeh and Mamaghani (2019) studied the mechanical properties of stiffened thin-wall square box steel pier columns through numerical simulation and cyclic load tests, and proposed corresponding strength and ductility calculation formulas. Hosseini et al. (2019) used the good ductility and durability of engineering cement-based composites (ECC) and the characteristics of multiple fine cracks under cyclic tensile loads to apply the material to the pier to increase the seismic damage limit of the pier.

\subsubsection{Self-centering pier}

Self-centering bridge piers refer to bridge piers that automatically restore to its original position after earthquake. The self-centering pier become one hot-pot since the concept proposed by Housner (1963). In last year, several self-centering piers were developed. Zhou et al. (2019e) studied the seismic response of a doublecolumn swing bridge pier structure system and gave a rigid body dynamic analysis model for calculating the dynamic response of the bridge pier structure system. Sun et al. (2019f) explored the rationality and effectiveness of the numerical modeling method for seismic response of swing bridge piers by comparing different modeling methods with existing tests. Liu et al. (2019d) proposed a new type of elastic rocking pier column and studied the seismic performance of the new pier column under cyclic load test. Han et al. (2019a) proposed a new swinging pier that uses unbonded post-tensioning and has an alternative energy dissipation device at the bottom of the pier, and has conducted experimental studies on the pier with different types of energy dissipation devices. Zhang et al. (2019h) proposed a dimensionless regression analysis method to estimate the seismic response of rocking pier-foundation system under near-fault ground motion.

\subsubsection{Seismic retrofit of pier}

Under the action of ground motion, many important structural members of the bridge will suffer serious earthquake damage, especially the earthquake damage of the pier. How to quickly repair the bridge piers and improve the seismic performance of the bridge piers and the bridge as a whole is of great significance for the 
rapid restoration of the transportation system and the earthquake relief. Some scholars have studied the seismic strengthening of bridge piers. Krish et al. (2019) repaired six pier columns with large-scale plastic hinge damage, conducted a postrepair test of the pier column, and proposed a new analytical model to accurately predict the behavior of the pier column after repair. Ni et al. (2019a) established a finite element model of a double-limb thin-walled high-pier long-span rigid frame bridge, compared and analyzed the seismic response of the two models before and after the reinforcement of the enlarged pier section. Yan et al. (2019b) conducted experiments and numerical simulations on the seismic performance of selfcompacting concrete-filled steel tube reinforced pier columns under cyclic loading with the diameter-thickness ratio of steel tubes, axial compression ratio and concrete strength as parameters. Yang et al. (2019f) proposed a three-dimensional truss modeling method to predict the seismic performance of concrete pier columns reinforced with carbon fiber cloth.

\subsection{Development of seismic protecting device}

\subsubsection{Seismic isolation device}

The seismic isolation device is in a key position where the superstructure connects to the substructure, and plays an irreplaceable role. It not only supports the superstructure, but also needs to transmit the horizontal inertial force generated by the superstructure to the substructure under the earthquake. Studying the seismic performance of seismic isolation devices has a positive significance for the earthquake resistance of bridges, for which scholars have conducted a lot of research. The research on isolation devices is mainly aimed at isolation bearings, ordinary plate rubber bearings and new types of bearings, such as shape memory alloy (SMA) bearings.

Cao et al. (2019) proposed a multi-level fortification SMA shock absorber. The device is composed of three-stage SMA cable and lead rubber support in parallel. Using the characteristics of the SMA material, as the seismic intensity increases, the SMA cables at all levels are sequentially tensioned to meet the performance requirements of earthquakes of different strengths. Bai (2019) proposed a new type of soft steel damperelastoplastic limit vibration isolation device suitable for high-speed railway simply supported box girder bridges. Cui et al. (2019c) conducted quasi-static loading tests on four concrete supports with different concrete margins and different seismic isolation measures, and studied the failure mode, hysteretic curve, stirrup strain, etc. of the concrete support. Zhou and Li (2019) developed two new types of shock-absorbing devices suitable for railway bridges-shock-absorbing tenons and tenon-shaped anti-drop beams, and proposed a simplified calculation method for the corresponding seismic design of railway simply supported beam bridges. Fang et al. (2019c) proposed a cantilever pier safety device that allows the cantilever pier and the fixed pier to share the seismic load generated by the superstructure to reduce the seismic response of the fixed pier. Rahnavard and Thomas (2019) numerically simulated the performance of steel-rubber base isolation bearings under the coupling of axial tension, compression and base shear, and studied the influence of the number and size of rubber cores in the bearings on its seismic isolation performance. 


\subsubsection{Energy dissipation device}

The energy dissipation device mainly plays the role of dissipating energy under ground motion excitation, so as to reduce the seismic damage of important structural members such as bridge piers. Energy dissipation devices mainly include viscous dampers, rubber buffers, buckling constrained brace, etc. Scholars at home and abroad have also conducted corresponding research in this field.

Fan et al. (2019a) studied the effect of nonlinear viscous dampers on the seismic performance of bridges. Zhou et al. (2019c) studied the influence of two different transverse strength dampers on the seismic performance of cable-stayed bridges through the shaking table test. On this basis, the residual bearing capacity of the lateral damper after the earthquake was further tested and its fatigue performance was evaluated. Yang et al. (2019c) studied the response of the bridge under lateral impact and the effect of rubber shock absorbers on energy dissipation through a series of shaking table tests on the bridge model. Upadhyay et al. (2019) established a finite element model of the bridge with self-resetting energy dissipation device and buckling constrained brace, and evaluated the seismic performance of the bridge under the ultimate failure state.

\subsubsection{Passive control structural system in bridge}

The research on seismic isolation system mainly focuses on the simplified calculation method of bridge seismic response and the research of displacement-based seismic isolation design method, mainly adopting the method of theoretical analysis. Gkatzogias and Kappos (2019) proposed a calculation method that can be used to directly estimate the peak inelastic response of isolation and energy dissipation systems with reduced degrees of freedom. Ye et al. (2019b) proposed a design method of base-isolated structure based on direct displacement, so that the base-isolated structure with lead-core rubber bearing can meet the performance index specified by the critical displacement value. Nassar et al. (2019) proposed a probabilistic reliability assessment method that considers the change of isolation performance under different conditions, and takes temperature, earthquake risk, size of key structural elements and mechanical properties of materials as random variables. Based on the simplified mechanical model of the friction pendulum system, Li and Shao (2019) gave a simplified calculation method for seismic isolation of a vibration-isolated bridge with friction pendulum bearing considering pile-soil effect, bridge stiffness and bearing nonlinearity.

\section{Bridge hydrodynamics}

This section covers hydrodynamic wave and current loads on bridge sub- and superstructures, bridge structure-wave interaction, wave and current induced structural dynamic response, multi-hazards on bridges including seismic effects, disaster reduction and prevention, and foundation scour. Compared with inland bridges, marine bridges are facing more threatening wind, wave, and current environments. For coastal low-rise bridges, hurricanes or tsunamis induced extreme storm surge and waves are major agents for their severe damage and potential risks, while for sea-crossing flexible bridges, such as cable-stayed bridges and suspension bridges, wind effects play a significant role in the dynamic analysis of the freestanding bridge tower and whole structure system. To cross straits with a large depth or very soft bottom, floating bridges can be an 
alternative in replacing ferries. Note that seismic effects should be evaluated for deepwater bridges, located in inland or coastal seismic zones.

\subsection{Low-rise bridge}

A considerable number of coastal low-rise bridges in the southern U.S. and Japan were severely damaged in the past hurricane and tsunami events, triggering many efforts input on this issue. Istrati and Buckle (2019) investigated tsunami-induced effects on two common bridge types, with cross-frames and solid diaphragms, respectively, in a large scale of 1:5, under solitary waves and tsunami bores. Xiao and Guo (2019) investigated the efficacy of air relief openings on mitigating solitary induced wave forces on the bridge deck through hydrodynamic experiments and OpenFoam. Fang et al. (2019b) experimentally considered oblique wave induced loadings on the bridge deck, where a full bridge specimen with substructure and neighboring segments was fabricated and tested. Montoya et al. (2019) numerically evaluated two damaged bridges in Hurricane Katrina using the Coupled Eulerian-Lagrangian (CEL) approach in Abaqus and analyzed the effects of foundation flexibilities on the uplift and shear forces. Moideen et al. (2019) generated solitary wave in the open source model REEF3D and studied its vertical impact force on the bridge deck. Qu et al. (2019b) implemented the SIFUM-FVCOM multiscale system to study the hydrodynamic loads on coastal highway bridges under the impact of real-world tsunami. Qu et al. (2020) numerically investigated the effects of floating breakwater on the cnoidal wave induced wave loads on the low-lying bridge deck using REEF3D. Zhao et al. (2020a) developed a numerical tank for generating tsunami-like waves recorded in the Iwate station during 2011 Japan tsunami and studied the wave impact on coastal bridges by using the Immersed Boundary method (IBM). Xu et al. (2020) presented a methodology for sequentially updating surrogate models with augmented data in order to substantially enhance the design of experiments in the bridge deck-wave interaction under solitary wave actions. Huang et al. (2019a, b) analyzed tsunami forces on the box-girder shaped coastal bridge deck through experimental and numerical approaches.

Greco et al. (2020) analyzed the vulnerability of bridges impacted by extreme flood and tsunamis by proposing a combined three-dimensional (3D)/2D model based on phase field theory and 3D solid modeling of the structure-fluid-interaction system. Webb and Cleary (2019) evaluated forensicly a simply supported bridge span damaged during Hurricane Katrina (2015) using advanced hydrodynamic models (ADCI $\mathrm{RC}+\mathrm{SWAN}, \mathrm{SBeach})$ to simulate hurricane scenarios in reproducing storm surge, waves, and flow field at the bridge location. For the quantification of vulnerability and resilience of the bridge system under extreme wave loadings, Balomenos et al. (2020) developed fragility models for individual spans of different bridge classes and whole bridge system, accounting for different types of superstructures within the bridge, vulnerable to hurricane induced wave loadings by including spatial variability of wave loads and variations in structural characteristics. Qeshta et al. (2019) and Qeshta (2019) evaluated the resilience of coastal low-lying bridges under extreme wave-induced loadings by providing a comprehensive vulnerability assessment framework with strong connectivity between the super- and sub-structure. 


\subsection{Long-span sea-crossing flexible bridges}

With the deveopment of economy, many sea-crossing bridges connecting islands and mainland have been built in China and other places. However, extreme met-ocean conditions, such as strong wind, huge wave and storm surge in the near-shore areas, generated by strong typhoons pose a substantial threat to the safety of sea-crossing bridges.

\subsubsection{Substructure}

The wave and current loads on the bridge substructure are one of the decisive factors for the safety and economy of the bridge. Wei et al. (2019a) presented a calculation method for wave forces on large round-ended caisson foundation. Zhang et al. (2019b) analyzed the structural response of the caisson-pile foundation for the will-be-built Qiongzhou Strait Bridge under long-term cyclic loading and erosion, and proposed an exponential expression to predict the cumulative cyclic displacement for the composite foundation, the caisson-pile system.

\subsubsection{Bridge tower}

In the bridge construction stage, the freestanding bridge tower is susceptible to strong wind and waves where its natural frequency is possibly located within the period regime of ocean waves. The combined wind and wave forces on the corresponding foundation and upper structure contribute to the structural local damage, strength failure, or fracture. For this purpose, Wei et al. (2019b) experimentally studied wave and wavecurrent actions on a gate-type bridge tower with a pile-group foundation at a scale of 1 : 100. It is found that the longitudinal incident waves trigger the most adverse scenario for the base shear forces and the dynamic motion at the tower top. Li et al. (2019n) proposed a frequency domain method for the dynamic analysis of a freestanding bridge pylon with a copula model to consider wind and waves.

\subsubsection{Whole bridge}

Wei et al. (2019d) simulated typhoon wind field by superimposing the Holland model wind field with Miyazaki model wind field and ERA-Interim wind field and reproduced the environmental wave and storm surge conditions in the Pingtan strait under the strong typhoon "Maria". Ti et al. (2019) developed a framework to investigate the stochastic response of a long-span sea-crossing bridge under extreme nonlinear wave loads based on the combined use of the spectral wave model MIKE21 SW and AQWA. Fang et al. (2019a) extended the previous wind-vehicle-bridge model and developed a wind-wave-vehicle-bridge dynamic analysis model for sea-crossing railway bridge under wind and wave loadings, which involves multipoint fluctuating wind field, irregular wave field, finite element model of the bridge, and mass-spring-damper model of the vehicle. Wei et al. (2019c) developed a nonlinear analysis framework based on pushover approach to assess the nonlinear response of offshore steel trestle (OST) subjected to wave and current loads.

\subsection{Floating bridge system}

Floating bridges have been considered as an option for strait crossings. Geuzaine and Denoël (2019) presented a fast spectral analysis of structures under wind and wave 
loadings and applied it to a large scale floating bridge. Currently, the Norwegian Public Road Administration (NPRA) is considering transportation alternatives to replace ferries across 8 fjords on the Coastal Highway Route E39 Project. The width of the strait crossings is up to $5 \mathrm{~km}$ with a maximum water depth of $1300 \mathrm{~m}$. In total, three floating bridge alternatives are under consideration and the popular one is a curved, end anchored floating bridge, which has 19 supporting pontoons. To renew our understanding on this topic, Moan and Eidem (2020) reviewed relevant concepts and technology of floating bridges and submerged tunnels. Wei et al. (2019f) investigated the linear hydroelastic responses of the curved floating bridge under irregular wave impacts with spatially varying significant wave heights and peak periods. Hong (2019) analyzed various damping effects on the global dynamic response of the curved floating bridge and found that the damping effects are not noticeable and increasing the number of pontoons can effectively reduce the bending moment about the weak axis and the overall static effect. Cheng et al. (2019d, e, f) systematically studied the dynamic analysis of the curved, end anchored floating bridge under wind, wave, and current loads. Their results show that turbulent wind can cause noticeable larger resonant responses than the wave loads and current contributes the damping effects, thus reducing the variations of sway motion, axial force, and strong axix bending moment. Viuff et al. $(2019,2020)$ and Viuff (2020) evaluated the uncertainty of the wave- and current-induced global extreme response of the curved floating pontoon bridge by considering different main wave directions and compared two common computer programs, Sima and OrcaFlex.

Other than the above studies, Xiang and Loken (2019) constructed a hydroelastic global analysis model by considering the bridge as large radiation/diffracting floaters connected by elastic beams in order to validate numerical modelling results. Dai et al. (2020) studied the hydroelastic response of a straight, supported by 35 pontoons, $4.6 \mathrm{~km}$ long fjord crossing floating bridge subjected to wave loads, where various effects of inhomogeneous wave loads are examined. Petersen et al. (2019) used inverse methods to identify, in full scale, the ambient stochastic wave loads on a floating bridge; however, uncertainties still exist in the assumptions made and models behind the force estimates.

\subsection{Seismic effects}

Many new achievements of earthquake-induced fluid-structure interaction that is critical in the seismic design of deepwater bridges, have been made in 2019. Zhang et al. (2019g) developed an efficient potential-based numerical model to determine the hydrodynamic added mass for immersed column with arbitrary cross - section. Zhang et al. (2019f) also employed potential-based fluid elements to set up a threedimensional numerical fluid-structure interaction model to account for the hydrodynamic effects of a nonuniform bridge hollow pier submerged in a reservoir. Wei et al. (2019e) assessed the dynamic responses of the deepwater rigid-frame bridge by underwater shaking table tests and numerical simulations and proposed a practical method for seismic design of deepwater rigid-frame bridge. Wang et al. (2019h) proposed simplified formulas for the added mass of the round-ended and rectangular cylinders to estimate the hydrodynamic pressure on uniform vertical cylinder. Wang

et al. (2019i) investigated the interaction of water with multiple circular cylinders under 
the earthquake and incident linear waves using the finite element models and proposed the simplified formulas of the added mass coefficients of pile group. Moreover, Deng et al. (2019) study the individual and combination influences of pounding and fluidstructure interaction on a typical deep-water bridge with hollow piers. In Yang et al. (2020a), an analytical calculation method of hydrodynamic force on pile group is proposed Yang et al. (2020b) deduced the analytical calculation method of the hydrodynamic force on twin columns of deep-water bridge.

\subsection{Bridge scour}

Local scour of bridge piers is one of the main threats responsible for bridge damage. Xiang et al. (2019) presented a comprehensive review of the current research on scour at bridge foundations. Adopting scour countermeasures to protect bridge foundations from scour has become an important issue for the design and maintenance of bridges located in erodible sediment beds. Wang et al. (2019n) studied the protective effect of one active countermeasure named an "anti-scour collar" on local scour around the cylindrical bridge pier by a live-bed scour experimental program. The effects of three design parameters including collar installation height, collar external diameter and collar protection range, on the scour depth and scour development were investigated parametrically.

\section{Bridge informatization and intelligent bridge}

\subsection{CMM (construction, management and maintenance) of bridge information}

In informatization for bridge design, BIM technology provides a platform of threedimensional digital design, which can be directly used for creative expression and structural optimization of complex shapes. Sun et al. (2019c) and Zhang and Liu (2019) et al. studied the 3D parameterized standard modeling method based on BIM, so as to avoid the construction rework caused by design errors.

In informatization for bridge construction, BIM can realize multi-party collaborative operation of information sharing, total-simulation for reduce security risks. The information management technology of bridge construction is based on BIM, which can realize the whole process information management of dynamic simulation of construction. Lu et al. (2019a) applies intelligent construction technology to the field of railway engineering, and combines BIM and PHM (prediction and health management) to build ICRE (Intelligent construction technology of railway engineering) from three dimensions: life cycle, management level, and intelligent functions.

In informatization for bridge management and maintenance, the integrated platform for CMM built by information technology can provide decision-making reference for daily inspection, planned maintenance of the bridge to ensure traffic safety. Considering the needs of modern operation, management and maintenance of long-span railway bridges, Zhang et al. (2019c) proposed a digital bridge management and maintenance platform design scheme based on BIM multi-source information acquisition and management; it can realize structural intelligent analysis and status assessment. The 3D information and image processing digital inspection system established by Shim et al. (2019) can exchange and update continuously all relevant information during the entire 
life cycle of the bridge. Then Shim has defined the digital twin model to realize preventive maintenance of prestressed concrete bridges.

There are still a lot of basic applications that need to be solved: (1) The information technology represented by BIM failed to form a unified standard in bridge design. (2) It is a challenge for old bridges to achieve intelligent management with modern information technology. (3) The application of digital twin model in bridge engineering is still in the preliminary exploration stage.

\subsection{Bridge intelligent inspection}

\subsubsection{Intelligent testing equipment and technology}

A series of bridge intelligent testing equipment and technologies have been proposed, including intelligent robots, UAV, etc., to replace the traditional manual detection methods, so as to detect defects in various complex, hidden, high-altitude parts of the bridge (Zhong et al. 2019). Many scholars combined UAV with 3D modeling technology to achieve intelligent detection of bridge, and used image processing to achieve intelligent extraction image information (Chen et al. 2019c; Jung et al. 2019b; Morgenthal et al. 2019). The research and development of inspection robots also promoted the development of bridge intelligent inspection. Phillips and Narasimhan (2019), Xu and Jiang (2019), Hirai and Ishii (2019) developed various inspection robots for adapting to difficult environments on land, high altitude and underwater, which realized comprehensive inspection of bridges. In addition, some advanced bridge intelligent detection technologies such as radar (Wang et al. 2019g), acoustic emission (Yuan et al. 2019b), infrared thermal imaging (Sun and Zhen 2019), and other new intelligent detection methods (Wang et al. 2019f; Oskoui et al. 2019) also improve the accuracy and efficiency of bridge detection.

\subsubsection{Intelligent identification and data analysis}

Data acquisition and processing technologies have attracted intense research interests, corresponding to intelligent detection equipment. La et al. (2019) and Li et al. (2019i) developed surface defect recognition technology using climbing robots based on computer vision, and realized intelligent recognition of structural performance evaluation. Based on deep learning, Zhu et al. (2019a), Liang (2019) and Dung et al. (2019) realized intelligent evaluation of the detection results, avoided the influence of human subjective or empirical factors on the judgment of the detection results. Many scholars have optimized the intelligent algorithm to achieve accurate search for bridge defects, intelligent assessment of damage degree, and budget optimization (Cheng et al. 2019b; Xin et al. 2019). Hüthwohl et al. (2019) trained three separate deep neural networks based on multi-source dataset, and proposed a three-staged concrete defect classifier. The method could realize the defect classification of potential unhealthy areas of bridges. Zhao et al. (2020b) and Xia et al. (2019) studied the commonality and personality of bridges at networks level, and proposed a networks-level assessment method. It could realize the crackwarning of concrete box girder bridge. Qu et al. (2019a) proposed an innovative method based on eigensystem realization algorithm and a virtual frequency response function. This method could identify more precise mode parameters. Ni 
et al. (2019b) proposed a novel deep-learning-enabled data compression and reconstruction framework. This method could detect abnormal data with high accuracy. They promotes the further improvement of the intelligent detection of bridges.

Intelligent detection equipment, technology and intelligent algorithms have been extensively researched and applied in engineering, but there are still some shortcomings: (1) A single intelligent detection device is difficult to meet multi-detection tasks. (2) The data have not been fully utilized to provide effective support for data-driven scientific decision-making. (3) Theories on intelligent detection technology have not been well developed.

\subsection{Other smart technologies for bridges}

\subsubsection{High-performance smart materials}

The current application of smart materials is mainly reflected in non-destructive testing, health monitoring and vibration control, such as shape memory alloys (SMA), optical fibers, and carbon fibers, etc.

SMA is widely used in bridge vibration control (Zheng et al. 2019b; Wang et al. 2019d). Meanwhile, some scholars have applied SMA to suppress fatigue cracks in steel bridges. Izadi et al. (2019) used iron-based shape memory alloy to improve the fatigue cracking riveted joints of steel bridges. It improves the fatigue life of the material significantly and suppresses the occurrence of fatigue cracks.

Optical fiber is mainly used for optical fiber sensors. Compared with traditional sensors, it has the advantages of high sensitivity, simple structure, small size, and it's easy to adjust for long-distance. Many scholars use it in bridge detection and monitoring (Bonopera et al. 2019; Zhang et al. 2019a).

Ultra-High-Performance Concrete (UHPC) is featured with extremely high workability, mechanical strength, and long-term durability. Farzad et al. (2019). applies UltraHigh-Performance Fiber Reinforced Concrete (UPFRC) to the Accelerated Bridge Construction $(\mathrm{ABC})$, which has advanced structural performance and high-speed of construction.

Carbon fiber has been widely used to fabricate carbon fiber-reinforced polymer (CFRP) and other reinforcing materials. Cheng et al. (2019c) and Fan et al. (2019b) et al. developed a bridge reinforcement method based on CFRP, which reduced the seismic response of the bridge effectively and improved the seismic performance of the structure.

\subsubsection{Intelligent disaster prevention and mitigation}

To ensure safe operation of major infrastructures in complex natural environments, intelligent disaster prevention and mitigation of structures has become an emerging topic. Bao and Li (2019) established a structure maintenance value network that considered the structural status and service life, which achieved optimal decision of maintaining structural safety under the minimum cost. For different disasters, scholars have also built various disaster prevention and mitigation systems. Gou et al. (2019) built a large-scale disaster data analysis platform, and described the application of AI algorithms in high-speed railway disaster monitoring, forecasting and early warning of wind, rain, snow, earthquakes and landslides etc. 


\subsection{Future opportunities}

To promote sustainable development of the bridge for improved safety, longevity, greenness, efficiency, and intelligence, there are some research needs:

(1) Bridge informatization should integrate BIM and asset management to transform from facility management to asset-based maintenance management. Digital twinning will be further applied to bridge maintenance for physical asset optimization, intelligent operation and maintenance, decision-making, and preventive maintenance and reinforcement.

(2) In bridge intelligent inspection, more advanced bridge intelligent inspection equipment and lighter and faster test technology should be developed, and more accurate, scientific intelligent assessment theory based on multi-source data should be established.

(3) In intelligent disaster prevention and mitigation, more research on rapid detection and evaluation of post-disaster performance of large bridges is needed. The postdisaster performance index system and rapid detection method should be proposed, and post-disaster performance intelligent evaluation technology system should be established.

\section{Prefabricated concrete bridge structures}

Compared with conventional concrete bridge construction, prefabricated construction can accelerate the construction speed, and improve the quality and safety. Therefore, prefabricated concrete bridges are particularly suitable for complicated highway and railway constructions. With the increasing application of prefabricated concrete bridges, researchers have conducted fruitful research on construction technologies, structural detailing and safety of prefabricated concrete bridges.

The studies on prefabricated concrete bridges focus on the prefabricated pier and superstructure. Recently, the prefabricated piers attract more attention since its first application on Pontchartrain bridge in New Orleans in 1955, whereas the prefabricated concrete superstructure has been fully developed after years of study and application. In this part, both studies of the prefabricated concrete piers and superstructure were reviewed.

\subsection{Prefabricated concrete pier}

Pier is the essential load-bearing element of the substructure. The prefabrication of concrete piers is, therefore, one of the critical parts in the full prefabrication of concrete bridges. With the increasing demand for prefabricated piers in bridge engineering in recent years, the research on prefabricated piers has gradually increased. In 2019, the research on prefabricated concrete piers mainly included four categories: the connection detailing of prefabricated concrete pier/column and its performance, the seismic performance of prefabricated concrete pier, the application of innovative high-performance materials, and the new system of the prefabricated pier.

The development in the connection detailing and its performance are the primary issues for the prefabricated concrete piers. Currently, sleeve grouting connections are 
widely used connections to connect precast concrete members. Xu et al. (2019c) experimentally studied the local and global bond stress-slip behavior of the grouted sleeve connection, with the focus on the construction eccentricity of reinforcing bar and the loading time after grouting. The confinement effect of the sleeve on the bond strength was evaluated by using the measured circumferential strain at the surface of the sleeve. An analytical model was proposed to assess the bond-slip behavior of the grouted sleeve connection with a long embedment length. Lu et al. (2019b) measured the mechanical properties of the wedge-shaped and wedge-shaped thread grouted sleeves under uniaxial tension, studied the influence of the embedding length of the steel bar, the slope of the wedge and the thread of the sleeve. Kuang et al. (2019) proposed that the content of the grouted material in the sleeve affected the failure modes of the connection (pull-out failure or broken failure) and the bearing capacity.

The connection detailing between the precast concrete members always influences the seismic performance of the prefabricated concrete piers. For grouted sleeve connection, Fan et al. (2019e) found that the designed prefabricated pier with grouted sleeve connections embedded either in the foundation or in the precast pier can perform well under seismic. The socket connection requires less construction accuracy than the grouted sleeve connection and the grouted corrugated connection. Moreover, it needs less on-site constructionthan wet joint connection and prestressed connection. Xu et al. (2019e) studied the influence of socket depth on the seismic performance of the prefabricated concrete pier. The results showed that the socket depth has little effect on the overall seismic performance of the piers under good construction conditions. The minimum socket depth assessment was also proposed. Cheng and Sritharan (2019) found that the lateral shear mechanism in the socket connection can provide significant resistance, which is beneficial to the transmission of large vertical loads.

Due to the compression applied by the prestressed force, the influences of the reinforcing steel bars in joint area andand precast member can be neglected for the prefabricated concrete piers with prestress connections. This connection has been widely used in low seismic zones. However, a minimal application can be found in the medium or high seismic zones as its seismic performance is Not widely investigated $\mathrm{Yu}$ et al. (2019c) found that the prefabricated piers with an axial compression ratio of $10 \%$ to $20 \%$ have an excellent seismic performance. Bao et al. (2019a) found that the bearing capacity, yield force, and energy dissipation capacity of the prefabricated concrete pier have been enhanced with the increase in the prestress degree, whereas it has little effect on ductility and residual displacement. Furthermore, the configuration of the tenons and mortises between segments can improve the anti-slip effect.

For innovative high-performance materials, UHPC was used in the bottom of pier column of the prefabricated segmented pier due to its high compressive strength, tensile strength, and ductility (Zhang et al. 2019d). Moreover, the high-strength energy dissipation steel reinforcing bar was adopted in prefabrication concrete piers to improve its seismic performance (Tong et al. 2019; Zhuo et al. 2019). For the new system of prefabricated pier, Yang et al. (2019a) studied the effect of friction coefficient and initial tension on the performance of self-resetting pier; Han et al. proposed a self-resetting double-column pier system; Mashal and Palermo (2019) 
proposed a self-resetting pier system with metal energy dissipation devices installed at the bottom of an assembled pier. Due to little research in application of hoghperformance matrials has done, in further, more studies should be carried out on the designed application of innovative high-performance materials in prefabricated concrete bridge to achieve the balance between cost and obtained performance.

\subsection{Prefabricated bridge superstructure}

In 2019, the research on prefabricated bridge superstructure mainly included three categories: the joint detailing of the prefabricated concrete deck and its performance, the overall performance of the prefabricated concrete deck, and the prefabrication of the steel-concrete composite beam.

The joint detailing has a significant influence on the performance of the prefabricated bridge deck. Many innovative detailings have been proposed to improve the ultimate strength or serviceability of the prefabricated deck joint. Shoushtari et al. (2019) proposed a seismic performance optimization strategy for six types of connection detailing including rebar hinge pocket connection, grouted duct connection, SDCL girder-to-cap beam connection, girder-to-deck grouted pocket connection, UHPC-filled joints between the deck panels, and deck panel UHPC-filled connection. Shen et al. (2019c) proposed a formula with this coefficient to reflect the change trend and peak effect of shear stress in multi-keys. Ahmed and Aziz (2020) tested the influence of prestressing force, concrete compressive strength, presence of epoxy, and the number of shear keys. Some ways of improving the performance of shear keys were proposed. Huang et al. (2019c) proposed that UHPC connections are suitable for medium/high seismic areas. Dong et al. (2019) analyzed the factors affecting the performance of the pre-tensioned bent cap and suggested to use the general, noniterative sectional shear design method to design the section. zhang et al. $(2019 \mathrm{~m})$ suggested that the cracking of the U-shaped steel bar wet joints of steel plate girder bridges and the construction joints of bridge decks should be prevented. Qi et al. (2019) proposed a method of using reinforced mesh to enhance the dovetail UHPC joints. Youssef et al. (2019) tested the bending and shear performance of UHPFRC joints. Tawadrous and Morcous (2019) proposed a notch connection scheme for the bridge deck.

Representative progress in the direction of the overall performance of the prefabricated bridge decks includes: Koh et al. (2019) stated that special attention should be paid to the maintenance of T-shaped joint beams. Tawadrous et al. (2019) developed a new type of precast concrete bridge deck system that is pre-tensioned in a horizontal direction and post-tensioned in a longitudinal direction. Ha et al. (2019) found that containing fly ash can improve the mechanical properties of the bridge deck.

Steel-concrete composite beam has been widely used in bridge as it can improve the overall performance of deck and it has an excellent workability. Additionally, the assemblability of structural steel members can be used to achieve the prefabrication of steel-concrete composite beams. As a result, the mechanical properties and durability of prefabricated composite beams become hot spots in 2019. Zhao et al. (2019a) introuuced the fully dry connection of prefabricated UHPC composite bridge deck with prestressed countersunk to enhance the crack resistance of the steel-UHPC interface. The 
model test results verified the excellent properties of this connection. The recommendations of rebar pre-tension force and beam stiffener height were provided by numerical model analysis. Zhao et al. (2018) proposed the dovetail-shaped RPC wet joint in the slab-beam connection structure to improve the durability of the interface between wet joint andprecast RPC layer. The reinforcement ratio and the inclined angle of the dovetail-shaped area were recommended according toboth finite-element modelling and experimental results. Wang et al. (2019e) proposed the connection structure of embedded bolts to achieve a fully dry connection of prefabricated UHPC panel, and Isection beam. Full-scale tests showed that the structure has excellent stiffness and bearing capacity. Balkos et al. (2019) adopted the slip-resistant through-bolt shear connectors to achieve the prefabricated assembly of steel-concrete composite beams and experimentally verified their static and fatigue performance. Farzad et al. (2019) proposed a steel-UHPPFC-steel web prefabricated bridge deck with the quick construction. Zhang et al. (2019d) proposed a new type of short rebar connectors with advantages of simple construction and low cost. However, two brittle failure models ofthis connector need to be optimized. As structural performance requirements, serviceability and durability are also important. However, Compared with the safety, theresearch on the serviceability and durability of prefabricated concrete bridges is still insufficient, which may restrict the application range of prefabricated concrete bridges. Furthermore, as a key infrastructure servicing in a challenging environment, the long-term performance, non-destructive testing technology, and the rehabilitation technology of the prefabricated connection and structures should be addressed further.

At the same time, the calculation methods for such an innovative prefabrication system of the composite beam have also been studied, such as the model taking the newold concrete age difference into account (Huang et al. 2019d), SBSC shear capacity calculation formula (Wang et al. 2019o), and full-depth precast concrete deck panel system connector shear strength calculation method (Leblouba et al. 2019).

\section{Conclusions}

The paper reviews some advances in bridge engineering in 2019, including concrete bridges and the high-performance materials, the latest research on steel-concrete composite girders, advances in box girder and cable-supported bridge analysis theories, advance in steel bridges, the theory of bridge evaluation and reinforcement, bridge model tests and new testing techniques, steel bridge fatigue, wind resistance of bridges, vehicle-bridge interactions, progress in seismic design of bridges, bridge hydrodynamics, bridge informatization and intelligent bridge and prefabricated concrete bridge structures. With the development of bridge science and technology and the needs of national development and construction, we hope that this review article can promote bridge workers get a more comprehensive understanding of the latest progress in the bridge industry.

\section{Abbreviations}

SCC: Self-compacting concrete; UHPC: Ultra-high performance concrete; ECC: Engineering cement-based composite materials; ITZ: Transition zone between the binder and the aggregate interface; FRP: Fiber-reinforced polymer; LWC: Frp-lightweight concrete; PCPS: Prestressed concrete precast slab; HSC: High-strength concrete; SMA: Shape memory alloy; CFST: Concrete-filled steel tube; GBT: General beam theory; DSW: Double-side welding;

OSDs: Orthotropic steel decks; TEU: Thickened edge u-ribs; UHS: Concrete constitutive parameters; AAF: Aerodynamic admittance function; VIV: Vortex-induced vibration; EKF-UI: Extended kalman filter with unknown input; SEF: Self excited force; VIF: Vortex shedding force; CFD: Computational fluid dynamics; LMS: Low-to-medium-speed; 
RC: Reinforced concrete; CEL: Coupled eulerian-lagrangian; IBM: Immersed boundary method; NPRA: Norwegian public road administration; Al: Artificial intelligence; CMM: Construction, management and maintenance; BIM: Building information modeling; PHM: Prediction and health management; ICRE: Intelligent construction technology of railway engineering; UAV: Unmanned aerial vehicle; ABC: Accelerated bridge construction; UPFRC: Ultra-high-performance fiber reinforced concrete; CFRP: Carbon fiber-reinforced polymer

\section{Acknowledgements}

This paper is the result of the joint efforts of dozens of teachers in the Department of Bridge Engineering. The authors have only compiled their contributions for peer reference. Only some major contributors are listed as follows: Shiyu Yang, Zongyi Wen, Bailun Hua, Junlin Heng, Hecong Jin, Yu Hong, Chuang Cui, Mingshui Li, Lifeng Xin, Kailai Deng, Kai Wei, Yu Liu. We are very grateful to all the authors who contributed to the article.

\section{Authors' contributions}

Section 1 to section 13 of this paper were conceived, written and checked by Yuan Yuan, Xing Wei, Ruili Shen, Kaifeng Zheng, Yongjiu Qian, Qianhui Pu, Qinghua Zhang, Haili Liao, Xiaozhen Li, Canhui Zhao, Guoji Xu, Hongye Gou, and Ziyang Zhang respectively. Renda Zhao and Chuanjin Yu were responsible for the integration and revision of this paper. The author(s) read and approved the final manuscript.

\section{Funding}

Not applicable.

\section{Availability of data and materials}

Not applicable.

\section{Competing interests}

The authors declare that they have no competing interests.

\section{Received: 5 August 2020 Accepted: 24 September 2020}

Published online: 30 October 2020

\section{References}

Ahmad S, Rasul M, Adekunle SK, Al-Dulaijan SU, Maslehuddin M, Ali SI (2019) Mechanical properties of steel fiber-reinforced UHPC mixtures exposed to elevated temperature: effects of exposure duration and fiber content. Compos B Eng 168: 291-301

Ahmed GH, Aziz OQ (2020) Stresses, deformations and damages of various joints in precast concrete segmental box girder bridges subjected to direct shear loading. Eng Struct 206:110151 Elsevier Sci Ltd, Oxford

Akhnoukh AK (2019) Accelerated bridge construction projects using high performance concrete. Case Stud Construct Mater 12:e00313

Al-Azzawi Z, Stratford T, Rotter M, Bisby L (2019) FRP strengthening of web panels of steel plate girders against shear buckling. Part-II: fatigue study and cyclic series of tests. Compos Struct 210:82-95 Elsevier Sci Ltd, Oxford

Alexander M, Beushausen H (2019) Durability, service life prediction, and modelling for reinforced concrete structures review and critique. Cement Concr Res 122:17-29 Pergamon-Elsevier Science Ltd, Oxford

Al-Kaseasbeh Q, Mamaghani IHP (2019) Buckling strength and ductility evaluation of thin-walled steel stiffened square box columns with uniform and graded thickness under cyclic loading. Eng Struct 186:498-507 Elsevier Sci Ltd, Oxford

Al-Salih H, Juno M, Collins W, Bennett C, Li J, Sutley EJ (2019) Evaluation of a digital image correlation bridge inspection methodology on complex distortion-induced fatigue cracking. Procedia Structural Integrity, Funchal, Madeira, Portugal, $17,682-689$

Ataei A, Zeynalian M, Yazdi Y (2019) Cyclic behaviour of bolted shear connectors in steel-concrete composite beams. Eng Struct 198:UNSP 109455 Elsevier Sci Ltd, Oxford

Bai L, Shen R, Zhang X, Wang L (2019a) In-plane stability of self-anchored suspension bridge. J Jilin Univ (Engineering and Technology Edition) 49(05):1500-1508 (In Chinese)

Bai Q (2019) Application research on the new elastic-plastic limit seismic isolation device in high-speed railway simple supported girder bridges. J Railway Eng Soc 36(10):66-71 (in Chinese)

Bai Y, Duan Z, Liu J (2019b) Time-variant reliability analysis for widened reinforced concrete girder bridge. Railway Eng 59(07): 32-36 (In Chinese)

Balkos KD, Sjaarda M, West JS, Walbridge S (2019) Static and fatigue tests of steel-precast composite beam specimens with through-bolt shear connectors. J Bridge Eng 24(5):04019036 Asce-Amer Soc Civil Engineers, Reston

Balomenos GP, Kameshwar S, Padgett JE (2020) Parameterized fragility models for multi-bridge classes subjected to hurricane loads. Eng Struct 208:110213

Bao L, Song J, Ling Y (2019a) Research on effect of prestress degree on seismic performance of segmental assembly piers. J Dalian Univ Technol 59(3):302-309

Bao Y, Chen Z, Wei S, Xu Y, Tang Z, Li H (2019b) The state of the art of data science and engineering in structural health monitoring. Engineering 5(2):234-242 Elsevier Science Bv, Amsterdam

Bao Y, Li H (2019) Artificial intelligence for civil engineering. Chin Civil Eng J 52(5):1-11 (In Chinese)

Beneberu E, Yazdani N (2019) Residual strength of CFRP strengthened prestressed concrete bridge girders after hydrocarbon fire exposure. Eng Struct 184:1-14

Bonopera M, Chang K, Chen C, Lee Z, Sung Y, Tullini N (2019). Fiber Bragg Grating-Differential Settlement Measurement System for Bridge Displacement Monitoring: Case Study. J Bridge Eng 24(10):05019011.

Brito MB, Ishibashi H, Akiyama M (2019) Shaking table tests of a reinforced concrete bridge pier with a low-cost sliding pendulum system. Earthquake Eng Struct Dyn 48(3):366-386 Wiley, Hoboken 
Cai T, Jiang S, Yao W, Tao S (2018) Research on long-term creep of RC beams strengthened with externally bonded FRP plates. Synthetic Fiber China 47(05):35-41 (In Chinese)

Cai ZK, Wang Z, Yang TY (2019) Cyclic load tests on precast segmental bridge columns with both steel and basalt FRP reinforcement. J Compos Constr 23(3):04019014 Asce-Amer Soc Civil Engineers, Reston

Cao S, Wu S, Zhuo S, Huan W, Jun Y (2019) A multi - level performance SMA - based isolation system in girder bridges. J Vibration Shock 38(24):209-217 (in Chinese)

Carreras L, Renart J, Turon A, Costa J, Bak BL, Lindgaard E, Martin de la Escalera F, Essa Y (2019) A benchmark test for validating 3D simulation methods for delamination growth under quasi-static and fatigue loading. Compos Struct 210: 932-941 Elsevier Sci Ltd, Oxford

Chen J, Zhang H, Yu Q-Q (2019a) Static and fatigue behavior of steel-concrete composite beams with corroded studs. J Constr Steel Res 156:18-27 Elsevier Sci Ltd, Oxford

Chen L, Huang T (2019b) The dynamic prediction method of RC bridge reliability based on Bayesian update. Proc 28th Natl Conf Struct Eng 2(4):10-15 (In Chinese)

Chen S, Hou C, Zhang H, Han L-H (2019c) Structural behaviour and reliability of CFST trusses with random initial imperfections. Thin Walled Struct 143:UNSP 106192 Elsevier Sci Ltd, Oxford, 143, UNSP

Chen S, Laefer DF, Mangina E, Zolanvari SMI, Byrne J (2019d) UAV bridge inspection through evaluated 3D reconstructions. J Bridge Eng 24(4):05019001 Asce-Amer Soc Civil Engineers, Reston

Chen WL, Yang W-H, Li H (2019e) Self-issuing jets for suppression of vortex-induced vibration of a single box girder. J Fluid Struct 86:213-235

Chen Y, Dong J, Xu T, Xiao Y, Jiang R, Nie X (2019f) The shear-lag effect of composite box girder bridges with corrugated steel webs and trusses. Eng Struct 181:617-628 Elsevier Sci Ltd, Oxford

Cheng J, Xu M, Xu H (2019a) Mechanical performance study and parametric analysis of three-tower four-span suspension bridges with steel truss girders. Steel Compos Struct 32(2):189-198 Techno-Press, Daejeon

Cheng M-Y, Chiu Y-F, Chiu C-K, Prayogo D, Wu Y-W, Hsu Z-L, Lin C-H (2019b) Risk-based maintenance strategy for deteriorating bridges using a hybrid computational intelligence technique: a case study. Struct Infrastruct Eng 15(3):334350 Taylor \& Francis Ltd, Abingdon

Cheng X, Li X, Kang T, Su J, Xiang Q, Liu B (2019c) Seismic response of a box bridge after reinforcement with prestressed CFRP textile. Aust J Civil Eng Taylor \& Francis Ltd, Abingdon,18(1), 29-45

Cheng Z, Gao Z, Moan T (2019d) Extreme response analysis of an end-anchored floating bridge. In: Proceedings of the Asme 38th International Conference on Ocean, Offshore and Arctic Engineering, 2019, vol 7a. Amer Soc Mechanical Engineers, New York UNSP V07AT06A051. (In Chinese)

Cheng Z, Gao Z, Moan T (2019e) Numerical modeling and dynamic analysis of a floating bridge subjected to wind, wave, and current loads. J Offshore Mech Arct Eng Trans Asme 141(1):011601

Cheng Z, Sritharan S (2019) Side shear strength of preformed socket connections suitable for vertical precast members. J Bridge Eng 24(5):04019025 Asce-Amer Soc Civil Engineers, Reston

Cheng Z, Svangstu E, Moan T, Gao Z (2019f) Long-term joint distribution of environmental conditions in a Norwegian fjord for design of floating bridges. Ocean Eng 191:106472 Pergamon-Elsevier Science Ltd, Oxford

Chou CC, Wu SC (2019) Cyclic lateral load test and finite element analysis of high-strength concrete-filled steel box columns under high axial compression. Eng Struct 189:89-99 Elsevier Sci Ltd, Oxford

Cui C, Zhang Q, Bao Y, Bu Y, Luo Y (2019a) Fatigue life evaluation of welded joints in steel bridge considering residual stress. J Constr Steel Res 153:509-518 Elsevier Sci Ltd, Oxford

Cui C, Zhang Q, Bao Y, Han S, Bu Y (2019b) Residual stress relaxation at innovative both-side welded rib-to-deck joints under cyclic loading. J Constr Steel Res 156:9-17

Cui Y, Hongtao L, Xiaoyu G (2019c) Experimental study on seismic behavior of roof joint with different seismic isolation measure. J Earthq Eng Eng Vib 39(1):180-188 (in Chinese)

Dai J, Leira BJ, Moan T, Kvittem MI (2020) Inhomogeneous wave load effects on a long, straight and side-anchored floating pontoon bridge. Mar Struct 72:102763

Demis S, Papadakis VG (2019) Durability design process of reinforced concrete structures - Service life estimation, problems and perspectives. J Build Eng 26:100876 Elsevier, Amsterdam

Deng Y, Guo Q, Xu L (2019) Effects of pounding and fluid-structure interaction on seismic response of long-span deep-water bridge with high hollow piers. Arab J Sci Eng 44(5):4453-4465 Springer Heidelberg, Heidelberg

Dong L, Barooah UR, McKee CD, Birely AC, Mander JB (2019) Recommendations for design of concentrically pretensioned, precast concrete bent caps. Pract Period Struct Des Constr 24(1):UNSP 04018034 Asce-Amer Soc Civil Engineers, Reston

Dung CV, Sekiya H, Hirano S, Okatani T, Miki C (2019) A vision-based method for crack detection in gusset plate welded joints of steel bridges using deep convolutional neural networks. Autom Constr 102:217-229 Elsevier, Amsterdam

Ellingwood BR (2005) Risk-informed condition assessment of civil infrastructure: state of practice and research issues. Struct Infrastruct Eng 1(1):7-18 Taylor \& Francis Ltd, Abingdon

El-Zohairy A, Salim H, Saucier A (2019) Steel-concrete composite beams strengthened with externally post-tensioned tendons under fatigue. J Bridge Eng 24(5):04019027 Asce-Amer Soc Civil Engineers, Reston

European Committee for Standardization (CEN). (2017). CEN/TC250 structural Eurocodes business plan

Fan D, Liu J, Ruan H, Wang X (2019a) Study on parameters of nonlinear viscous dampers of Dinhai bridge. J China Foreign Highway 39(04):60-63 (in Chinese)

Fan W, Shen D, Yang T, Shao X (2019b) Experimental and numerical study on low-velocity lateral impact behaviors of RC, UHPFRC and UHPFRC-strengthened columns. Eng Struct 191:509-525 Elsevier Sci Ltd, Oxford

Fan X, Liu J, Hu S, Lu J (2019c) General introduction of the research for FRP reinforced concrete. Concrete 12:156-160 (In (hinese)

Fan X, Qu G, Liu Y (2019d) Improved particle filter prediction algorithm of time-variant reliability indices for bridges. J Tongji Univ Nat Sci 47(8):1115 In Chinese

Fan Z, Zeng M, Hu Z (2019e) Seismic performance analysis of precast segmental bridge piers connection configuration. J Wuhan Univ Technol Transp Sci Eng 43(02):357-362 (In Chinese) 
Fang C, Li Y, Wei K, Zhang J, Liang C (2019a) Vehicle-bridge coupling dynamic response of sea-crossing railway bridge under correlated wind and wave conditions. Adv Struct Eng 22(4):893-906 Sage Publications Inc, Thousand Oaks

Fang Q, Hong R, Guo A, Li H (2019b) Experimental investigation of wave forces on coastal bridge decks subjected to oblique wave attack. J Bridge Eng 24(4):04019011 Asce-Amer Soc Civil Engineers, Reston

Fang R, Zhang W, Chen Y, Zhang L (2019c) Aseismic effect and parametric analysis of the safe-belt device for a continuous bridge with equal height piers. Eng Struct 199:UNSP 109553 Elsevier Sci Ltd, Oxford

Farzad M, Shafieifar M, Azizinamini A (2019) Experimental and numerical study on an innovative sandwich system utilizing UPFRC in bridge applications. Eng Struct 180:349-356 Elsevier Sci Ltd, Oxford

Gao G, Zhu L, Li J, Han W (2020a) Modelling nonlinear aerodynamic damping during transverse aerodynamic instabilities for slender rectangular prisms with typical side ratios. J Wind Eng Ind Aerodyn 197:104064 Elsevier, Amsterdam

Gao G, Zhu L, Wang F, Bai H, Hao J (2020b) Experimental investigation on the nonlinear coupled flutter motion of a typical flat closed-box bridge deck. Sensors 20(2):568 Mdpi, Basel

Gao Z, Ruan H, Qin S, Ma R, Mei D (2019) Technical status, challenges, and solutions of marine bridge engineering. Eng Sci 21(3):1-4 (In Chinese)

Geuzaine M, Denoël V (2019) A framework for the efficient spectral analysis of large wind-and wave-loaded structures. The 15th International Conference on Wind Engineering Beijing, China

Ghaffar A, Hou Y-L, Liu W-Y, Dharejo FA, Zhang H-X, Jia P, Yanyun H, Liu J, Yunjun Z, Nasir Z (2019) Two-dimensional displacement optical fiber sensor based on macro-bending effect. Opt Laser Technol 120:105688 Elsevier Sci Ltd, Oxford

Ghassemi P, Toufigh V (2020) Durability of epoxy polymer and ordinary cement concrete in aggressive environments. Constr Build Mater 234:UNSP 117887 Elsevier Sci Ltd, Oxford

Gkatzogias KI, Kappos AJ (2019) Direct estimation of seismic response in reduced-degree-of-freedom isolation and energy dissipation systems. Earthq Eng Struct Dyn 48(10):1112-1133 Wiley, Hoboken

Gong C, Frangopol DM (2019) An efficient time-dependent reliability method. Struct Saf 81:101864

Gou H, Yang L, Mo Z, Guo W, Shi X, Bao Y (2019) Effect of long-term bridge deformations on safe operation of high-speed railway and vibration of vehicle-bridge coupled system. Int I Struct Stab Dyn 19(9):1950111 World Scientific Publ Co Pte Ltd, Singapore

Greco F, Lonetti P, Blasi PN (2020) Vulnerability analysis of bridge superstructures under extreme fluid actions. J Fluids Struct 93:UNSP 102843 Academic Press Ltd- Elsevier Science Ltd, London

Guo H, Gu X, Zhou B, Zhang W (2019a) Time-dependent reliability analysis for corroded RC beams based on probability density evolution theory. J Build Struct 40(1):67-73 (In Chinese)

Guo X, Tang J (2019) Effects of wind barrier porosity on the coupled vibration of a train-bridge system in a crosswind. Struct Eng Int 29(2):268-275 Taylor \& Francis Ltd, Abingdon

Guo YB, Gao GF, Jing L, Shim VPW (2019b) Quasi-static and dynamic splitting of high-strength concretes - tensile stress-strain response and effects of strain rate. Int J Impact Eng 125:188-211 Pergamon-Elsevier Science Ltd, Oxford

Guo Z, Li L, Zhang J (2019c) Theoretical analysis for shear-lag effect of variable box section cantilever girder based on bar simulation method. Chin Civil Eng J 52(8):72-80 (In Chinese)

Ha TM, Ura S, Fukada S, Torii K (2020) Development and application of a highly durable precast prestressed concrete slab deck using fly ash concrete. Struct Infrastruct Eng 16(9):1228-1246 Taylor \& Francis Ltd, Abingdon

Hallmark R, Collin P, Hicks SJ (2019) Post-installed shear connectors: fatigue push-out tests of coiled spring pins. J Constr Steel Res 153:298-309 Elsevier Sci Ltd, Oxford

Han Q, Jia Z, Xu K, Zhou Y, Du X (2019a) Hysteretic behavior investigation of self-centering double-column rocking piers for seismic resilience. Eng Struct 188:218-232 Elsevier Sci Ltd, Oxford

Han X, Xiang H, Li Y, Wang Y (2019b) Predictions of vertical train-bridge response using artificial neural network-based surrogate model. Adv Struct Eng 22(12):2712-2723 Sage Publications Inc, Thousand Oaks

Hao X, Tang H, Shao S, Wang L (2019) Study of seismic performance of transversely unequal-height double-columned piers. World Bridges 47(03):54-59 (in Chinese)

He X, Fang D, Huan L, Kang S (2019a) Parameter optimization for improved aerodynamic performance of louver-type wind barrier for train-bridge system. J Cent South Univ 26(1):229-240 Journal of Central South Univ, Hunan

He X, Shi K, Wu T (2019b) An efficient analysis framework for high-speed train-bridge coupled vibration under non-stationary winds. Struct Infrastruct Eng Taylor \& Francis Ltd, Abingdon, 16(9):1326-1346

Heng J, Zheng K, Gou C, Zhang Y, Bao Y (2017) Fatigue performance of rib-to-deck joints in orthotropic steel decks with thickened edge U-ribs. J Bridge Eng 22(9):04017059 Asce-Amer Soc Civil Engineers, Reston

Heng J, Zheng K, Kaewunruen S, Zhu J, Baniotopoulos C (2020) Probabilistic fatigue assessment of rib-to-deck joints using thickened edge U-ribs. Steel Compos Struct 35(6):799-813

Henriques D, Goncalves R, Camotim D (2019) A visco-elastic GBT-based finite element for steel-concrete composite beams. Thin Walled Struct 145:106440 Elsevier Sci Ltd, Oxford

Hirai H, Ishii K (2019) Development of dam inspection underwater robot. J Robot Netw Artif Life 6(1):18-22 Atlantis Press, Paris

Hong S (2019) The effect of damping on the dynamic responses of a floating bridge in wind and waves. Master, NTNU, Norway

Hooton RD (2019) Future directions for design, specification, testing, and construction of durable concrete structures. Cement Concrete Res 124:UNSP 105827 Pergamon-Elsevier Science Ltd, Oxford

Hosseini F, Gencturk B, Jain A, Shahzada K (2019) Optimal design of bridge columns constructed with engineered cementitious composites and Cu-Al-Mn superelastic alloys. Eng Struct 198:UNSP 109531 Elsevier Sci Ltd, Oxford

Housner GW (1963) The behavior of inverted pendulum structures during earthquakes. Bull Seismolog Soc Am 53(2):403-417 GeoScienceWorld

Hu C, Zhao L, Chen H, Zhou Z, Ge Y (2019) Reynolds number effects on aerodynamic forces of a streamlined closed-box girder during vortex-induced vibrations. J Vib Shock 38(12):118-125 (In Chinese)

Huang B, Duan L, Yang Z, Zhang J, Kang A, Zhu B (2019a) Tsunami forces on a coastal bridge deck with a box girder. J Bridge Eng 24(9):04019091 Asce-Amer Soc Civil Engineers, Reston 
Huang B, Yang Z, Zhu B, Zhang J, Kang A, Pan L (2019b) Vulnerability assessment of coastal bridge superstructure with box girder under solitary wave forces through experimental study. Ocean Eng 189:106337

Huang C, Song J, Zhang N, Lee GC (2019c) Seismic performance of precast prestressed concrete bridge girders using fieldcast ultrahigh-performance concrete connections. J Bridge Eng 24(6):04019046 Asce-Amer Soc Civil Engineers, Reston

Huang D, Wei J, Liu X, Xiang P, Zhang S (2019d) Experimental study on long-term performance of steel-concrete composite bridge with an assembled concrete deck. Constr Build Mater 214:606-618 Elsevier Sci Ltd, Oxford

Huang H, Hao R, Zhang W, Huang M (2019e) Experimental study on seismic performance of square RC columns subjected to combined loadings. Eng Struct 184:194-204 Elsevier Sci Ltd, Oxford

Huang Y, Zhang Q, Bao Y, Bu Y (2019f) Fatigue assessment of longitudinal rib-to-crossbeam welded joints in orthotropic steel bridge decks. J Constr Steel Res 159:53-66 Elsevier Sci Ltd, Oxford

Hui Y, Law S-S, Liu M, Li S (2019) Parameter and aerodynamic force identification of single-degree-of-freedom system in wind tunnel test. J Eng Mech 145(1):04018120 American Society of Civil Engineers

Hüthwohl P, Lu RD, Brilakis I (2019) Multi-classifier for reinforced concrete bridge defects. Autom Constr 105:102824

Istrati D, Buckle I (2019) Role of trapped air on the tsunami-induced transient loads and response of coastal bridges. Geosciences 9(4):191 Multidisciplinary Digital Publishing Institute

Izadi M, Motavalli M, Ghafoori E (2019) Iron-based shape memory alloy (Fe-SMA) for fatigue strengthening of cracked steel bridge connections. Constr Build Mater 227:UNSP 116800 Elsevier Sci Ltd, Oxford

Jia D, Mao J, Guo Q, Yang Z, Xiang N (2019a) A flexure-capacity design method and seismic fragility assessment of FRP/steel double-reinforced bridge piers. Struct Infrastruct Eng 16(9):1311-1325

Jia Y, Zhao R, Ping P, Li F, Zhan Y (2019b) Experimental investigation on seismic behavior of bridge piers with polypropyleneengineered cementitious composite in plastic hinge regions. China J Highway Transp 32(7):100-110 (In Chinese)

Jiang H, Zhang T, Tian L (2018) Review of FRP reinforced damaged RC beams. Low Temp Architect Technol 40(09):64-66 (In Chinese)

Jiang L, Kang X, Li C, Shao G (2019a) Earthquake response of continuous girder bridge for high-speed railway: a shaking table test study. Eng Struct 180:249-263 Elsevier Sci Ltd, Oxford

Jiang L, Liu X, Xiang P, Zhou W (2019b) Train-bridge system dynamics analysis with uncertain parameters based on new point estimate method. Eng Struct 199:UNSP 109454 Elsevier Sci Ltd, Oxford

Jie ZY, Li YD, Wei X (2017) A study of fatigue crack growth from artificial corrosion pits at welded joints under complex stress fields. Fatigue Fract Eng Mater Struct 40(9):1364-1377 Wiley, Hoboken

Jin D, Hou C, Shen L, Han L-H (2019) Numerical investigation of demountable CFST K-joints using blind bolts. J Constr Steel Res 160:428-443 Elsevier Sci Ltd, Oxford

Jin Z, Yuan L, Pei S (2020) Efficient evaluation of bridge deformation for running safety of railway vehicles using simplified models. Adv Struct Eng 23(3):454-467 Sage Publications Inc, Thousand Oaks

Jing H, Liao H, Ma C, Chen K (2019) Influence of elevated water levels on wind field characteristics at a bridge site. Adv Struct Eng 22(7):1783-1795 Sage Publications Inc, Thousand Oaks

Jung D, Deogekar P, Andrawes B (2019a) Seismic performance of bridges with high strength concrete columns reinforced with SMA-FRP jackets. Smart Mater Struct 28(3):035008 lop Publishing Ltd, Bristol

Jung HJ, Lee J-H, Yoon S, Kim I-H (2019b) Bridge inspection and condition assessment using Unmanned Aerial Vehicles (UAVs): major challenges and solutions from a practical perspective. Smart Struct Syst 24(5):669-681

Kanjo N, Sugiyama H, Agano Y, Fujihira S, Okumura M, Okubo N, Natsuakim Y $(2011$, 2011) Welding procedure test of inner fillet welding set for high durable orthotropic steel deck with trough rib. Proc Constr Steel (in Japanese)

Khan I, Xu T, Castel A, Gilbert RI, Babaee M (2019) Risk of early age cracking in geopolymer concrete due to restrained shrinkage. Constr Build Mater 229:116840 Elsevier Sci Ltd, Oxford

Kim J, Williamson EB (2019) Ultimate behavior of stud connections within haunches. J Bridge Eng 24(1):04018106 Asce-Amer Soc Civil Engineers, Reston

Kim JM, Kim T, Son K, Yum S-G, Ahn S (2019a) Measuring vulnerability of typhoon in residential facilities: focusing on typhoon Maemi in South Korea. Sustainability 11(10):2768 Mdpi, Basel

Kim S, Kim S (2019) Flexural behavior of concrete beams with steel bar and FRP reinforcement. J Asian Architect Build Eng 18(2):89-97

Kim S, Won D, Kang YJ (2019c) Ultimate behavior of steel cable-stayed bridges during construction. Int J Steel Struct 19(3): 932-951 Korean Soc Steel Construction-Kssc, Seoul

Kinoshita K, Banno Y, Ono Y, Yamada S, Handa M (2019a) Fatigue strength improvement of welded joints of existing steel bridges by shot-peening. Int I Steel Struct 19(2):495-503 Korean Soc Steel Construction-Kssc, Seoul

Kinoshita K, Banno Y, Ono Y, Yamada S, Handa M (2019b) Fatigue strength improvement and fatigue crack closure by portable pneumatic needle-peening treatment on welded joints. Int I Steel Struct 19(3):693-703 Korean Soc Steel Construction-Kssc, Seoul

Koh TH, Kim MK, Yang KH, Yoon YS, Kwon SJ (2019) Service life evaluation of RC T-girder under carbonation considering cold joint and loading effects. Constr Build Mater 226:106-116 Elsevier Sci Ltd, Oxford

Krish ZF, Kowalsky MJ, Nau JM (2019) Seismic repair of circular reinforced concrete bridge columns by plastic hinge relocation with grouted annular ring. J Earthq Eng Taylor \& Francis Ltd, Abingdon

Kruszewski D, Zaghi AE, Wille K (2019) Finite element study of headed shear studs embedded in ultra-high performance concrete. Eng Struct 188:538-552 Elsevier Sci Ltd, Oxford

Kuang Z, Zheng G, Jiao X (2019) Experimental study on effect of mechanical behavior of grout sleeve splicing for reinforced bars due to lack of grout. J Tongji Univ 47(7):934-945 Natural Science

Kueres S, Will N, Hegger J (2020) Shear strength of prestressed FRP reinforced concrete beams with shear reinforcement. Eng Struct 206:110088

Kuhlmann U, Schmidt-Rasche C (2017) Next generation of Eurocode 3 - evolution by improvements and harmonization. ce/ papers 1(4):497-506

La HM, Dinh TH, Pham NH, Ha QP, Pham AQ (2019) Automated robotic monitoring and inspection of steel structures and bridges. Robotica 37(5):947-967 Cambridge Univ Press, New York 
Leblouba M, Barakat S, Ahmed MSA, Al-Toubat S (2019) Shear strength at the interface of precast bridge concrete decks and girders subjected to cyclic loading with varying speeds. Eng Struct 196:UNSP 109296 Elsevier Sci Ltd, Oxford

Lezgy-Nazargah M, Vidal P, Polit O (2019) A sinus shear deformation model for static analysis of composite steel-concrete beams and twin-girder decks including shear lag and interfacial slip effects. Thin Walled Struct 134:61-70 Elsevier Sci Ltd, Oxford

Li C, Chen B, Huang Q (2019a) Experimental research on shrinkage of ultra-high performance concrete under restrained rings. Eng Mech 36(8):49-58 (In Chinese)

Li H, Dong H, Li C (2020) Research progress on life-cycle performance-based seismic maintenance decision method for bridge structures. China J Highway Transp 33(02):1-14 (In Chinese)

Li H, Liu Y, Zhang N, Liu J (2019b) Experimental study on shear performance of stud shear connectorafter undergoing freezethaw cycles. J Build Struct 40(05):149-155 (In Chinese)

Li H, Yuan C, Ren L, Jiang T (2019c) Structural health-monitoring system for roof structure of the Dalian gymnasium. Adv Struct Eng 22(7):1579-1590 Sage Publications Inc, Thousand Oaks

Li J, Chen J, Zhang X (2018a) Time-dependent reliability analysis of deteriorating structures based on phase-type distributions. J Transp Sci Eng 34(2):39-44

Li J, Shao C (2019) A simplified calculation method for seismic analysis of friction pendulum bearing isolated continuous girder bridge. Railway Eng 59(06):10-13 (in Chinese)

Li J, Zhang Q, Bao Y, Zhu J, Chen L, Bu Y (2019d) An equivalent structural stress-based fatigue evaluation framework for ribto-deck welded joints in orthotropic steel deck. Eng Struct 196:UNSP 109304 Elsevier Sci Ltd, Oxford

Li K, Zhang D, Li Q, Fan Z (2019e) Durability for concrete structures in marine environments of HZM project: design, assessment and beyond. Cement Concr Res 115:545-558 Pergamon-Elsevier Science Ltd, Oxford

Li M, Li M, Su Y (2019f) Experimental determination of the two-dimensional aerodynamic admittance of typical bridge decks. J Wind Eng Ind Aerodyn 193:UNSP 103975 Elsevier, Amsterdam

Li M, Li M, Zhong Y, Luo N (2019g) Buffeting response evaluation of long-span bridges with emphasis on the threedimensional effects of gusty winds. J Sound Vib 439:156-172 Academic Press Ltd- Elsevier Science Ltd, London. (In Chinese)

Li Q, Wang H, Shen G (2019h) Research on control method of Maglev vehicle-guideway coupling vibration system based on particle swarm optimization algorithm. J Vib Control 25(16):2237-2245 Sage Publications Ltd, London

Li X, Gao C, Guo Y, He F, Shao Y (2019i) Cable surface damage detection in cable-stayed bridges using optical techniques and image mosaicking. Opt Laser Technol 110:36-43 Elsevier Sci Ltd, Oxford

Li X, Hu Z, Fan L, Shah YI (2019j) Experimental investigation of perfobond hoop shear connector's bearing capacity and slip. Eng Struct 198:UNSP 109461 Elsevier Sci Ltd, Oxford

Li X, Lifeng L, Xiao L, Yang D (2019k) A stochastic analysis method of train-bridge interactions considering full probability distribution of track irregularities. China Civil Eng J 52(11):71-78 (in Chinese)

Li X, Tang Q, Wu J, Mao X, Jun J, Wang M (2019l) Influence of the bridge tower shielding effect on aerodynamic parameters and running safety of moving train. China J Highway Transp 32(10):191-199 (in Chinese)

Li X, Wan S, Mo YL, Shen K, Zhou T, Nian Y (2019m) An improved method for analyzing shear lag in thin-walled box-section beam with arbitrary width of cantilever flange. Thin Walled Struct 140:222-235 Elsevier Sci Ltd, Oxford

Li X, Wang D, Liu D, Xin L, Zhang X (2018b) Dynamic analysis of the interactions between a low-to-medium-speed maglev train and a bridge: field test results of two typical bridges. Proc Inst Mech Eng F J Rail Rapid Transit 232(7):2039-2059 Sage Publications Ltd, London

Li Y, Fang C, Wei K, Zhai G, Tang H (2019n) Frequency domain dynamic analyses of freestanding bridge pylon under wind and waves using a copula model. Ocean Eng 183:359-371 Pergamon-Elsevier Science Ltd, Oxford

Liang X (2019) Image-based post-disaster inspection of reinforced concrete bridge systems using deep learning with Bayesian optimization. Comput Aided Civil Infrastruct Eng 34(5):415-430 Wiley, Hoboken

Liao H, Jing H, Ma C, Tao Q, Li Z (2020) Field measurement study on turbulence field by wind tower and Windcube Lidar in mountain valley. J Wind Eng Ind Aerodyn 197:104090 Elsevier, Amsterdam

Lin S, Wang Q, Nikitas N, Liao H (2019) Effects of oscillation amplitude on motion-induced forces for 5:1 rectangular cylinders, J Wind Eng Ind Aerodyn 186:68-83 Elsevier Science Bv, Amsterdam

Liu H, Lei J (2019) Identification of three-component coefficients of double deck truss girder for long-span bridge. J Zhejiang Univ Eng Sci 53(6):1092-1100

Liu K, Yu R, Shui Z, Li X, Ling X, He W, Yi S, Wu S (2019a) Effects of pumice-based porous material on hydration characteristics and persistent shrinkage of ultra-high performance concrete (UHPC). Materials 12(1):11 Mdpi, Basel

Liu Q, Wang M (2019) The reliability analysis of structures based on failure probability of first-passage time. Chin J Appl Mech 36(2):480-484 (In Chinese)

Liu W, Yang N, Bai F, Weng K (2019b) Time-dependent reliability calculation model of corroded purlin under typhoon hazard. J Beijing Jiaotong Univ 43(6):67-74 (In Chinese)

Liu X, Yu C, Quan W, Chen L (2019c) Inspection, materials testing and field testing of a prestressed concrete box bridge after fire exposure. Fire Saf J 108:102852

Liu Y, Guo Z, Liu X, Chicchi R, Shahrooz B (2019d) An innovative resilient rocking column with replaceable steel slit dampers: experimental program on seismic performance. Eng Struct 183:830-840 Elsevier Sci Ltd, Oxford

Liu Y, Xin H, Liu Y (2019e) Experimental and analytical study on shear mechanism of rubber-ring perfobond connector. Eng Struct 197:109382 Elsevier Sci Ltd, Oxford

Liu Y, Zhang Q, Bao Y, Bu Y (2019f) Static and fatigue push-out tests of short headed shear studs embedded in Engineered Cementitious Composites (ECC). Eng Struct 182:29-38 Elsevier Sci Ltd, Oxford

Lu C, Liu J, Liu Y, Liu Y (2019a) Intelligent construction technology of railway engineering in China. Front Eng Manage 6(4): 503-516 Higher Education Press, Beijing

Lu Z, Huang J, Li Y, Dai S, Peng Z, Liu X, Zhang M (2019b) Mechanical behaviour of grouted sleeve splice under uniaxial tensile loading. Eng Struct 186:421-435 Elsevier Sci Ltd, Oxford

Luo P, Zhang Q, Bao Y, Bu Y (2019) Fatigue performance of welded joint between thickened-edge U-rib and deck Chock in orthotropic steel deck. Eng Struct 181:699-710 Elsevier Sci Ltd, Oxford 
LV J, Zhou T, Du Q, Li K (2020) Experimental and analytical study on uniaxial compressive fatigue behavior of self-compacting rubber lightweight aggregate concrete. Constr Build Mater 237:117623

Lyu L, Bing C, Zhong H, Gu Y, Guo Z (2019) Study on nonlinear stability of structure for main bridge of fifth Changjiang river bridge in Nanjing. Bridge Construct 49(4):40-45 (In Chinese)

Ma C, Wang J, Li QS, Liao H (2019) 3D aerodynamic admittances of streamlined box bridge decks. Eng Struct 179:321-331 Elsevier Sci Ltd, Oxford

Macho M, Ryjacek P, Matos J (2019) Fatigue life analysis of steel riveted rail bridges affected by corrosion. Struct Eng Int 29(4): 551-562 Taylor \& Francis Ltd, Abingdon

Mao J, Yu Z, Jiang L (2019) Stochastic analysis of vehicle-bridge coupled interaction and uncertainty bounds of random responses in heavy haul railways. Int I Struct Stab Dyn 19(12):1950144 World Scientific Publ Co Pte Ltd, Singapore

Mashal M, Palermo A (2019) Emulative seismic resistant technology for accelerated bridge construction. Soil Dyn Earthq Eng 124:197-211 Elsevier Sci Ltd, Oxford

Megid WA, Chainey M-A, Lebrun P, Hay DR (2019) Monitoring fatigue cracks on eyebars of steel bridges using acoustic emission: a case study. Eng Fract Mech 211:198-208 Pergamon-Elsevier Science Ltd, Oxford

Mei H (2019) Study on multi-hazard probability risk of life cycle bridge. Master, Harbin University of Technology, Harbin (In Chinese)

Moan T, Eidem ME (2020) Floating bridges and submerged tunnels in Norway-the history and future outlook. In: Wang CM, Lim SH, Tay ZY (eds) WCFS2019, lecture notes in civil engineering. Springer, Singapore, pp 81-111

Moideen R, Ranjan Behera M, Kamath A, Bihs H (2019) Effect of girder spacing and depth on the solitary wave impact on coastal bridge deck for different airgaps. J Mar Sci Eng 7(5):140 Multidisciplinary Digital Publishing Institute

Montoya, A., Matamoros, A., Testik, F., Nasouri, R., Shahriar, A., and Majlesi, A. (2019). Structural vulnerability of coastal bridges under extreme hurricane conditions. Publications

Morgenthal G, Hallermann N, Kersten J, Taraben J, Debus P, Helmrich M, Rodehorst V (2019) Framework for automated UASbased structural condition assessment of bridges. Autom Constr 97:77-95 Elsevier, Amsterdam

Nair A, Cai CS, Kong X, Hou S (2019) Bridge retrofitting using FRP-wrapped balsa wood deck: experimental study and field evaluation. J Aerospace Eng, Asce-Amer Soc Civil Engineers, Reston 32(5):04019065

Naser MZ, Hawileh RA, Abdalla JA (2019) Fiber-reinforced polymer composites in strengthening reinforced concrete structures: a critical review. Eng Struct 198:UNSP 109542 Elsevier Sci Ltd, Oxford

Nassar M, Guizani L, Nollet M-J, Tahan A (2019) A probability-based reliability assessment approach of seismic base-isolated bridges in cold regions. Eng Struct 197:109353 Elsevier Sci Ltd, Oxford

Ni FT, Zhang J, Noori MN (2019b) Deep learning for data anomaly detection and data compression of a long-span suspension bridge. Comput Aid Civil Infrastruct Eng 35(7):685-700

$\mathrm{Ni}$ G, Liu Q, Bing H, Ge Y, Zhang M, Zhang H (2019a) Finite element analysis on seismic reinforcement of long-span rigid frame bridge with high piers. World Earthq Eng 35(2):193-202 (in Chinese)

Norhasri MSM, Hamidah MS, Fadzil AM (2019) Inclusion of nano metaclayed as additive in ultra high performance concrete (UHPC). Constr Build Mater 201:590-598 Elsevier Sci Ltd, Oxford

Oskoui EA, Taylor T, Ansari F (2019) Method and monitoring approach for distributed detection of damage in multi-span continuous bridges. Eng Struct 189:385-395 Elsevier Sci Ltd, Oxford

Pan S, Cui Y, Zhang Z, Zhu W (2019) Behaviour and design of three-tower, self-anchored suspension bridge with a concrete girder. Proc Inst Civil Eng Bridge Eng 172(3):190-203 Ice Publishing, Westminister

Pang B (2018) Optimization of PC bridge life cycle comprehensive maintenance strategy considering climate change. Doctor, Beijing Jiaotong University, Beijing (In Chinese)

Papapetrou VS, Tamijani AY, Brown J, Kim D (2019) Design optimization of hybrid FRP/RC bridge. Appl Compos Mater 26(1): $249-270$

Pei XY, Yi TH, Li HN (2019) Dual-type sensor placement optimization by fully utilizing structural modal information. Adv Struct Eng 22(3):737-750 Sage Publications Inc, Thousand Oaks

Peng F, Xue W (2019) Reliability-based design provisions for flexural strength of fiber-reinforced polymer prestressed concrete bridge girders. Aci Struct J 116(1):251-260 Amer Concrete Inst, Farmington Hills

Peng J, Tian Y, Yang Y, Zhang J (2018) Reliability analysis of prestressed concrete box girder bridge under deicing salt environment. J Transp Sci Eng 34(02):39-44

Petersen OW, Oiseth O, Lourens E (2019) Full-scale identification of the wave forces exerted on a floating bridge using inverse methods and directional wave spectrum estimation. Mech Syst Signal Process 120:708-726 Academic Press LtdElsevier Science Ltd, London

Phillips S, Narasimhan S (2019) Automating data collection for robotic bridge inspections. J Bridge Eng 24(8):04019075 AsceAmer Soc Civil Engineers, Reston

Pu Q, Xie H, Fan S, Wang W, Liu J, Gou H (2019) Analysis method of bearing capacity of stud connector in steel-concrete composite structures under push-out failure. Adv Eng Sci 51(1):89-95 (In Chinese)

Qeshta IMI (2019) Fragility and resilience of bridges subjected to extreme wave-induced forces. Doctor, RMIT University, Melbourne

Qeshta IMI, Hashemi MJ, Gravina R, Setunge S (2019) Review of resilience assessment of coastal bridges to extreme waveinduced loads. Eng Struct 185:332-352 Elsevier Sci Ltd, Oxford

Qi H, Wei Y (2018) Nonparametric estimation for the reliability of a series system stress-strength model based on multiple copula function. J Wuhan Univ Nat Sci Ed 64(3):269-277 (In Chinese)

Qi J, Bao Y, Wang J, Li L, Li W (2019) Flexural behavior of an innovative dovetail UHPC joint in composite bridges under negative bending moment. Eng Struct 200:109716 Elsevier Sci Ltd, Oxford

Qu CX, Yi TH, Li HN (2019a) Mode identification by eigensystem realization algorithm through virtual frequency response function. Struct Control Health Monit 26(10):e2429

Qu K, Sun WY, Kraatz S, Deng B, Jiang CB (2020) Effects of floating breakwater on hydrodynamic load of low-lying bridge deck under impact of cnoidal wave. Ocean Eng 203:107217 
Qu K, Sun WY, Tang HS, Jiang CB, Deng B, Chen J (2019b) Numerical study on hydrodynamic load of real-world tsunami wave at highway bridge deck using a coupled modeling system. Ocean Eng 192:106486 Pergamon-Elsevier Science Ltd, Oxford

Raheem AHA, Mahdy M, Mashaly AA (2019) Mechanical and fracture mechanics properties of ultra-high-performance concrete. Constr Build Mater 213:561-566 Elsevier Sci Ltd, Oxford

Rahnavard R, Thomas RJ (2019) Numerical evaluation of steel-rubber isolator with single and multiple rubber cores. Eng Struct 198:UNSP 109532 Elsevier Sci Ltd, Oxford

Ren M (2019) Study on the failure mechanism of bridge under the coupling load of flood wave and current. Master, Dalian University of Technology, Dalian (In Chinese)

Sajedi S, Huang Q (2019) Reliability-based life-cycle-cost comparison of different corrosion management strategies. Eng Struct 186:52-63 Elsevier Sci Ltd, Oxford

Shao C, Qi Q, Wang W, Hu C, Meng W, Xiao L, Xiao Z (2019) Shaking table test of seismic performance of a simply-supported girder bridge with single column. J Vib Shock 38(16):49-55 (In Chinese)

Shen P, Lu L, He Y, Wang F, Hu S (2019a) The effect of curing regimes on the mechanical properties, nano-mechanical properties and microstructure of ultra-high performance concrete. Cement Concrete Res 118:1-13

Shen R, Kang H, Lu W (2019b) Requirements of vertical stiffness and anti-slip safety for three-pylon suspension bridge. J Southeast Univ Nat Sci Ed 49(3):474-480

Shen Y, Cai P, Chen L, Li G (2019c) Shear strength of keyed joints in segmental precast concrete bridges. J Tongji Univ 47(10): 1414-1420 Natural Science (In Chinese)

Shi J, Feng HD (2019) Reliability assessment of a curved heavy-haul railway track-bridge system. Struct Infrastruct Eng 16(3): 465-480 Taylor \& Francis Ltd, Abingdon

Shi Y, Long G, Ma C, Xie Y, He J (2019a) Design and preparation of ultra-high performance concrete with low environmental impact. J Clean Prod 214:633-643 Elsevier Sci Ltd, Oxford

Shi Z, Yang S, Pu Q, Zhang Y (2019b) Fatigue performance of orthotropic steel decks in long-span cable-stayed steel-box girder railway bridges. J Bridge Eng 24(5):04019035 Asce-Amer Soc Civil Engineers, Reston

Shi Z, Yong Z, Yang S, Pu Q (2019c) Research on fatigue performance of rib-to-diaphragm joint in railway orthotropic steel decks. Eng Mech 36(2):124-133

Shim CS, Dang N-S, Lon S, Jeon C-H (2019) Development of a bridge maintenance system for prestressed concrete bridges using 3D digital twin model. Struct Infrastruct Eng 15(10):1319-1332 Taylor \& Francis Ltd, Abingdon

Shoushtari E, Saiidi MS, Itani A, Moustafa MA (2019) Design, construction, and shake table testing of a steel girder bridge system with ABC sonnections. J Bridge Eng 24(9):04019088 Asce-Amer Soc Civil Engineers, Reston

Siwowski T, Rajchel M, Kulpa M (2019) Design and field evaluation of a hybrid FRP composite - lightweight concrete road bridge. Compos Struct 230:UNSP 111504 Elsevier Sci Ltd, Oxford

Soltanian H, Firouzi A, Mohammadzadeh S (2018) Time dependent reliability analysis of railway sleepers subjected to corrosion. Struct Concrete 19(5):1409-1418

Stewart MG, Rosowsky DV (1998) Time-dependent reliability of deteriorating reinforced concrete bridge decks. Struct Saf 20(1):91-109 Elsevier Science Bv, Amsterdam

Su J, Wang J, Li Z, Liang X (2019a) Effect of reinforcement grade and concrete strength on seismic performance of reinforced concrete bridge piers. Eng Struct 198:UNSP 109512 Elsevier Sci Ltd, Oxford

Su S, Ge J, Wang W, Guo H, Li C, Hu J (2019b) Experimental research on the corresponding relationship between stress concentration and magnetic memory effect of steel I-column of gabled framed. J Xian Univ Architect Technol Nat Sci Ed $51(06): 771-774+796$

Sun B, Xu YL, Wang F-Y, Li Z, Zhu Q (2019a) Multi-scale fatigue damage prognosis for long-span steel bridges under vehicle loading. Struct Infrastruct Eng 15(4):524-538 Taylor \& Francis Ltd, Abingdon

Sun B, Xu Y-L, Zhu Q, Li Z (2019b) Auto-adaptive multiblock cycle jump algorithm for fatigue damage simulation of longspan steel bridges. Fatigue Fract Eng Mater Struct 42(4):919-928 Wiley, Hoboken

Sun J, Jiang H, Yang W, Zhu S, Wang K (2019c) Method of three-dimensional parametric bridge standard modeling based on BIM technology. J Chongaing Jiaotong Univ (Natural Science) 38(10):19-24 (in Chinese)

Sun J, Zhen Z (2019) Application of infrared thermal imaging technology to steel structure coating inspection for bridges. World Bridge 47(05):69-73 (in Chinese)

Sun L, Xie W (2019) Full-model shaking table tests of seismic behavior of a super-long-span cable-stayed bridge with pile foundations. J Bridge Eng 24(11):04019102 Asce-Amer Soc Civil Engineers, Reston

Sun Y, Li M, Li M, Liao H (2019d) Spanwise correlation of vortex-induced forces on typical bluff bodies. J Wind Eng Ind Aerodyn 189:186-197

Sun Y, Xu J, Qiang H, Chen C, Lin G (2019e) Adaptive sliding mode control of maglev system based on RBF neural network minimum parameter learning method. Measurement 141:217-226 Elsevier Sci Ltd, Oxford

Sun Z, Zhao T, Yan S, Wang D (2019f) Research on numerical modeling method for rocking self-centering bridge piers. J Basic Sci Eng 27(6):1357-1369 (in Chinese)

Tan EL, Varsani H, Liao F (2019) Experimental study on demountable steel-concrete connectors subjected to combined shear and tension. Eng Struct 183:110-123 Elsevier Sci Ltd, Oxford

Tang Y, Hua XG, Chen ZQ, Zhou Y (2019a) Experimental investigation of flutter characteristics of shallow Pi section at postcritical regime. J Fluid Struct 88:275-291 Academic Press Ltd- Elsevier Science Ltd, London

Tang Y, Wu G, Sun Z, Zhang Y (2019b) Seismic performance of underwater bridge columns strengthened with prestressedconcrete panels and FRP reinforcement. J Compos Constr 23(3):04019019 Asce-Amer Soc Civil Engineers, Reston

Tao T, Wang H (2019a) Time-domain simulation and analysis of nonstationary buffeting responses of girder section model of a long-span bridge. J Vibration Eng 32(5):830-836

Tao T, Wang H (2019b) Modelling of longitudinal evolutionary power spectral density of typhoon winds considering highfrequency subrange. J Wind Eng Ind Aerodyn 193:UNSP 103957 Elsevier, Amsterdam

Tawadrous R, Morcous G (2019) Design of shear pocket connection in full-depth precast concrete deck systems. Eng Struct 179:367-386 Elsevier Sci Ltd, Oxford 
Tawadrous R, Morcous G, Maguire M (2019) Performance evaluation of a new precast concrete bridge deck system. J Bridge Eng 24(6):04019051 Asce-Amer Soc Civil Engineers, Reston

Ti Z, Zhang M, Li Y, Wei K (2019) Numerical study on the stochastic response of a long-span sea-crossing bridge subjected to extreme nonlinear wave loads. Eng Struct 196:UNSP 109287 Elsevier Sci Ltd, Oxford

Tong T, Zhuo W, Jiang X, Lei H, Liu Z (2019) Research on seismic resilience of prestressed precast segmental bridge piers reinforced with high-strength bars through experimental testing and numerical modelling. Eng Struct 197:109335 Elsevier Sci Ltd, Oxford

Upadhyay A, Pantelides CP, Ibarra L (2019) Residual drift mitigation for bridges retrofitted with buckling restrained braces or self centering energy dissipation devices. Eng Struct 199:UNSP 109663 Elsevier Sci Ltd, Oxford

Viuff T, Leira BJ, Xiang X, Oiseth O (2019) Effects of wave directionality on extreme response for a long end-anchored floating bridge. Appl Ocean Res 90:101843 Elsevier Sci Ltd, Oxford

Viuff T, Xiang X, Leira BJ, Oiseth O (2020) Software-to-software comparison of end-anchored floating bridge global analysis. J Bridge Eng 25(5):04020022 Asce-Amer Soc Civil Engineers, Reston

Viuff TH (2020) Uncertainty assessment of wave- and current-induced global response of floating bridges - a numerical investigation. Doctor, NTNU, Norway

Wang C, Dai J, Zang Y, Huayu X (2019a) Analysis on static stability of self-anchored suspension bridge with steel box girder. Bridge Constr 49(2):47-51 (In Chinese)

Wang C, Wang Y, Duan L, Wang S, Zhai M (2019b) Fatigue performance evaluation and cold reinforcement for old steel bridges. Struct Eng Int 29(4):563-569 Taylor \& Francis Ltd, Abingdon

Wang C, Zhang H (2018) Roles of load temporal correlation and deterioration-load dependency in structural time-dependent reliability. Comput Struct 194:48-59

Wang EL (2018) Construction monitoring on steel truss bridge's maintenance and reinforcement. Appl Mech Mater 878:8994 Trans Tech Publications Ltd

Wang G, Fan J, Cao J, Li P, Liu Z (2019c) Research on the vertical bending mechanical behaviors of new composite box girders. J Railway Eng Soc 36(09):23-30+48

Wang J, Li S, Dezfuli FH, Alam MS (2019d) Sensitivity analysis and multi-criteria optimization of SMA cable restrainers for longitudinal seismic protection of isolated simply supported highway bridges. Eng Struct 189:509-522 Elsevier Sci Ltd, Oxford

Wang K, Zhao C, Wu B, Deng K, Cui B (2019e) Fully-scale test and analysis of fully dry-connected prefabricated steel-UHPC composite beam under hogging moments. Eng Struct 197:109380 Elsevier Sci Ltd, Oxford

Wang L, Xiong C, Wang X, Li Y, Xu M (2018) Hybrid time-variant reliability estimation for active control structures under aleatory and epistemic uncertainties. J Sound Vib 419:469-492 Academic Press Ltd- Elsevier Science Ltd, London

Wang N-B, Ren W-X, Huang T-L (2019f) Baseline-free damage detection method for beam structures based on an actual influence line. Smart Struct Syst 24(4):475-490 Techno-Press, Daejeon

Wang P, Xing C, Xiang X (2019g) Vibration deformation measurement and modal analysis for large bridge span using ground-based interferometric radar IBIS-S. Bull Survey Map 10:35-39 Wang Peng, School of Environmental Science and Engineering (in Chinese)

Wang P, Zhao M, Du X (2019h) Simplified formula for earthquake-induced hydrodynamic pressure on round-ended and rectangular cylinders surrounded by water. J Eng Mech 145(2):04018137 Asce-Amer Soc Civil Engineers, Reston

Wang P, Zhao M, Du X, Cheng X (2019i) A finite element solution of earthquake-induced hydrodynamic forces and wave forces on multiple circular cylinders. Ocean Eng 189:106336 Pergamon-Elsevier Science Ltd, Oxford

Wang Q, Ji B, Fu Z, Ye Z (2019j) Evaluation of crack propagation and fatigue strength of rib-to-deck welds based on effective notch stress method. Constr Build Mater 201:51-61 Elsevier Sci Ltd, Oxford

Wang S, He J, Liu Y (2019k) Shear behavior of steel I-girder with stiffened corrugated web, Part I: experimental study. Thin Walled Struct 140:248-262 Elsevier Sci Ltd, Oxford

Wang S, Ke Z, Gao Y, Zhang Y (2019l) Long-term in situ performance investigation of orthotropic steel bridge deck strengthened by SPS and RPC solutions. J Bridge Eng 24(6):04019054 Asce-Amer Soc Civil Engineers, Reston

Wang S, Liu Y, He J, Xin H, Yao H (2019m) Experimental study on cyclic behavior of composite beam with corrugated steel web considering different shear-span ratio. Eng Struct 180:669-684 Elsevier Sci Ltd, Oxford

Wang S, Wei K, Shen Z, Xiang Q (2019n) Experimental investigation of local scour protection for cylindrical bridge piers using anti-scour collars. Water 11(7):1515 Mdpi, Basel

Wang X, Chai S (2019) Stiffness value of the middle tower in triple-tower suspension bridges. J Beijing Univ Technol 45(4): 353-358 (In Chinese)

Wang Y-H, Yu J, Liu J, Chen YF (20190) Experimental and numerical analysis of steel-block shear connectors in assembled monolithic steel-concrete composite beams. J Bridge Eng 24(5):04019024 Asce-Amer Soc Civil Engineers, Reston

Webb BM, Cleary JC (2019) Drag-induced displacement of a simply supported bridge span during hurricane Katrina. J Perform Constr Fac 33(4):04019040 Asce-Amer Soc Civil Engineers, Reston

Wei C, Zhou D, Ou J (2019a) Calculation method of wave forces on large round-ended caisson foundation. J Shanghai Jiaotong Univ (Science) 24(02):184-189 (In Chinese)

Wei C, Zhou D, Ou J (2019b) Wave and wave-current actions on a bridge tower: an experimental study. Adv Struct Eng 22(6): 1467-1478 Sage Publications Inc, Thousand Oaks

Wei K, Liu Q, Qin S (2019c) Nonlinear assessment of offshore steel trestle subjected to wave and current loads. Ships and Offshore Structures, Taylor \& Francis Ltd, Abingdon

Wei K, Shen Z, Wu L, Qin S (2019d) Coupled numerical simulation on wave and storm surge in coastal areas under strong typhoons. Eng Mech 36(11):139-146 (In Chinese)

Wei K, Zhang J, Qin S (2019e) Experimental and numerical assessment into frequency domain dynamic response of deep water rigid-frame bridge. J Earthq Eng Taylor \& Francis Ltd, Abingdon

Wei W, Fu S, Moan T, Song C, Deng S, Lie H (2019f) A time-domain method for hydroelasticity of a curved floating bridge in inhomogeneous waves. J Offshore Mech Arct Eng Trans Asme 141(1):014501 Asme, New York 
Wen J, Han Q, Du X (2019a) Shaking table tests of bridge model with friction sliding bearings under bi-directional earthquake excitations. Struct Infrastruct Eng 15(9):1264-1278 Taylor \& Francis Ltd, Abingdon

Wen Z, Wei X, Xiao L, He K (2019b) Experimental evaluation of the shear buckling behaviors of corrugated webs with artificial corrosion pits. Thin Walled Struct 141:251-259 Elsevier Sci Ltd, Oxford

Wu B, Chen X, Wang Q, Liao H, Dong J (2020) Characterization of vibration amplitude of nonlinear bridge flutter from section model test to full bridge estimation. J Wind Eng Ind Aerodyn 197:104048 Elsevier, Amsterdam

Wu B, Wang Q, Liao H (2019a) Characteristics of amplitude dependence of a flat box girder in a post-flutter state. Chin J Highway Transp 32(10):96-106 (In Chinese)

Wu C, Wei X, Wen Z, He K (2019b) Research on hot spot stress concentration factor of welded concrete-filled steel tubular truss joints. Steel Struct 34(01):23-26+14 (In Chinese)

Wu X, He Q, Zheng P, Xiao K (2019c) Influence analysis of concrete strength on time-varying reliability of widening T-beam bridge based on support vector method. J Chongqing Jiaotong Univ 38(5):33-38 Natural Science (In Chinese)

Wu Z, Liu J, Zou D, Wang X, Shi J (2019d) Status Quo and development trend of light-weight, high-strength, and durable structural materials applied in marine bridge engineering. Eng Sci 21(3):31-40 (In Chinese)

Wu Z, Shi C, Khayat KH (2019e) Investigation of mechanical properties and shrinkage of ultra-high performance concrete: influence of steel fiber content and shape. Compos B Eng 174:UNSP 107021 Elsevier Sci Ltd, Oxford

Xia Y, Wang P, Sun LM (2019) A condition assessment method for bridges at network level based on multi-source information. J Tongji Univ Nat Sci 47(11):1574-1584 (in Chinese)

Xiang Q, Li Y, Wei K, Wang S, Yao C (2019) Review of bridge foundation scour. J Southwest Jiaotong Univ 54(02):235-248 (In Chinese)

Xiang X, Loken A (2019) Hydroelastic analysis and validation of an end-anchored floating bridge under wave and current loads. In: Proceedings of the Asme 38th International Conference on Ocean, Offshore and Arctic Engineering, 2019, Vol 9. Amer Soc Mechanical Engineers, New York UNSP V009T12A018

Xiao L, Liu L, Wei X, Liu D (2019a) Mechanical behavior and structural optimization of steel-concrete composite cable-pylon anchor. J Southwest Jiaotong Univ 54(5):923 (In Chinese)

Xiao S, Guo A (2019) Effects of air relief openings on the mitigation of solitary wave forces on bridge decks. J Hydrodyn 31(3):594-602 Springer, New York

Xiao X, Yan Y, Chen B (2019b) Stochastic dynamic analysis for vehicle-track-bridge system based on probability density evolution method. Eng Struct 188:745-761 Elsevier Sci Ltd, Oxford

Xie W, Sun L (2019) Experimental studies on seismic response characteristics of dynamic interaction system of pile-soil-cablestayed bridges. Chin I Geotech Eng 41(7):1319-1328 (In Chinese)

Xin J, Zhang H, Zhou J, Li X, Ma H (2019) Damage identification of bridge system based on a hybrid algorithm. Int J Robot Autom 34(2):104-111 Acta Press, Calgary

Xin L, Li X, Zhang J, Zhu Y, Xiao L (2020a) Resonance analysis of train-track-bridge interaction systems with correlated uncertainties. Int J Struct Stab Dyn 20(1):2050008 World Scientific Publ Co Pte Ltd, Singapore

Xin L, Li X, Zhu Y, Liu M (2020b) Uncertainty and sensitivity analysis for train-ballasted track-bridge system. Vehicle Syst Dyn 58(3):453-471 Taylor \& Francis Ltd, Abingdon

Xing L, Kong X (2018) Research progress on structural performance of RC beams strengthened with externally bonded FRP sheets. Concrete, 000(009):40-44, Liaoning (In Chinese)

Xu F, Jiang Q (2019) Dynamic obstacle-surmounting analysis of a bilateral-wheeled cable-climbing robot for cable-stayed bridges. Ind Robot 46(3):431-443 Emerald Group Publishing Ltd, Bingley

Xu G, Kareem A, Shen L (2020) Surrogate modeling with sequential updating: applications to bridge deck-wave and -wind interactions. J Comput Civil Eng, 34(4)

Xu J, Dong J, Li H, Zhang C, Ho SC (2019a) Looseness monitoring of bolted spherical joint connection using electromechanical impedance technique and BP neural networks. Sensors 19(8):1906 Mdpi, Basel

Xu J, Sun H, Cai S, Sun W, Zhang B (2019b) Fatigue testing and analysis of I-girders with trapezoidal corrugated webs. Eng Struct 196:UNSP 109344 Elsevier Sci Ltd, Oxford

Xu L, Zhai W (2019) A three-dimensional model for train-track-bridge dynamic interactions with hypothesis of wheel-rail rigid contact. Mech Syst Signal Process 132:471-489 Academic Press Ltd- Elsevier Science Ltd, London

XU T, Li Q, Zhao R, Ding J, Zhan Y (2019c) On the early-age bond-slip behavior of an eccentric bar embedded in a grouted sleeve. Eng Struct 190:160-170 Elsevier Sci Ltd, Oxford

Xu Y, Bao Y, Chen J, Zuo W, Li H (2019d) Surface fatigue crack identification in steel box girder of bridges by a deep fusion convolutional neural network based on consumer-grade camera images. Struct Health Monit 18(3):653-674 Sage Publications Ltd, London

Xu Y, Zeng Z, Ge J, Wang Z (2019e) Minimum reasonable socket depth of precast pierfooting with socket connection. J Tongji Univ Nat Sci 47(12):1706-1711 (In Chinese)

Xu YL, Tan ZX, Zhu LD, Zhu Q, Zhan S (2019f) Buffeting-induced stress analysis of long-span twin-box-beck bridges based on POD pressure modes. J Wind Eng Ind Aerodyn 188:397-409 Elsevier Science Bv, Amsterdam

Xu YL, Wang ZL, Li GQ, Chen S, Yang Y-B (2019g) High-speed running maglev trains interacting with elastic transitional viaducts. Eng Struct 183:562-578 Elsevier Sci Ltd, Oxford

Yan L, Xu LD, He XH, Flay RGJ (2019a) Experimental determination of aerodynamic admittance functions of a bridge deck considering oscillation effect. J Wind Eng Ind Aerodyn 190:83-97 Elsevier, Amsterdam

Yan Y, Liang H, Lu Y, Liu Z, Gong T (2019b) Behaviour of RC columns strengthened with SCC-filled steel tubes under cyclic loading. Eng Struct 199:UNSP 109603 Elsevier Sci Ltd, Oxford

Yang C, Okumus P, Ren R (2019a) A hysteretic model for self-centering precast concrete piers with varying shear-slip between segments. Eng Struct 188:350-361 Elsevier Sci Ltd, Oxford

Yang H, He H, Yan W (2019b) Time-dependent reliability analysis on reinforced concrete beam bridge considering carbonization and chloride accumulation effect. J Harbin Inst Technol 51(6):71-78 (In Chinese)

Yang M, Meng D, Gao Q, Zhu Y, Hu S (2019c) Experimental study on transverse pounding reduction of a high-speed railway simply-supported girder bridge using rubber bumpers subjected to earthquake excitations. Eng Struct 196:UNSP 109290 Elsevier Sci Ltd, Oxford 
Yang S, Wang X, Dong Y, Wang X, Long S, Zhou X (2019d) Time-dependent reliability analysis of corroded reinforce concrete beams in the atmosphere environment. Chin J Comput Mech 37(4):504-510 (In Chinese)

Yang W, Li A, Deng L, Liu T, Li F (2020a) Study on characteristics and calculation method of hydrodynamic force on pile group under earthquake. Ocean Eng 207:107375

Yang W, Li A, Feng X, Deng L, Li F (2020b) Calculation method of hydrodynamic force on one column of the twin columns under earthquake. Ocean Eng 197:106874

Yang Y, Fahmy MFM, Cui J, Pan Z, Shi J (2019e) Nonlinear behavior analysis of flexural strengthening of RC beams with NSM FRP laminates. Structures 20:374-384 Elsevier Science Inc, New York

Yang Y, He R, Sneed L, Saiidi MS, Belarbi A (2019f) Truss modeling of as-built and CFRP-repaired RC bridge columns subjected to combined cyclic lateral loading and torsion. Eng Struct 200:109664 Elsevier Sci Ltd, Oxford

Yang Y, Li M, Liao H (2019g) Three-dimensional effects on the transfer function of a rectangular-section body in turbulent flow. J Fluid Mech 872:348-366 Cambridge Univ Press, New York

Yang Y, Li M, Su Y, Sun Y (2019h) Aerodynamic admittance of a 5:1 rectangular cylinder in turbulent flow. J Wind Eng Ind Aerodyn 189:125-134 Elsevier Science Bv, Amsterdam

Yao Y, Ji B, Fu Z, Zhou J, Wang Y (2019) Optimization of stop-hole parameters for cracks at diaphragm-to-rib weld in steel bridges. J Constr Steel Res 162:UNSP 105747 Elsevier Sci Ltd, Oxford

Yau JD, Martinez-Rodrigo MD, Domenech A (2019) An equivalent additional damping approach to assess vehicle-bridge interaction for train-induced vibration of short-span railway bridges. Eng Struct 188:469-479 Elsevier Sci Ltd, Oxford

Ye C, Butler L, Elshafie MZEB, Middleton CR (2020) Evaluating prestress losses in a prestressed concrete girder railway bridge using distributed and discrete fibre optic sensors. Constr Build Mater 247:118518

Ye H, Wang L, Zhang Q, Xu X, Wei X (2019a) Trigonometric series solution of bending deformation for composite beam with steel corrugated webs. J Southwest Jiaotong Univ 54(4):701 (In Chinese)

Ye K, Xiao Y, Hu L (2019b) A direct displacement-based design procedure for base-isolated building structures with lead rubber bearings (LRBs). Eng Struct 197:109402 Elsevier Sci Ltd, Oxford

Ye X, Wang C, Li Q (2018) New method for calculation of time-dependent reliability of Rc bridges. Eng Mech 35(11):86-91 (In (hinese)

Yin T, Zhu HP, Fu SJ (2019) Model selection for dynamic reduction-based structural health monitoring following the Bayesian evidence approach. Mech Syst Signal Process 127:306-327 Academic Press Ltd- Elsevier Science Ltd, London

Youssef MH, Ahmed EA, Benmokrane B (2019) Structural behavior of GFRP-RC bridge deck slabs connected with UHPFRC joints under flexure and shear. J Bridge Eng 24(9):04019092 Asce-Amer Soc Civil Engineers, Reston

Yu C, Li Y, Zhang M, Zhang Y, Zhai G (2019a) Wind characteristics along a bridge catwalk in a deep-cutting gorge from field measurements. J Wind Eng Ind Aerodyn 186:94-104 Elsevier Science Bv, Amsterdam

Yu X, Chen D, Bai Z (2019b) A stability study of the longest steel truss deck cable-stayed bridge during construction. Ksce J Civil Eng 23(4):1717-1724 Korean Society of Civil Engineers-Ksce, Seoul

Yu Z, Pan H, He S (2019c) Influence of prestressed axial compression ratio on mechanical properties of segmental bridge piers. J Guangdong Univ Technol 36(04):85-91 (In Chinese)

Yuan H, Wu Q, Chen B, Cai H (2019a) Peseudo-dynamic test of Cfst lattice columns with flat lacing tubes. Eng Mech 36(07): $67-78$

Yuan M, Huang L, Zhuo P, Yan D, Yun L (2019b) Experimental investigation of static damage of concrete beam under bending-shear based on acoustic emission technology. J Chang'An Univ Nat Sci Ed 39(02):73-81 (in Chinese)

Yuan Y, Wu C, Jiang X (2019c) Experimental study on the fatigue behavior of the orthotropic steel deck rehabilitated by UHPC overlay. J Constr Steel Res 157:1-9 Elsevier Sci Ltd, Oxford

Yuan Y, Wu Q, Chen B, Cai H (2019d) Pseudo-dynamic test of Cfst lattice columns with flat lacing tubes. Eng Mech 36(7):6778 (In Chinese)

Zhai W, Han Z, Chen Z (2019) Train-track-bridge dynamic interaction: a state-of-the-art review. Vehicle Syst Dyn 57(7):9841027

Zhang C, Ge Y, Hu Z, Zhou K, Ren G, Wang X (2019a) Research on deflection monitoring for long span cantilever bridge based on optical fiber sensing. Opt Fiber Technol 53:102035 Elsevier Science Inc, New York

Zhang C, Zhang X, Huang M, Tang H (2019b) Responses of caisson-piles foundations to long-term cyclic lateral load and scouring. Soil Dyn Earthq Eng 119:62-74 Elsevier Sci Ltd, Oxford

Zhang G, Zhao W, Hao Z (2019c) Design and development of digital operation and maintenance system for Hutong Yangtze river bridge. J China Railway Soc 41(5):16-26

Zhang H, Shao X, Cao J, Xiong M (2019d) Preliminary study on shear performance of ultra thin lightweight composite bridge deck with short rebar connections. Highway Eng 44(02):8-13+35 (In Chinese)

Zhang H, Wei X, Ding Y, Jiang Z, Ren J (2019e) A low noise capacitive MEMS accelerometer with anti-spring structure. Sensors Actuat A Phys 296:79-86 Elsevier Science SA, Lausanne

Zhang J, Wei K, Pang Y, Zhang M, Qin S (2019f) Numerical investigation into hydrodynamic effects on the seismic response of complex hollow bridge pier submerged in reservoir: case study. J Bridge Eng 24(2):05018016 Asce-Amer Soc Civil Engineers, Reston

Zhang J, Wei K, Qin S (2019g) An efficient numerical model for hydrodynamic added mass of immersed column with arbitrary cross - section. Ocean Eng 187:106192 Pergamon-Elsevier Science Ltd, Oxford

Zhang J, Xie Y, Wu G (2019h) Seismic responses of bridges with rocking column-foundation: a dimensionless regression analysis. Earthq Eng Struct Dyn 48(1):152-170 Wiley, Hoboken

Zhang L, Huang J (2019) Dynamic interaction analysis of the high-speed maglev vehicle/guideway system based on a field measurement and model updating method. Eng Struct 180:1-17 Elsevier Sci Ltd, Oxford

Zhang M, Wu T, Xu F (2019i) Vortex-induced vibration of bridge decks: describing function-based model. J Wind Eng Ind Aerodyn 195:UNSP 104016 Elsevier, Amsterdam

Zhang M, Xu F, Zhang Z, Ying X (2019j) Energy budget analysis and engineering modeling of post-flutter limit cycle oscillation of a bridge deck. J Wind Eng Ind Aerodyn 188:410-420 Elsevier Science Bv, Amsterdam

Zhang Q, Jia D, Bao Y, Dong S, Cheng Z, Bu Y (2019k) Flexural behavior of steel-concrete composite beams considering interlayer slip. J Struct Eng 145(9):04019084 Asce-Amer Soc Civil Engineers, Reston 
Zhang Q, Liu T (2019) Application of BIM technology in the design of Pingtang major bridge. Highway 64(09):27-31 (in (hinese)

Zhang Q, Yuan D, Bu Y (2018) Fatigue performance of rib-to-deck joint in orthotropic steel bridge deck with new type of both-side fillet welded joints. In: Proceedings of the 40th IABSE Symposium, Nantes, France

Zhang W, Yang C, Wang Z, Liu Z (20191) An analytical algorithm for reasonable central tower stiffness in the three-tower suspension bridge with unequal-length main spans. Eng Struct 199:UNSP 109595 Elsevier Sci Ltd, Oxford

Zhang Y, Cao S, Ye P, Chen J, Tian H (2019m) Experimental study on mechanical properties of U-shaped steel bar wet joint of steel plate girder bridge. China Munic Eng 44(05):95-97+114 (In Chinese)

Zhang Y, Zhang Y, Zhang H, Sun Y (2019n) Analysis on shear lag warping stress of thin-walled box girders with boundary constraint effect. J Basic Sci Eng 27(5):1042-1053 (In Chinese)

Zhang Z, Jin X, Gan Y (20190) Vertical bending mechanical properties of box composite girder with corrugated steel webs. China Railway Sci 40(6):52-59 (In Chinese)

Zhang Z, Tan B, Chen T (2019p) Study on field measurement of wind properties near a Canyon Deep-cut to Hilly Land. J Hunan Univ Nat Sci 46(7):113-122 (In Chinese)

Zhao C, Wang K, Xu R, Deng K, Cui B (2019a) Development of fully prefabricated steel-UHPC composite deck system. J Struct Eng 145(7):04019051 Asce-Amer Soc Civil Engineers, Reston

Zhao C, Wang K, Zhou Q, Deng K, Cui B (2018) Full-scale test and simulation on flexural behavior of dovetail-shaped reactive powder-concrete wet joint in a composite deck system. J Bridge Eng 23(8):04018051 Asce-Amer Soc Civil Engineers, Reston

Zhao E, Sun J, Tang Y, Mu L, Jiang H (2020a) Numerical investigation of tsunami wave impacts on different coastal bridge decks using immersed boundary method. Ocean Eng 201:107132 Pergamon-Elsevier Science Ltd, Oxford

Zhao G, Cao Y, Jia R, Gao P (2019b) Experimental study on pull-out performance of studs under monotonic and cyclic loading. J Build Struct 40(S1):418-423 (In Chinese)

Zhao HW, Ding YL, Li AQ (2020b) Live-load strain evaluation of the prestressed concrete box-girder bridge using deep learning and clustering. Struct Health Monit 19(4):1051-1063

Zhao L, Cui W, Ge Y (2019c) Measurement, modeling and simulation of wind turbulence in typhoon outer region. J Wind Eng Ind Aerodyn 195:UNSP 104021 Elsevier, Amsterdam

Zhao L, Li K, Wang C, Liu G, Liu T, Song S, Ge Y (2019d) Review on passive aerodynamic countermeasures on main girders aiming at wind-induced stabilities of long-span bridges. China J Highway Transp 32(10):34-48 (In Chinese)

Zhao R, Yuan Y, Cheng Z, Wen T, Li J, Li F, Ma ZJ (2019e) Freeze-thaw resistance of Class F fly ash-based geopolymer concrete. Constr Build Mater 222:474-483 Elsevier Sci Ltd, Oxford

Zhao Y, Chen M (2018) Fatigue analysis of orthotropic steel deck based on time-variant reliability theory. Highway 63(09): 135-138 (In Chinese)

Zhao Z, Huang L, Xie J (2019f) Effects of mix proportion and curing condition on the microstructure of ultra-high performance concrete. China J Highway Transp 32(7):111-119 (In Chinese)

Zheng K, Feng X, Heng J, Zhu J, Zhang Y (2019a) Fatigue reliability analysis of rib-to-deck joints using test data and in-situ measurements. Appl Sci-Basel 9(22):4820 Mdpi, Basel

Zheng Y, Dong Y, Chen B, Anwar GA (2019b) Seismic damage mitigation of bridges with self-adaptive SMA-cable-based bearings. Smart Struct Syst 24(1):127-139 Techno-Press, Daejeon

Zheng Y, McCartney JS, Shing PB, Fox PJ (2019c) Physical model tests of half-scale geosynthetic reinforced soil bridge abutments. II: dynamic loading. J Geotech Geoenviron Eng 145(11):04019095 Asce-Amer Soc Civil Engineers, Reston

Zhong J, Wang B, Wang X, Wang Z (2019) Research of bridge intelligent inspection technology and application. Bridge Construct 49(S1):1-6 (in Chinese)

Zhou C, Li L, Wang L (2019a) Improved softened membrane model for prestressed composite box girders with corrugated steel webs under pure torsion. J Construct Steel Res 153:372-384 Elsevier Sci Ltd, Oxford

Zhou J, Zhao Y, He Q, Zhang P, Zhang H (2019b) Corrosion test of galvanized steel strand based on magnetic memory. J Chang'an Univ Nat Sci Ed 39(01):81-89

Zhou L, Wang X, Ye A (2019c) Low cycle fatigue performance investigation on Transverse Steel Dampers for bridges under ground motion sequences using shake-table tests. Eng Struct 196:UNSP 109328 Elsevier Sci Ltd, Oxford

Zhou M, Liu Y, Deng W, Hassanein MF, Zhang H (2019d) Transverse analysis of full-scale precast segmental box girder segments with corrugated steel webs: experimental tests and FE modelling. Eng Struct 187:231-241 Elsevier Sci Ltd, Oxford

Zhou X, Zhang X (2019) Thoughts on the development of bridge technology in China. Engineering 5(6):1120-1130 Elsevier, Amsterdam

Zhou Y, Du X, Han Q (2019e) Seismic response and overturning of double-column rocking column bridge system. Eng Mech 36(7):136-145 (in Chinese)

Zhou Y, Li C (2019) Simplified calculation method for steel bar damper and steel bar restrainer applied to high-speed railway simply supported beam bridge. Railway Stand Des 63(05):65-70 (in Chinese)

Zhou Y-L, Han Q, Du X-L, Jia Z (2019f) Shaking table tests of post-tensioned rocking bridge with double-column bents. J Bridge Eng 24(8):04019080 Asce-Amer Soc Civil Engineers, Reston

Zhu J, Zhang C, Qi H, Lu Z (2019a) Vision-based defects detection for bridges using transfer learning and convolutional neural networks. Struct Infrastruct Eng Taylor \& Francis Ltd, Abingdon, 16(7):1037-1049

Zhu L, Li M, Chen C, Sun H, Han D, Zhao Y (2019b) Constrained torsion, distorsion and bidirectional interface slip effects of curved steel-concrete composite box beams. J Build Struct 40(S1):299-307 (In Chinese)

Zhu M, Wu B, Bursi OS, Xu G, Wang Z, Wang T, Ning X, Liu Y (2019c) Hybrid simulation with online model updating: application to a reinforced concrete bridge endowed with tall piers. Mech Syst Signal Process 123:533-553 Academic Press Ltd- Elsevier Science Ltd, London

Zhu Q, Chen W, Zhu L, Cui Y (2019d) Flutter performance of a super-long-span cable-stayed bridge under large attack angles via wind tunnel sectional model tests. China J Highway Transp 32(10):67-74 (In Chinese) 
Zhu Z, Gong W, Wang L, Bai Y, Yu Z, Zhang L (2019e) Efficient assessment of 3D train-track-bridge interaction combining multi-time-step method and moving track technique. Eng Struct 183:290-302 Elsevier Sci Ltd, Oxford

Zhu Z, Xiang Z (2019) Fatigue cracking investigation on diaphragm cutout in a self-anchored suspension bridge with orthotropic steel deck. Struct Infrastruct Eng 15(10):1279-1291 Taylor \& Francis Ltd, Abingdon

Zhuo W, Tong T, Liu Z (2019) Analytical pushover method and hysteretic modeling of precast segmental bridge piers with high-strength bars based on cyclic loading test. J Struct Eng 145(7):04019050 Asce-Amer Soc Civil Engineers, Reston

Zou H, Lu Z, Yu Z (2019a) Time-dependent camber deformation reliability of high-speed railway PSC box girder considering creep effect. J China Railway Soc 41(6):107-114 (In Chinese)

Zou S, Wenliuhan H, Zhou F (2019b) Shaking table test of a high-speed railway bridge with a new isolation system. Eng Struct 196:UNSP 109315 Elsevier Sci Ltd, Oxford

\section{Publisher's Note}

Springer Nature remains neutral with regard to jurisdictional claims in published maps and institutional affiliations.

Submit your manuscript to a SpringerOpen ${ }^{\odot}$ journal and benefit from:

- Convenient online submission

Rigorous peer review

- Open access: articles freely available online

- High visibility within the field

- Retaining the copyright to your article

Submit your next manuscript at $\boldsymbol{\nabla}$ springeropen.com 